Florida International University FIU Digital Commons

FIU Electronic Theses and Dissertations

University Graduate School

5-26-2011

\title{
Essays on Corporate Reputation: Antecedents and Consequences
}

\author{
Abrahim Soleimani \\ Florida International University, absoleimani@gmail.com
}

DOI: $10.25148 /$ etd.FI1 1072502

Follow this and additional works at: https://digitalcommons.fiu.edu/etd

\section{Recommended Citation}

Soleimani, Abrahim, "Essays on Corporate Reputation: Antecedents and Consequences" (2011). FIU Electronic Theses and Dissertations. 419.

https://digitalcommons.fiu.edu/etd/419

This work is brought to you for free and open access by the University Graduate School at FIU Digital Commons. It has been accepted for inclusion in FIU Electronic Theses and Dissertations by an authorized administrator of FIU Digital Commons. For more information, please contact dcc@fiu.edu. 


\section{FLORIDA INTERNATIONAL UNIVERSITY}

Miami, Florida

ESSAYS ON CORPORATE REPUTATION:

ANTECEDENTS AND CONSEQUENCES

A dissertation submitted in partial fulfillment of the

requirements for the degree of

DOCTOR OF PHILOSOPHY

in

BUSINESS ADMINISTRATION

by

Mohammad Abrahim Soleimani

2011 
To: Dean Joyce Elam

College of Business Administration

This dissertation, written by Mohammad Abrahim Soleimani, and entitled Essays on Corporate Reputation: Antecedents and Consequences, having been approved in respect to style and intellectual content, is referred to you for judgment.

We have read this dissertation and recommend that it be approved.

William Schneper

Nathan Hiller

James Jaccard

William Newburry, Major Professor

Date of Defense: May 26, 2011

The dissertation of Mohammad Abrahim Soleimani is approved.

\begin{tabular}{r} 
Dean Joyce Elam \\
College of Business Administration \\
\hline Interim Dean Kevin O’Shea \\
University Graduate School
\end{tabular}

Florida International University, 2011 


\section{DEDICATION}

To my parents Mehdi and Ada and my brother Esmaeil without whose love, support, and encouragement, the completion of this work would not have been possible. 


\section{ACKNOWLEDGMENTS}

I am sincerely grateful to my dissertation committee, Dr. William Newburry (Committee Chair), Dr. William Schneper, Dr. Nathan Hiller, and Dr. James Jaccard. I am deeply indebted to my magnificent advisor, Dr. William Newburry, whose leadership and guidance throughout my dissertation was flawless. I appreciate his sincere dedication, unreserved support, and continued encouragement. I am especially grateful to my other great mentor, Dr. William Schneper, for giving tremendous insights and inspiration for my research. This dissertation has benefited immensely from his ingenious ideas, generous devotion of time, insightful discussions, and constructive feedbacks. I also give special thanks to Dr. Nathan Hiller and Dr. James Jaccard for providing excellent advice in the theoretical and methodological development of my dissertation. I extend my gratitude to all other faculty in the Management \& International Business Department for their active role in creating a collegial environment for learning and research. I also appreciate administrative support and helps from Cassandra Alonso, Rosa Garcia, and Cristobal Ruiz.

I would like to acknowledge and thank the Reputation Institute and University Graduate School which had significant roles in the completion of this dissertation. I specially thank Dr. Charles Fombrun, Dr. Leonard Ponzi, and Sebastian Taciak at the Reputation Institute, for providing me with unique and detailed Corporate Reputation data which is central to this dissertation. I also would like to thank University Graduate School for providing financial support through "Dissertation Year Fellowship".

My heartfelt thanks goes to my fellow PhD students, Abdul Rahman Beydoun, Armando Borda, Sokol Celo, Wei He, Kun Yang, Moriah Meyskens, Watcharaphong 
Leartsurawat, Yu-Kai Wang, Marcelo Alvaro-vargas, Keith Kelley, and Yannick Thams for their friendship, consistent support, endless encouragement, and invaluable feedback.

Finally, I would like to express my deepest gratitude to my family and friends who have always encouraged and supported me, and especially to my beloved parents, who always pray for me. 


\title{
ABSTRACT OF THE DISSERTATION \\ ESSAYS ON CORPORATE REPUTATION: \\ ANTECEDENTS AND CONSEQUENCES
}

\author{
by \\ Mohammad Abrahim Soleimani \\ Florida International University, 2011 \\ Miami, Florida \\ Professor William Newburry, Major Professor
}

This dissertation studied the determinants and consequences of corporate reputation. It explored how firm-, industry-, and country-level factors influence the general public's assessment of a firm's reputation and how this reputation assessment impacted the firm's strategic actions and organizational outcomes. The three empirical essays are grounded on separate theoretical paradigms in strategy, organizational theory, and corporate governance. The first essay used signaling theory to investigate firm-, industry-, and country-level determinants of individual-level corporate reputation assessments. Using a hierarchical linear model, it tested the theory based on individual evaluations of the largest companies across countries. Results indicated that variables at multiple analysis levels simultaneously impact individual level reputation assessments. Interactions were also found between industry- and country-level factors. Results confirmed the multi-level nature of signaling influences on reputation assessments.

Building on a stakeholder-power approach to corporate governance, the second essay studied how differences in the power and preferences of three stakeholder groups shareholders, creditors, and workers - across countries influence the general public's 
reputation assessments of corporations. Examining the largest companies across countries, the study found that while the influence of stock market return is stronger in societies where shareholders have more power, social performance has a more significant role in shaping reputation evaluations in societies with stronger labor rights. Unexpectedly, when creditors have greater power, the influence of financial stability on reputation assessment becomes weaker.

Exploring the consequences of reputation, the third essay investigated the specific effects of intangible assets on strategic actions and organizational outcomes. Particularly, it individually studied the impacts of acquirer acquisition experience, corporate reputation, and approach toward social responsibilities as well as their combined effect on market reactions to acquisition announcements. Using an event study of acquisition announcements, it confirmed the significant impacts of both action-specific (acquisition experience) and general (reputation and social performance) intangible assets on market expectations of acquisition outcomes. Moreover, the analysis demonstrated that reputation magnifies the impact of acquisition experience on market response to acquisition announcements. In conclusion, this dissertation tried to advance and extend the application of management and organizational theories by explaining the mechanisms underlying antecedents and consequences of corporate reputation. 


\section{TABLE OF CONTENTS}

CHAPTER

PAGE

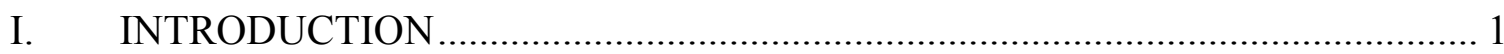

II. ESSAY 1: MULTI-LEVEL SIGNALING IMPACTS ON INDIVIDUAL CORPORATE REPUTATION ASSESSMENTS ……..................................... 10

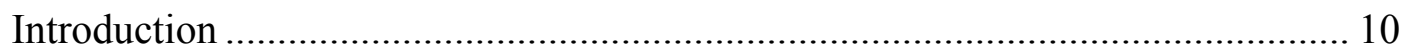

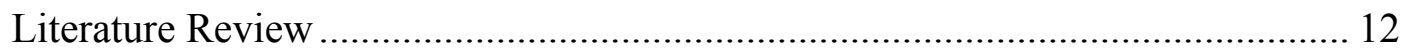

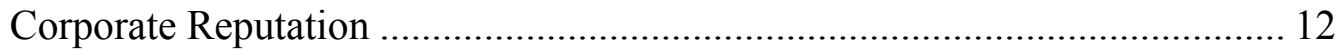

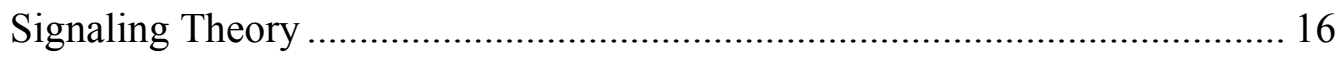

Hypotheses Development.......................................................................... 19

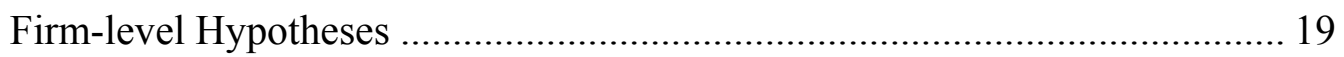

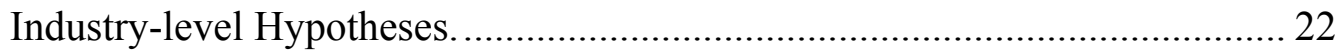

Country-level Hypotheses .......................................................................... 25

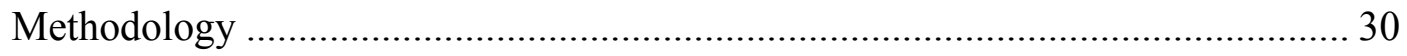

Sample

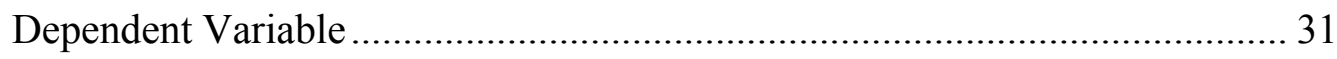

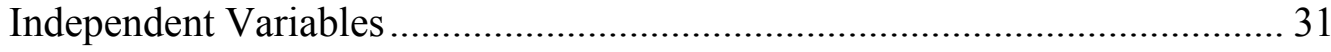

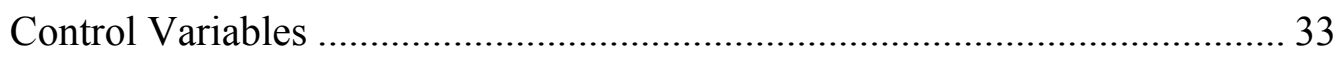

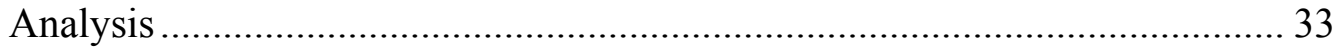

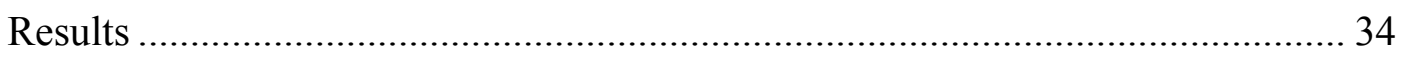

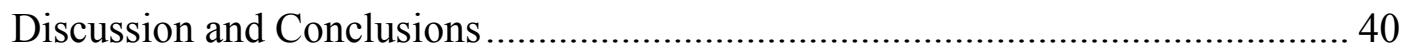

III. ESSAY 2: THE IMPACT OF STAKEHOLDER POWER ON CORPORATE REPUTATION: A CROSS-COUNTRY CORPORATE GOVERNANCE

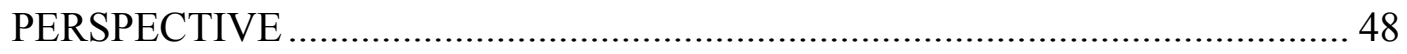

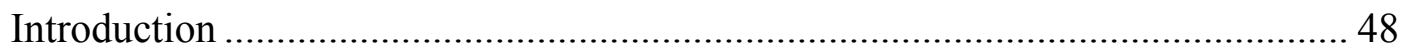

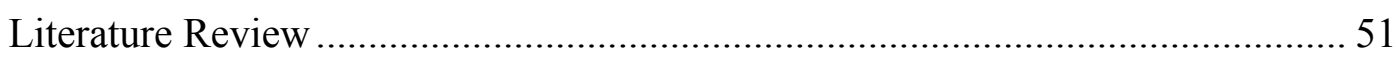

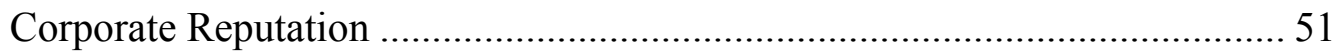

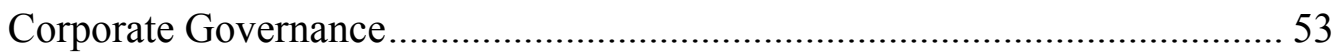

Stakeholder Power, Corporate Reputation and the Corporate Objective Function 57

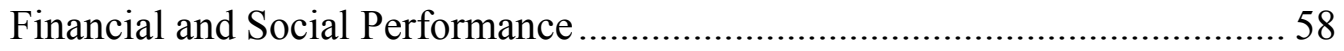

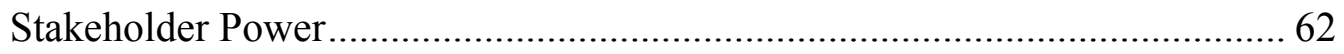

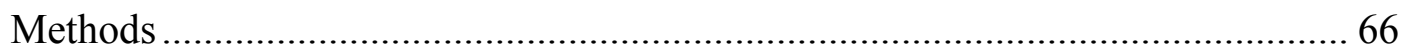

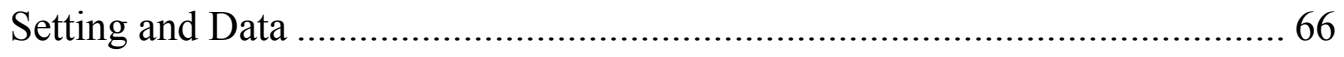

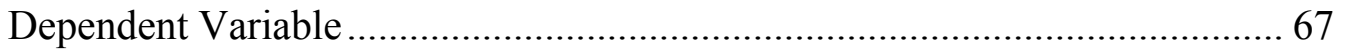

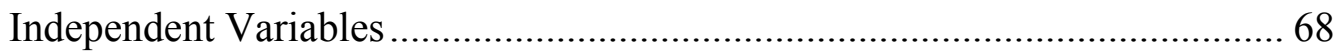

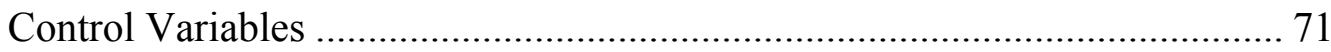




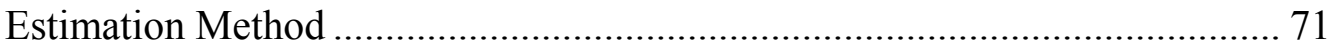

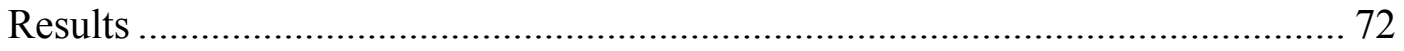

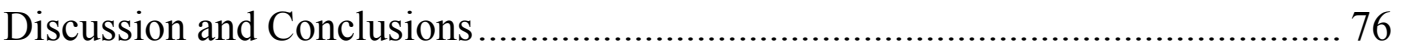

IV. ESSAY 3: NO SUBSTITUTE FOR EXPERIENCE? THE IMPACT OF CORPORATE REPUTATION ON STOCK MARKET REACTIONS TO

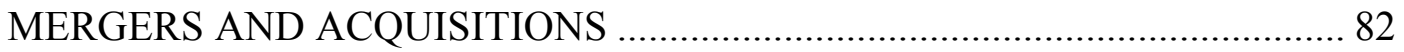

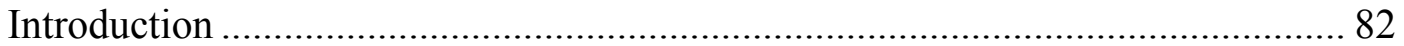

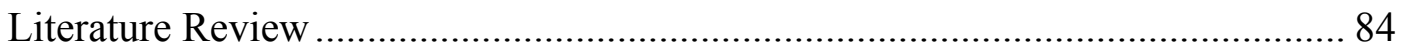

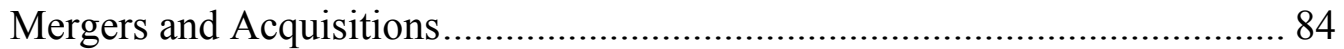

Corporate Reputation and Consequences .................................................... 90

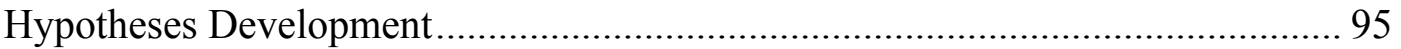

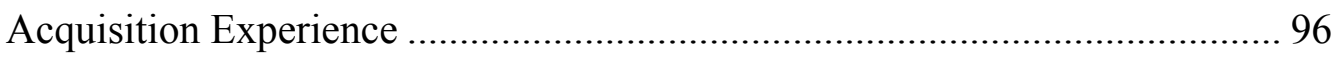

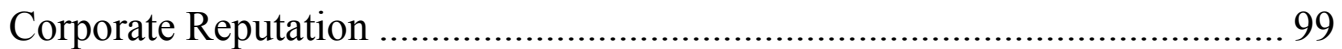

Impact of Acquirer's Reputation on its Acquisition Experience ................... 102

Acquirer's Social Responsibility Approach .................................................. 105

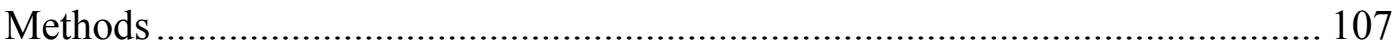

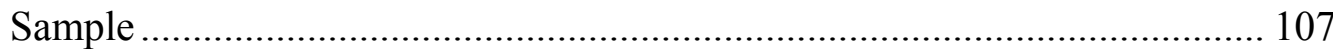

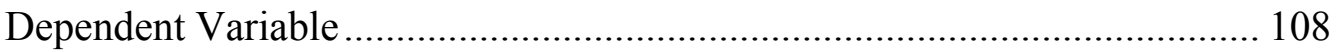

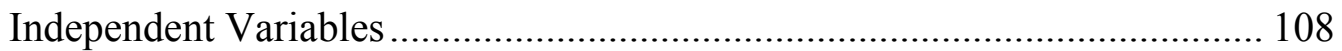

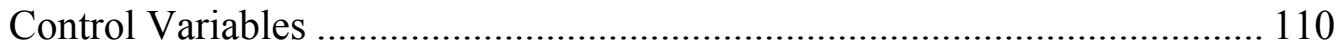

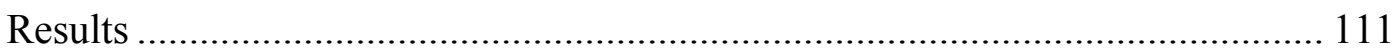

Discussion and Conclusions ............................................................................. 116

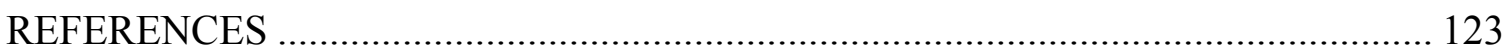

VITA ……… 


\section{LIST OF TABLES}

TABLE

PAGE

1. TABLE 1.1: Individual-level Variables: Descriptive Statistics and Correlations.......34

2. TABLE 1.2: Firm-level Variables: Descriptive Statistics and Correlations...............34

3. TABLE 1.3: Country-level Variables: Descriptive Statistics and Correlations........34

4. TABLE 1.4: Regression Analysis Predicting Corporate Reputation Perception........38

5. TABLE 1.5: Regression Analysis Predicting Corporate Reputation Perception.......39

6. TABLE 2.1: Descriptive Statistics and Correlations.......................... 73

7. TABLE 2.2: Tobit Regression Results for Corporate Reputation..................75

8. TABLE 3.1: Descriptive Statistics and Correlations......................... 112

9. TABLE 3.2: Regression Results for Market Reaction to M\&A Announcements....113 


\section{INTRODUCTION}

Corporate reputation is a collective perception of stakeholders of a firm (Fombrun, 1996) and an intangible asset which can be a source of competitive advantage (Barney, 1991). The Resource-based View (RBV) proposes that rare, socially complex, and difficult to imitate intangible assets significantly contribute to performance differences among organizations (Amit \& Schoemaker, 1993; Barney, 1991; Peteraf, 1993; Rao, 1994). Firms place a high priority on building a favorable reputation, and they deploy significant resources towards this purpose. In academia, corporate reputation attracts attention of scholars from different disciplines such as economics, accounting, finance, sociology, management, strategy, and marketing (Gotsi \& Wilson, 2001). Two areas in which scholars have concentrated their attention are the antecedents (determinants) and consequences of corporate reputation.

Although extensive research has investigated the antecedents of corporate reputation, relatively few works have studied its industry- and country-level determinants. In addition to the need for simultaneously investigating the effects of industry- and country-level factors, it is important to pay attention to the interdependence of these levels. Most prior reputation research does not account for the interdependence of individual-level data being nested within higher levels of observation, which could significantly influence past results (Raudenbush, Bryk, Cheong, Congdon, \& du Toit, 2004). Besides their direct effects on reputation, firm-level determinants are influenced by industry-level characteristics which are dependent on country-level factors. Reputation literature, which has primarily focused its analysis at the firm-level, implicitly assumes determinants of reputation are universal (see Love \& Kraatz, 2009). The impact of 
national institutional, legal/political, and cultural differences that influence the way the general public evaluates corporate reputation has received comparatively less attention and is not fully understood (Gardberg, 2006). In a comparative research, Aperia, SimcicBronn, and Schultz (2004) studied perceptions of corporate reputation across Scandinavian countries which are often considered very similar and found surprising differences among them. Their findings confirms that national institutions influence widely-held beliefs about the role of the business corporation in society and people use these expectations as criteria to evaluate corporate reputations (Chen, Newburry, \& Park, 2009; Deephouse, Li, \& Newburry, 2009; Schneper \& Guillén, 2004).

In addition to studying the determinants of reputation, scholars showed interests in investigating the consequences of reputation. However, despite a large body of research in this area, most prior studies focused on the general consequences of reputation such as overall firm performance, customer loyalty, and supportive behavior (Fombrun \& Shanley, 1990; Newburry, 2010; Walsh et al, 2009) and little research has examined the instrumentality of corporate reputation in determining corporate strategic actions. More specifically, the literature is limited in its coverage of the impacts of reputation on specific corporate actions. Furthermore, focusing on a specific organizational action allows researchers to compare the influence of reputation with other intangible assets as well as to investigate their joint effects on the organizational action.

In order to fill these theoretical gaps, this dissertation presents three empirical essays to investigate the multi-level determinants of corporate reputation, explain differences among reputed companies across countries, and examine the impact of reputation on an organizational action. While the focus of all three essays is on corporate 
reputation, each of them approaches reputation from a unique perspective, is grounded in a different theoretical paradigm, and applies a distinct empirical method.

The first essay, using signaling theory, sets out to investigate the effects of corporate reputation determinants at different levels, including firm-level signals, industry differences, and country-level signals in forming the general public's perceptions of firms. At the firm level, it studies the effects of financial performance, social performance, and firm size. Financial performance, social performance, and firm size are separating signals that a firm can send to its audiences to distinguish itself from its counterparts. By lowering information uncertainty between a firm and the general public, these signals help the firm gain trust, respect, and admiration among its constituents and consequently form a favorable reputation assessment. At the industry level, industries are differentiated based on their output (manufacturing vs. service), customer (B2B vs. B2C), and reputation (controversial vs. non-controversial). It is argued that general public opinion depends on information availability. Therefore, it is expected that the public evaluates firms lower in industries with higher information uncertainty. At the country-level, direct effects of three aspects of country development including economic, institutional, and human development on corporate reputation are analyzed. Information uncertainty is lower in more developed countries due to more information dissemination channels, higher information disclosure standards, and a more educated and information seeking public. As a result, the general public in more developed countries is more informed about their focal firms and industries and consequently evaluates them better.

The result of analyses including firm-, industry-, and country-level determinants 
of reputation confirmed the significant influence of social performance on public assessments about corporate reputation. In addition, it showed that although the general public has lower evaluations about companies in service, B2B, and controversial industries, in more advanced countries, these evaluations are less negative for companies in service and B2B industries and more negative for those in controversial industries. Interestingly, the results reported that country development has a significant impact on the general public's perception about its focal companies but not in the expected direction. In other words, people in more developed countries have less favorable opinions about companies in their countries.

This essay contributes to the corporate reputation literature in two ways. Theoretically, there is a lack of studies analyzing industry- and country-level antecedents of corporate reputations, and this study helps overcome this limitation by finding significant industry- and country-level effects, in addition to more commonly studied firm-level variables. Methodologically, the first essay recognizes the interdependence among the variables at different analysis levels and captures more accurate effects of higher level variables on the criterion variable by using multi-level analysis techniques.

Following interesting country-level results in Essay 1, the second essay studies how national institutions influence the general public's assessment of the reputations of corporations. Inspired by comparative corporate governance studies, this study investigates which companies gain higher reputation in a society by analyzing the distribution of power in that society. Corporations can be described as a nexus of contracts (Jensen \& Meckling, 1976), which is a collection of contracts between different stakeholders (e.g., shareholders, managers, employees, banks, and government). 
Stakeholders have different interests in the corporation and compete for limited resources of the firm (Aguilera \& Jackson, 2003). Therefore, corporations can be viewed as place for political contest (Fligstein, 2001; Ocasio, 1994; Perrow, 1986) among stakeholders. The stakeholder with more power wins the contest and determines the role of corporations in a society. A stakeholder's power originates in a country's institutional and legal systems (Schneper \& Guillen, 2004). In other words, the stakeholder which a country's institutions favor is more powerful than other stakeholders, and therefore will be the winner of a political contest among stakeholders, and consequently have a stronger influence in determining the role of corporations in a society. As a result of defined roles of corporations in society (Chen, Newburry \& Park, 2009), the worldview and expectations of the people in the society regarding corporations will be formed and will be used as a base for interpreting companies' behaviors (Fligstein, 1996). People use these expectations as criteria to evaluate corporate reputations. Accordingly, depending on differences in institutions across countries, firms with more favorable reputations vary from country to country.

To investigate which companies have more favorable reputations across countries and the reasons behind their superior reputations, this essay, in the first step, examines the direct impacts of firms' financial performance (via stock market returns and financial performance stability) and social performance on reputation evaluations within society in order to disentangle the multiple impacts of firm performance on reputation. These firm attributes are valued by a broad range of constituencies across countries. Most stakeholder groups tend to favor firms that are financially vigorous and act responsibly, even if they place a different priority on each of these objectives. In the second step, the 
essay studies the comparative importance of financial and social performance to reputation assessment, which depends on the allocation of power and legal rights within society. In particular, the essay examines variation in the protection of rights of shareholders, creditors, and labor. These are the most frequently cited stakeholders for their varying levels of influence across countries. These stakeholders have a comparatively direct claim on the firm's resources as a result of their invested stake in the firm (see Mitchell, Agle \& Wood, 1997; Schneper \& Guillén, 2004) across countries, which influences general public assessment of corporate reputation and the determination of reputed companies. Results of the analysis reported significant impacts of stock market return, financial stability, and social performance on public evaluation of corporation reputation. Moreover, results confirmed that variation in reputed companies across countries can be explained based on the powerful stakeholders in that society.

The second essay contributes to several streams of research. First, this paper is among the few studies that examine corporate reputation in a wide range of countries from both developed and developing economies and therefore generates important new insights into how national institutional differences affect the performance-reputation relationship. Second, this study contributes to the field of corporate governance by extending the relevance of this literature to a new study domain, the area of corporate reputation. The second essay reaffirms the utility of conceptualizing national corporate governance systems by stakeholder influence. Countries must not be segregated too quickly into dichotomies or other simplified categorization schemes (e.g., shareholderversus stakeholder-centered models). The analysis underscores how the use of more finegrained measures of stakeholder power can produce more nuanced insights. Third, this 
research contributes to the debate on convergence and the global diffusion of business practices (Davis \& Marquis, 2005; Guillén, 2001; Weber, Davis \& Lounsbury, 2009). Corporate governance and other practices are unlikely to converge in the foreseeable future since the very concept of the firm differs significantly across countries. Finally, this study examines reputation using a measure based on the assessments of the general population of a country. This differs significantly from studies that examine measures based on a specific segment of elite evaluators, such as financial analysts. By taking this approach, the study is able to better capture the effects of stakeholder power on society. The third essay investigates the effects of three intangible assets - corporate reputation, acquisition experience, and business approach toward societal responsibilities - on market reaction to acquisition announcements. It examines the nature of the relationship between these three intangible assets, individually and combined, and market expectation of acquisition success. In particular, an acquirer's reputation signals the acquirer's capability in integrating the target company and creating synergy out of an acquisition. On the other hand, past acquisition experience of an acquirer is not simply transferable and applicable to future acquisitions since acquisition experience is contextdependent and cannot be applied to dissimilar situations without enough knowledge and expertise. In practice, due to the complexity and heterogeneity of acquisitions, novice acquirers with limited acquisition experience are not capable of realizing the underlying factors impacting acquisitions and differences across acquisitions, and therefore make inappropriate generalizations of their past acquisition experience (Haleblian \& Finkelstein, 1999). However, expert acquirers with extended numbers of past acquisitions can benefit from their expertise and in-depth knowledge. Therefore, it is expected that 
acquisition experience and market reaction to acquisition announcement will have a Ushaped relationship. Furthermore, reputation magnifies the U-shaped relation between acquisition experience and market reaction by making an acquirer more visible, bringing organizational actors and media praise, and enhancing an acquirer's responsibility to maintain its favorable reputation. This essay also studies the impact of an acquirer's approach toward social responsibility on market expectation about the future of the acquisition. Due to failure of the majority of acquisitions, the market is very conservative in evaluating the future outcome of an acquisition attempt. Accordingly, companies with good social performance which are expected to behave consistently with societal norms and values are less likely to adopt strategies such as lay-offs that are legitimate, but not socially-favorable. Therefore, the market has lower confidence in socially responsible acquirers to create value out of acquisition announcements. While results supported the U-shaped relationship between acquisition experience and market reaction and the magnifying impact of reputation on the U-shaped relationship, they did not show a positive, but rather a significant negative impact of reputation on market reaction. Also, they confirmed the negative effect of superior social performance on market expectation about the future of on acquisition. Overall, the third essay compares the impact of reputation, which is a general intangible asset, with acquisition experience, which is an action-specific intangible asset, on a specific strategic action, in this case acquisition strategy. Accordingly, this study investigates the generalizability of corporate reputation by testing its impacts on a specific organizational practice.

This study contributes to the strategy literature and advances our understanding of intangible assets in four ways. First, confirming the RBV perspective (Amit \& 
Schoemaker, 1993; Barney, 1991), this paper empirically shows that both action-specific factual and general perceptual intangible assets have a significant impact on strategic actions and organizational outcomes. Second, the results report that the impacts of intangible assets could go beyond a simple linear relation and might be in contrast to general expectations depending on the context of organizational practice (Haleblian \& Finkelstein, 1999). Third, the study demonstrates that companies can take advantage of "economies of scale" benefits of action-specific factual intangible assets and of "economies of scope" benefits of general perceptual intangible assets. Finally, Capron and Shen (2007) indicated that most acquisition research studied only public targets. This research contributes by including both publically and privately held targets as well as disclosed and undisclosed deals.

In conclusion, this dissertation tries to advance the current understanding of corporate reputation by examining the underlying mechanisms of corporate reputation formation as well as its influence on organizational actions both theoretically by applying different theoretical paradigms and empirically by utilizing distinct analytical techniques. The results of the three essays provide insights that help advance academic knowledge in the reputation field as well as related disciplines. 


\section{ESSAY 1:}

\section{MULTI-LEVEL SIGNALING IMPACTS ON INDIVIDUAL CORPORATE REPUTATION ASSESSMENTS INTRODUCTION}

Corporate reputation is a collective perception of firm stakeholders (Fombrun, 1996) and an intangible asset which can be a source of competitive advantage (Barney, 1991). Firms place a high priority on building a favorable reputation, and they deploy significant resources towards this purpose. In academia, corporate reputation attracts attention of scholars from different disciplines such as economics, accounting, finance, sociology, management, and marketing (Gotsi \& Wilson, 2001). One area of particular scholarly focus is the antecedents (determinants) of corporate reputation. Research studies report a wide range of reputation antecedents, such as financial performance, product/service quality, employee quality, social responsibility (Fombrun, 1998; Lewis, 2001), customer satisfaction and trust (Walsh, Mitchell, Jackson, \& Beatty, 2009), and financial disclosure and corporate governance (Gabbioneta, Ravasi, \& Mazzola, 2007), which have been predominantly examined at the firm level. By contrast, the multi-level nature of reputation determinants has received limited attention, despite the multi-level nature of reputation influences or signals and the fact that some of the most meaningful reputation assessments are conducted by individuals, who use these assessments to make decisions about firm supportive behavior (Newburry, 2010). We attempt to further this research by examining the signals driving individual-level reputation assessments using a multi-level perspective.

We believe this topic is important for multiple reasons. First, while most 
corporate reputation studies have identified firm-level determinants, much less work has investigated industry- and country-level impacts on reputation. A firm's reputation is highly affected by its industry's reputation (Barnett \& Hoffman, 2008; Winn, MacDonald, \& Ziestsma, 2008). While firm-level reputation determinants such as financial performance, product/service quality, and social responsibility are essential across industries, the importance of industry factors should not be underestimated. For example, the forestry industry, due to environmental group pressures, has a lower industry reputation (Winn et al., 2008), which impacts assessments of firms operating in that industry. Additionally, country-level factors may affect corporate reputation (Deephouse, Li \& Newburry, 2009). Low corruption levels, high environmental standards, and efficient business environments impact perceptions of a country's population, which consequently may affect their evaluations of firms.

Second, most previous work only examined the determinants of corporate reputation at one analysis level. In addition to investigating the effects of industry- and country-level reputation determinants, it is important to pay attention to the interdependence of these levels. Most prior reputation research does not account for the interdependence of individual-level data being nested within higher levels observation levels, which could significantly influence past results (Raudenbush, Bryk, Cheong, Congdon, \& du Toit, 2004). In addition to directly impacting the general public's assessment of an organization's reputation, firm- and industry-level factors are influenced by country-level factors, which can only be captured in a cross-level model.

Third, prior research has established the importance of environment signals in influencing firm reputations (Maheswaran, 1994). However, this theory has not 
considered the multi-level nature of signals that individuals receive when evaluating reputations. Accordingly, we theoretically contribute to reputation research by applying signaling theory at multiple levels to enrich our understanding of this topic.

Accordingly, in order to further develop the reputation literature, this study analyzes firm-, industry-, and country-level effects on individual-level corporate reputation assessments. The manuscript is structured in four sections. The first part reviews past research on corporate reputation and signaling theory. Next, hypotheses are developed. Third, methodology, analysis, and results are presented. Using data from the Reputation Institute's 2009 RepTrak Pulse study, in a hierarchical linear model, we test our theory using 71,368 individual evaluations of 615 firms operating in 33 countries. Finally, the manuscript ends with a discussion and conclusion section.

\section{LITERATURE REVIEW}

\section{Corporate Reputation}

The definition and measurement of corporate reputation have been long debated. Fombrun and Van Riel (1997) regarded corporate reputation as an ambiguous concept. Since then, significant work has clarified the meaning of reputation by studying differences and similarities in existing reputation definitions. According to Fombrun and Rindova's (1996) cross-disciplinary literature review, one reason for this ambiguity is the application of the corporate reputation concept by scholars in different disciplines: economists (Weigelt \& Camerer, 1988), sociologists (Shaphiro, 1987), strategists (Caves \& Porter, 1977), and marketing researchers (Dowling, 1986), among others.

Another reason for this ambiguity is a lack of consensus on the relationship of corporate image, corporate identity, and corporate reputation. Gotsi and Wilson (2001) 
categorized corporate reputation definitions into two schools of thought: analogous and differentiated. Scholars in the analogous school (e.g., Dowling, 1986) consider corporate image and reputation as the same concept and use them interchangeably. However, in the differentiated school, scholars separate these concepts. Three views exist in the differentiated school of thought on the relationship between corporate image and corporate reputation (Gotsi \& Wilson, 2001). Scholars having the first view (e.g., Brown \& Dacin, 1997) consider them as two separate concepts and even claim a negative association between them. According to this view, image can mean falsehood (Grunig, 1993) and is not necessarily a reflection of corporate reality. Contrary to the first view, the second view in the differentiated school of thought considers reputation as one dimension of corporate image (e.g., Barich \& Kotler, 1991). In this view, image is the perception of stakeholders about the company and reputation is one component which shape this perception. The third view in the differentiated school considers image as a component of corporate reputation (e.g., Fombrun \& Shanley, 1990). This view integrates two dimensions into corporate reputation: multi-stakeholder perceptions and history or time. Thus, Fombrun and Rindova (1996: 3) defined corporate reputation as “... a collective representation of a firm's past actions and results that describe the firm's ability to deliver valued outcomes to multiple stakeholders. It gauges a firm's relative standing both internally with employees and externally with its stakeholders, in both its competitive and institutional environments." In this view, corporate image is the perception of external stakeholders (customers, general public) about a corporation. Corporate identity is the perception of internal stakeholders (managers, employees) about the corporation and reputation is the combination of both perceptions. 
In a recent study, Barnett, Jermier, and Lafferty (2006) reviewed prior corporate reputation definitions to integrate them and push the concept toward 'one vision, one voice'. Building upon Bennett and Kottasz (2000), assembling corporate reputation definitions from 1965 to 2003 together, they clustered definitions into three categories: awareness, assessment, and assets. The awareness cluster includes scholars (e.g., Balmer, 2001; Roberts \& Dowling, 2002) who define corporate reputation as perception of audience. A second group of scholars (e.g., Gotsi \& Wilson, 2001; Deephouse, 2000) look at reputation as a judgment and estimation, forming the assessment cluster. Finally, the assets cluster includes definitions considering reputation as something of value to a firm (e.g., Goldberg, Cohen, \& Fiegenbaum, 2003). In addition, Barnett et al. (2006) defined corporate image and identity independently from a stakeholder perspective. Corporate identity is considered as the 'core' of the firm, a concept close to corporate culture. Corporate image is defined as an observer's (internal or external) perception of the firm, the outcome of a firm's public relation, marketing, and communication activities to shape the impressions of people. Consequently, corporate reputation is the judgment and assessment of observers influenced by corporate image and has value for a firm. Barnett et al. (2006: 34) concluded their work by proposing a definition for corporate reputation: "Observers' collective judgments of a corporation based on assessments of the financial, social, and environmental impacts attributed to the corporation over time".

The lack of consensus on a corporate reputation definition has lead to the development of different tools for measuring reputation. These tools differ in three ways. First, they differ in their underlying corporate reputation definitions. Second, the groups who answered and completed reputation surveys differ to achieve consistency with the 
underlying theory of the measurement tool. Finally, the items and dimensions in the measurement tools differ. A wide range of corporate reputation measures have been developed by business media and academic scholars, such as Fortune's Most Admired Companies (MAC), the RepTrack Pulse (Fombrun \& Van Riel, 2004), and the Corporate Personality Scale (Davies, Chun, Da Silva, \& Roper, 2003).

From the MAC perspective, reputed firms are those strong in characteristics important to executives and financial analysts. Therefore, every year CEOs and financial analysts are asked to rate the ten largest firms in their industry based on eight characteristics: quality of management, quality of products and services, innovativeness, financial soundness, ability to attract, develop, and keep talented people, long-term investment value, responsibility to the community and environment, and wise use of corporate assets. The main limitations of MAC lists are, first, the dominant dimension underlying the measures is financial performance (Fryxell \& Wang, 1994), and second, the lack of a sound theoretical framework (Fombrun \& Shanley, 1990).

The Reptrak Pulse (Fombrun \& Van Riel, 2004) is based on Fombrun's (1996) reputation definition, emphasizing the perceptional-judgmental nature of corporate reputation as well as its multi-stakeholder nature. Therefore, the general public is asked to complete an online survey which assesses multiple firm reputation drivers. This measure also takes a broader geographic sampling frame than MAC since it examines reputations of the largest firms on a global basis.

The Corporate Personality Scale (Davies et al., 2003) is based on the definition which defines corporate reputation as consisting of corporate image and identity. Therefore, customers (representative of external stakeholders and consistent with their 
definition of corporate image) and employees (representative of internal stakeholders and consistent with their definition of corporate identity) are surveyed regarding their perceptions of a firm's personality. The measure was developed based on Aaker's (1997) brand personality (sincerity, excitement, ruggedness, sophistication, competence) and extended from a brand level to an organizational level and includes seven dimensions: agreeableness, enterprise, competence, chic, ruthlessness, machismo, and informality.

In this study, we adopt Fombrun and Rindova's (1996) reputation definition (cited above) and use the RepTrack Pulse measure of corporate reputation which was developed in line with this definition to investigate the hierarchical effects of corporate reputation stimuli on perceptions of the general public. This definition is most consistent with our theory, which advances that members of the public receive reputation signals at multiple levels.

\section{Signaling Theory}

Signaling theory (Spence, 1973) is an information economics theory which discusses the behavior of interacting factors under information asymmetry and uncertainty conditions. In signaling theory, two parties interact with each other: agents or sellers and principals or buyers. The environment is uncertain and agents have information that principals do not have. For example, in a marketplace, there are sellers of a product competing with each other that have information about product quality which is not necessarily available to buyers. Therefore, sellers try to send signals such as price, warrantees, or return policies to buyers to demonstrate a higher quality of their products.

Spence (1973) explained signaling theory using the example of conditions 
employers face when reviewing job applicants. Employers receive two kinds of information from job applicants. One set of attributes are those job applicants generally do not have discretion to change, such as age, gender and ethnicity. Spence (1973) called this group of information "indices". The other attribute group includes characteristics which are subject to manipulation by job applications, like education, which Spence (1973) labeled as "signals." Spence (1973) consequently defined the signaling cost as the cost to adjust or manipulate the signal. A critical assumption is that signaling costs should be negatively correlated with the productive capability of job applicants (Spence, 1973). This critical assumption is the reason for a variety in job applicants' decisions toward education. In other words, without this balancing assumption, all job applicants would make the same decision and would have the same education level. In the example of multiple sellers of a product, the signaling costs incurred to a seller and their product quality are negatively correlated: the higher the product quality, the lower the signaling costs.

Signaling is a dynamic process. In the first point in time, agents (sellers or job applicants) send a signal and principals (buyers or employers) receive and translate the signal to separate (distinguish) agents and make the transaction (buy or hire). After the transaction, principals get feedback (of quality of product or job applicant), learn through this experience and are better able to separate agents next time. This learning process from agents to principals and vice versa continues until a state of equilibrium is achieved (Spence, 1973). Two equilibrium types are separating equilibrium and pooling equilibrium (Boulding \& Kirmani, 1993). In separating equilibrium, the value of a strategy and its cost lead agents to choose different actions. For example, utility 
maintenance companies can adopt a three-day guarantee strategy to show their service quality, which is a valuable strategy for buyers to distinguish between companies. If it takes five days for a maintenance company to deliver the service, the cost of a three-day guarantee would be more than its benefits. Therefore, a low-quality service company would not adopt this strategy. In other words, in separating equilibrium, principals can separate agents. Pooling equilibrium occurs when both low and high quality agents can choose the same strategy and principals cannot separate them. This is a condition in which both service companies can deliver their services in three days. Therefore, only if separating equilibrium occurs, the strategy is a signal which helps principals to distinguish between agents (Boulding \& Kirmani, 1993).

Signaling theory has been widely used in management, marketing, and finance contexts, including research studies on: board of director structure (Miller \& Triana, 2009), corporate social performance (Turban \& Greening, 1997), insider stock trading (Sanders \& Boivie, 2004), labor markets (Spence, 1973), organizational reputation (Behrend, Barker, \& Thomson, 2009), new product introduction (Akerlof, 1970), and price (Milgrom \& Roberts, 1986). However, one factor that has not been studied is the multilevel impacts of signals. Signaling studies investigated the predicting effects of different signals on the desired output factors, without examining the simultaneous impact of factors at multiple levels. Additionally, the interaction of signals with each other in a hierarchical manner is missing from previous studies. Thus, while previous studies demonstrated reputation impacts of firm-level (e.g., Miller \& Triana, 2009), industry-level (e.g., Winn et al., 2008) and country-level (e.g., Apéria, Simcic Brønn, \& Schultz, 2004) factors, these reputation signals have not been simultaneously examined. 
In addition to these direct effects, the interaction of factors at multiple levels has not been examined. In sum, this study intends to investigate not only the individual effect of each signal, but also the hierarchical effects of them.

\section{HYPOTHESES DEVELOPMENT}

In studying multilevel determinants of individual corporate reputation assessments, three sets of hypotheses are suggested: firm-, industry-, and country-level factors. By doing so, we attempt to disentangle the impacts of multi-level signals on individual-level corporate reputation perceptions.

\section{Firm-level Hypotheses}

In this section, we examine reputation assessments as they are impacted by financial performance, social performance, and firm size. Firm characteristics and performance send signals which help stakeholders learn 'true' attributions of the firm and consequently shape their perceptions about the firm.

Financial performance. From an economic perspective of reputation, under information asymmetries between a firm and it stakeholders, stakeholder perceptions are formed based on the signals they receive from a firm's past and current actions. One such signal is financial performance, which serves as a separating signal that allows observers to distinguish between firms. McGuire, Sundgren, and Schneweiss (1988) found that return on assets was significantly correlated with firm reputational rankings. Stakeholders interpret financial signals differently. To the general public, stronger financial results reflects superior business models, more effective management, better resource deployment, more productive personnel, and better overall fit between resources and strategies. This is consistent with the resource-based view, which equates firm success 
with its resources and capabilities (Barney, 1991). Therefore, high financial performance positively affects the general public's perceptions of firms (Fombrun \& Shanley, 1990). Investors and creditors, on the other hand, translate good financial performance to indicate a company's healthy and well-managed standing and that a company is able to achieve positive future results (Gabbioneta et al., 2007). Internal stakeholders, managers and employees, have access to internal information and can analyze the cause and effects of financial results for future modifications. In total, financial success affects internal and external stakeholders' perceptions in a consistent way and raises their admiration and respect for the firm. Therefore, we suggest:

Hypothesis 1 (H1): There is a positive relationship between financial performance and corporate reputation.

Social performance. An institutional perspective on corporate reputation argues that information exchange among diverse institutional actors reduces uncertainty about the 'true' attributes of an organization and shapes its reputation among its stakeholders (Rindova, Williamson, Petkova, \& Sever, 2005). The importance of institutional actors in acquiring and disseminating information about an organization becomes clearer considering that legitimacy is a critical resource for an organization (Pfeffer \& Salancik, 1978). Social performance encompasses a wide range of behaviors which contribute to interests of different stakeholders. Although social behaviors such as community engagement, transparency, philanthropic initiatives, and utilization of sustainable resources are strategic choices and signal an organization's intention to comply with its societal responsibilities, they are costly and therefore separating signals reflecting the 'true' capabilities of the firms. According to attribution theory (Weiner, 1985), 
stakeholders make inferences based on the signals they receive from firm behavior which lead them to possess good feelings about, to admire and to respect firms with characteristics that align with their interests. In fact, many scholars define social responsibility as an integral part of reputation (Fombrun, 1998). Brammer and Pavelin (2006) found that social performance is one of the determinants of good corporate reputation. Therefore, we hypothesize:

Hypothesis 2 (H2): There is a positive relationship between social performance and corporate reputation.

Firm size. According to Rindova and colleagues (2005), two organizational reputation dimensions are perceived products/services quality and firm prominence. Due to a lack of information, the general public is often not aware of the 'true' quality of a firm's products or services. Stakeholders attribute large firms as possessing financial resources, talented employees, advanced technology, and effective networks, all of which are instrumental in producing quality products/services. In other words, although stakeholders are uncertain about output quality, firm size signals clues for evaluating quality. Therefore, firm size reduces the information uncertainty of stakeholders, and shapes positive opinions about the firm. On the other hand, under conditions of uncertainty, stakeholders' opinions are influenced by the opinions of third parties (Rao, Davis, \& Ward, 2000). Hence, information dissemination by third parties determines the prominence of a firm. Larger firms are more visible and more covered by media and as a result, their signals are more available and richer. Therefore, stakeholders are better and more quickly informed about them. In total, larger firms obtain better perceived quality and are more prominent. Therefore, there is less uncertainty about them and stakeholders 
trust them more. Consequently, we suggest:

Hypothesis 3 (H3): There is a positive relationship between firm size and corporate reputation.

\section{Industry-level Hypotheses.}

While there is a large body of literature on corporate reputation, industry effects on reputation have been understudied. While firm-level factors send firm-specific signals to stakeholders, industry-level factors convey more general information about the nature and identity of member firms. Thus, they convey broader-level signals that influence perceptions of all firms in an industry. In this subsection, we examine how industry-level factors affect corporate reputation.

Service industries. Industries can be broadly categorized into manufacturing and services based on information uncertainty about the quality of their outputs. Scholars defined three groups of outputs (products/services): search, experience, and credence (Darby \& Karni, 1973; Nelson, 1970). While quality of search goods can be determined before purchase (electronic appliances), quality of experience goods can be learned only after use (automobile services) and quality of credence goods are difficult to ascertain even after use (management consulting). Services, which are intangible, perishable, customized, simultaneously produced and consumed, produced with consumer participation, and used without ownership (Boddewyn, Halbrich, \& Perry, 1986), fall under the experience and credence categories, where information uncertainty about their quality is higher than for manufacturing products, and this higher uncertainty lowers trust about a firm. From a transaction cost economics perspective (Williamson, 1975), stakeholders incur information gathering and measurement costs (North, 1990) to reduce 
information asymmetry. As these costs are lower for search goods and generally manufacturing products (Kim \& Choi, 2003), stakeholders are more informed about manufacturing businesses, lowering the level of information uncertainty in these industries compared to services. Therefore, manufacturing businesses are more reliable to stakeholders, leading individuals to possess more positive opinions about manufacturing firms. Accordingly, we hypothesize:

Hypothesis 4 (H4): Firms in manufacturing industries have more favorable reputations than those in the service sector.

Industrial products. Companies can also be categorized based on their customers. One category of companies mainly produces intermediary products and offers services to other businesses (B2B), while another category mainly offers services and products to end users (B2C). Unlike companies in B2C industries, companies in B2B businesses have more concentrated customers with larger transaction volumes per customer (Backhaus, 2006; Kotler \& Keller, 2006). In addition, B2B businesses do not have direct relationships with end-users, as this relationship passes through B2C companies (Kotler \& Keller, 2006). Furthermore, the products and services offered by B2B firms are more complicated and require more expertise than those offered by B2C counterparts. Therefore, information asymmetry is greater in $\mathrm{B} 2 \mathrm{~B}$ compared to $\mathrm{B} 2 \mathrm{C}$ businesses, which as a result, influences both the quality perception and prominence dimensions of reputation (Rindova et al., 2005). On the other hand, although both end users and business customers face information uncertainty about quality and credibility of producers and service providers, business customers are more inclined to pay information gathering costs. This reduces the efforts of B2B companies in communicating about 
themselves in more general communication media by concentrating mainly on expertise media. In contrast, in order to reduce information asymmetry and introduce their 'true' attributions, companies in $\mathrm{B} 2 \mathrm{C}$ industries send information and signals more frequently and in larger scope. As a result, there is less information asymmetry between B2C firms and the general public, which increases the public's level of trust and consequently leads to more positive opinions of these companies relative to $\mathrm{B} 2 \mathrm{~B}$ companies, where information uncertainty is higher. Accordingly, we suggest:

Hypothesis 5 (H5): Firms in $\mathrm{B} 2 \mathrm{C}$ industries have more favorable reputations than those in $\mathrm{B} 2 \mathrm{~B}$ industries.

Industry reputation. Industry reputation is defined as "the collective judgments of an industry by stakeholders and the general public, where that judgment is based on assessments of the economic, social and environmental impacts attributed to that industry over time" (Winn et al., 2008: 36). Under conditions of information asymmetry and uncertainty about practices, legitimacy, and the quality of a firm, industry reputation acts as a common characteristic of member firms which signals identity and general firm attributes and makes first impressions among stakeholders. While companies benefit from good industry reputations when firm-specific information is lacking, businesses in controversial industries such Tobacco suffer from stereotyping effects (Maheswaran, 1994). Industry reputations can strongly influence public perceptions of member firms. Specifically, growth of activism such as environmental or human rights activism accompanied with media coverage increases the sensitivity of society toward the social and environmental behavior of firms. Influence groups and media challenging the legitimacy of industries whose operations result in products or byproducts which harm 
society or the environment can cost all industry members by reducing the trust and respect of their stakeholders. Therefore, we hypothesize:

Hypothesis 6 (H6): Firms in controversial industries have less favorable reputations.

\section{Country-level Hypotheses}

Country-level factors influence individual reputation assessments in three ways. First, reputation is formed based on firm actions, which are highly dependent on the context of their operations. Second, a country's infrastructure facilitates information circulation, which affects general public perceptions. Third, people in different countries with different socio-cultural backgrounds interpret information they receive differently. Therefore, in this section, we examine the direct effects of three aspects of the business environment - economic, institutional, and human development - as well as their indirect influences through industry-level factors on reputation evaluations by the general public.

Economic development. Where there are uncertainty and asymmetries in information, a country's economic development level signals infrastructural, technological, and economic advancement of a corporation's environment. In other words, efficient infrastructure, advanced technologies, and potential economic opportunities are prerequisites of economic development. Efficient infrastructure and advanced technologies help firms lower production costs and improve the quality of and innovation in products and services, and consequently may result in more favorable evaluations of the general public about focal firms (Lewis, 2001). In addition, economic development paves the way for firms to invest in research and development and use more sustainable resources, which signal firms' responsible behavior towards society, and as result, facilitate customer trust, an instrument for developing corporate reputation (Walsh et al., 
2009). Furthermore, in economically advanced countries, the infrastructure is more effective in disseminating information, and therefore, signals are richer and more available. Companies can better communicate with their general publics due to greater communication media availability (newspapers, TV channels, and internet) and greater use and higher penetration of these media. Therefore, companies can better inform their audiences about their financial and social activities, which reduces information asymmetry and improves the general public's perceptions towards them (Aperia et al., 2004). Higher purchasing power and better distribution of wealth not only enable people to afford more expensive products/services, but also creates a larger market for innovative, higher quality, and more environmentally friendly products and services. In sum, an economically developed context creates a more suitable environment for firms to offer higher quality products and services, be more innovative, and act more responsible all essential factors in forming reputations. Therefore, we propose:

Hypothesis 7 (H7): There is a positive relationship between a country's economic development level and firm reputations in the country.

Institutional development. Institutional development is another contextual characteristic which signals a firm's stakeholders when they lack complete information about the firm. Developed institutional environments are characterized by high regulatory quality, better developed legal systems, less corruption, economic freedom, and greater competition (Hoskisson, Eden, Lau \& Wright, 2000; Chen, Newburry \& Park, 2009). In addition to setting high quality regulations, enforcement of these laws determines institutional system strength. Therefore, it is expected that strong institutional systems create competitive business environments, effective economic structures, and sustainable 
environmental conditions. Aperia et al. (2004) reports that monopolistic behavior of firms is one reason they achieve lower reputations. Therefore, companies in more developed institutional environments which are more competitive are expected to be perceived better by the public. Furthermore, companies in more competitive and effective environments are in better contexts to produce and offer higher quality products and services, be more innovative, and be more responsible to their internal and external stakeholders, all of which send positive signals to the general public. In more institutionally advanced systems, controlling mechanisms, media, and activist groups are more developed. These independent third parties are sources that disseminate information and influence general public perceptions. Therefore, the general public is better informed and information uncertainty is lower in institutionally developed environments where signals are transmitted more effectively, leading people to perceive firms as more reputable. Accordingly, we suggest:

Hypothesis 8 (H8): There is a positive relationship between a country's institutional development level and firm reputations in the country.

Human development. Human development is another aspect of a country which directly affects a company's business environment. Human development is positively correlated with life expectancy, knowledge and education, and standard of living (UNDP, 2009). Trust is one of the critical determinants of corporate reputation (Walsh et al., 2009). Knowing the complications of winning trust of the general public when they are educated and have access to a variety of information sources, firms become more considerate in their actions. Accordingly, similar to the prior hypotheses, human development of a country may lead the general public to assess firm reputations more 
positively.

On the other hand, people in more developed societies have higher expectations from their focal companies, which are perceived to be the engines for their country's development (Deephouse et al., 2009). One of these expectations is the firm's responsibility towards its society, which affects firm reputations. In Scandinavian countries, which are among the most developed countries in terms of human development, Aperia et al. (2004) found that "treatment of employees" and "treatment of environment" are the most important dimensions of corporate social responsibility. If their expectations are higher than the performance of firms, it could result in dissatisfaction and consequently lower opinions about focal firms (Deephouse et al., 2009). Nonetheless, this counterargument aside, we suggest that:

Hypothesis 9 (H9): There is a positive relationship between a country's human development level and firm reputations in the country.

Industries across countries. In addition to the direct effects hypothesized above, country characteristics interact with industry-level factors to influence corporate reputation assessments. Economic development which creates productive infrastructures and technologies and institutional development which brings quality institutional structure, along with human development which promotes critical minds, pave the way for organizations to be more innovative and produce quality products/services, for media and activism to more profoundly disseminate information, and for the general public to be more analytical and critical. Therefore, in more developed countries, information asymmetry and uncertainty between an organization and its stakeholders is lower and stakeholders are better aware of an organization's true attributes. As argued earlier, due 
to lower information uncertainty, manufacturing industries have relatively higher reputations than service industries. However, more developed environments bring opportunities for service industries to be more effective in conveying their signals and messages, and close the difference between manufacturing and service sectors. By lowering information asymmetry and consequently obtaining trust and esteem from their stakeholders, service firms improve their reputation. In other words, although service firms generally have lower reputations relative to manufacturing firms, development in business environments creates opportunities for them to close this gap. This leads to the following hypothesis:

Hypothesis 10 (H10): As a country's development level increases, the negative impact of operating in a service industry on firm reputation decreases.

Similar to service firms, firms in B2B industries benefit relatively more from business environment development than firms in B2C industries. Since it is more expensive to reduce information asymmetry in less developed economies, and information uncertainty is higher in B2B industries, economic, technological, and institutional development enable B2B businesses to communicate with their stakeholders and the general public more effectively and efficiently. Therefore, we suggest:

Hypothesis 11 (H11): As a country's development level increases, the negative impact of operating in a B2B industry on firm reputation decreases.

Institutional development in advanced countries prepares the environment for emergence and operation of critical media, non-governmental organizations (NGO), and stakeholder activist and movement groups, which have influential roles in monitoring businesses and informing society. More specifically, in advanced countries, these 
organizations closely observe firm behavior in controversial industries and disseminate more signals and information, and as a result, the general public in those countries is more aware and sensitive to social responsibilities of businesses. Therefore, while in general, industry reputation influences corporate reputation, controversial industries are specifically in the center of attention in more advanced countries by media, NGOs, and activist groups, which affects the reputations of member firms. Accordingly, we propose: Hypothesis 12 (H12): As a country's development level increases, the negative impact of operating in a controversial industry on firm reputation increases.

\section{METHODOLOGY}

\section{Sample}

In line with this multi-level special issue, our analyses rely on three levels of data. We utilized a sample of individual-level perception data regarding firm reputations collected by the Reputation Institute in February 2009. The Reputation Institute's 2009 study examined the 600 largest companies in the world based upon sales volume. Additional companies were added to the study to balance the sample for the purpose of comparison in industries and countries. The study companies come from 33 countries. The Reputation Institute administered a multi-item online survey about the perceptions of individuals on different aspects of corporate reputation. Respondents who have at least minimal familiarity with a focal company were selected from a pool of respondents based on a screening criterion to answer 3 out of 4 questions about the company (Asher, 2004). Respondents were also chosen to represent the general population of their countries based on gender and age. Respondents answered questions in their local language to eliminate biases associated with an English-only questionnaire (Harzing, 2005), which was 
translated and back translated by professionals fluent in both English and the language of questionnaire administration to ensure accuracy.

Firm/industry-level and country-level data are from 2007 to consider the lag effect of these signals on individual reputation perceptions. Firm-level data were collected from Compustat North America, Compustat Global, Compustat Financial Services, and Kinder, Lydenberg, Domini (KLD). Due to missing secondary data for some firms (described below), the resulting sample size was 615 firms for our main analyses. Country-level data were collected from different sources including: World Bank, IMF, UNDP, UNCTAD, CIA World Fact Book, and Heritage Foundation.

\section{Dependent Variable}

RepTrack Pulse is the Reputation Institute's measure for corporate reputation, consisting of four items: "good overall reputation;" "a company I have a good feeling about;" "a company that I trust;" and "a company that I admire and respect" (Reputation Institute, 2007). These general descriptors are consistent with past research finding that items measuring general perceptions tend to have greater face validity across cultures than more specific culturally derived items (e.g., Scandura, Williams, \& Hamilton, 2001). Respondents evaluated each item on a 7-point scale, where "1" indicates "I strongly disagree" and "7" indicates "I strongly agree". Respondents also had the option to indicate "Not Sure". Although interpretation of items can vary across cultures (Gardberg, 2006), their factor structure was evaluated in each country and found to be equivalent. LISREL analyses confirmed the unidimensionality, convergent validity, and fit of the scale items. The scale Chronbach Alpha is 0.963 .

\section{Independent Variables}


Firm-Level Variables. To measure Financial Performance (H1), we used ROE since our sample includes both manufacturing and service firms. Given a lack of comparable international data on Social Performance, we tested H2 in a smaller sample of 120 US firms. Social performance is measured by two variables from KLD: number of concerns and number of strengths, referring to the number of actions or behaviors of a firm which have been considered as negative social behavior by experts and the total number of positive social performance actions. An alternate individual-level measure based on perceptions of a firm's social performance was also used to corroborate the results. Firm Size (H3) was measured as total revenue in 2007.

Industry-Level Variables. Manufacturing (H4) is dichotomous, indicating if a firm was in a manufacturing or service industry. $B 2 B(\mathrm{H} 5)$ is dichotomous, indicating if a firm's customers are primarily other businesses, as opposed to end consumers. Controversial (H6) is dichotomous, indicating firms that operate in industries known to be controversial based on KLD categorizations. In our case, these included Alcohol, Tobacco, Military and firearms, and Petroleum.

Country-Level Variables. Economic Development (H7) is measured by GDP, and the GINI index, which indicates the degree of income inequality in a nation. We did not use GDP per capita due to high correlations with our other country-level variables. For Institutional Development (H8), we used the Heritage Foundation's Index of Economic Freedom, which is based on ten measures: business freedom, trade freedom, fiscal freedom, government size, monetary freedom, investment freedom, financial freedom, property rights, freedom from corruption, and labor freedom. Finally, Human Development (H9) is measured using country education levels, represented by the 
percentage of students in primary, secondary and tertiary education as reported by UNDP. Note that we considered using the UNDP's Human Development Index (HDI) for this variable, but chose education due to high correlations between HDI and our other country-level variables.

Interaction Variables. Interactions proposed in hypotheses 10-12 were created in the program HLM6. Business/industry variables were group centered in the model and country variables were grand centered to reduce multicollinearity issues.

\section{Control Variables}

We controlled for individual-level respondent demographic characteristics. Gender is dichotomous, coded as "1" for females and " 0 " for males. Respondent Age is categorical, ranging from " 1 " to " 10 " where " 1 " is for respondents under 18 years old and "10" for those of over 60 years old. Education is categorical, ranging from "1" for respondents with less than a basic education to " 7 " if a respondent completed graduate school. Household Income is measured through different scales due to variability of living standards across the countries in our sample, and thereafter, these scores were standardized to be included in the same dataset (Craig \& Douglas, 2000). The standardized Household Income variable is categorical with three levels: low income (coded as "1"), mid-level income (coded as "2"), and affluent (coded as "3").

\section{Analysis}

To analyze the multilevel effects of our nested data in three levels (individual within company/industry within country), we used the hierarchical linear modeling program HLM 6 (Raudenbush et al., 2004). This program allowed us to control for the effect of each level on its nested level(s) and simultaneously take into account the 
interdependence of individual-level data in higher level data, which ordinary least squares (OLS) regression does not account for. Note that for our statistical analyses, firm- and industry-level variables were collapsed into one category.

\section{RESULTS}

Tables 1.1,1.2, and 1.3 report the descriptive statistics and correlations for individual-, company/industry-, and country-level variables, respectively.

TABLE 1.1: Individual-level Variables: Descriptive Statistics and Correlations

\begin{tabular}{|c|c|c|c|c|c|c|c|}
\hline & Variable & Mean & $S D$ & 1 & 2 & 3 & 4 \\
\hline 1 & RepTrak Pulse & 4.83 & 1.53 & & & & \\
\hline 2 & Gender & 1.48 & 0.50 & $0.02 * *$ & & & \\
\hline 3 & Age & 2.94 & 1.06 & $-0.06^{* *}$ & $-0.08 * *$ & & \\
\hline 4 & Education & 2.48 & 0.68 & $0.02 * *$ & $-0.04 * *$ & $-0.11^{* *}$ & \\
\hline 5 & Income & 1.90 & 0.74 & -0.00 & $-0.05 * *$ & $0.08 * *$ & $0.17 * *$ \\
\hline
\end{tabular}

TABLE 1.2: Firm-level Variables: Descriptive Statistics and Correlations

\begin{tabular}{llcccccccc}
\hline \multicolumn{1}{c}{ Variable } & Mean & SD & $\mathbf{1}$ & $\mathbf{2}$ & $\mathbf{3}$ & $\mathbf{4}$ & $\mathbf{5}$ & $\mathbf{6}$ \\
\hline 1 & ROE (H1) & 0.18 & 1.60 & & & & & & \\
2 & Social: Concerns (H2) & 5.66 & 3.44 & 0.04 & & & & & \\
3 & Social: Strengths (H2) & 5.89 & 4.19 & -0.06 & $0.25^{* *}$ & & & & \\
4 & Revenue (H3) & 35803 & 51801 & 0.00 & $0.58^{* *}$ & $0.22^{* *}$ & & & \\
5 & Manufacturing (H4) & 0.58 & 0.49 & 0.03 & $0.28^{* *}$ & $0.42^{* *}$ & 0.13 & & \\
6 & B2B (H5) & 0.14 & 0.35 & -0.00 & 0.11 & 0.09 & $-0.14^{* *}$ & $0.37^{* *}$ & \\
7 & Controversial (H6) & 0.09 & 0.29 & 0.01 & $0.32^{* *}$ & -0.11 & $0.24^{* *}$ & $0.30^{* *}$ & 0.00 \\
\hline $\mathrm{N}=615$ except for social (concerns and strengths), where $\mathrm{N}=120 * * * \mathrm{p}<01 ; * \mathrm{p}<05$
\end{tabular}

TABLE 1.3: Country-level Variables: Descriptive Statistics and Correlations

\begin{tabular}{llccccc}
\hline \multicolumn{1}{c}{ Variable } & Mean & SD & $\mathbf{1}$ & $\mathbf{2}$ & $\mathbf{3}$ \\
\hline 1 & GDP (H7) & 1479.57 & 2508.13 & & & \\
2 & GINI Index (H7) & 36.66 & 9.91 & 0.13 & & \\
3 & Index of Economic Freedom (H8) & 69.49 & 9.54 & 0.13 & -0.26 & \\
4 & Education (H9) & 0.94 & 0.07 & 0.06 & $-0.52^{* *}$ & $0.52^{* *}$ \\
\hline & $\mathrm{N}=33 ; * \mathrm{p}<.01 ; * \mathrm{p}<.05$ & & & & &
\end{tabular}


Table 1.4 and 1.5 present the results of the hierarchical models used to test our hypotheses. Model 1 presents the base model testing hypotheses 1 and 3 to 9. Models 2, 3, and 4 repeat the analysis to test hypothesis 2 , where models 2 and 3 only use the US subsample, while model 4 uses the entire sample. Models 5 through 16 investigate moderating effects of country-level predictors on industry-level factors. All models had significant Chi-squares $(\mathrm{p}<.001)$. To minimize multicollinearity issues, each interaction is tested in a separate model.

At the firm/industry level, Hypothesis 1 predicted a positive relationship between a firm's financial performance and its reputation. The Model 1 results indicate that although the direction is as expected, the effect is not significant. Thus, hypothesis 1 is not supported.

Hypothesis 2 suggested that firm social performance has a positive impact on their reputations. Due to an inability to collect firm-level data on social performance cross-nationally, this hypothesis is tested in Model 2 using a subsample of US firms based on KLD measures of firm social performance concerns as well as strengths. The effect of the number of CSR concerns (number of negative actions) on corporate reputation is negative and significant $(\mathrm{p}<.05)$, while the number of CSR strengths (number of positive actions) is highly significant and positive $(\mathrm{p}<.01)$ in predicting corporate reputation. Both these results support H2. In Model 3, removing the highly correlated controversial industry variable makes these results even stronger. These results also maintain the same levels of significance when the variables are introduced individually into the models (not shown). Model 4 contains an alternate $\mathrm{H} 2$ test using an individual-level measure of perceptions of firm social performance, which allows us to 
examine the relationship for the full sample. This result confirms the Model 2 and 3 findings and is strongly significant $(\mathrm{p}<.001)$.

Hypothesis 3 proposed that larger firms have more positive reputations. Although the variable sign is in the expected direction in Model 1, the result is not significant. Hypothesis 4 predicted that the general public more positively assesses firms in manufacturing industries compared to those in the service sector. The results strongly support $(\mathrm{p}<.001)$ this prediction. Hypothesis 5 suggested that the public has more positive opinions about B2C versus B2B firms. Again, the result is high significant $(\mathrm{p}<.001)$, supporting the hypothesis. Hypothesis 6 hypothesized that firms in controversial industries have lower reputations. The Model 1 results strongly support $(\mathrm{p}<.001)$ the hypothesis.

At the country-level, Hypothesis 7 suggested that a country's economic development positively affects the reputations of its companies. Two aspects of economic development were tested. Production/infrastructure (GDP) is not significant. However, potential market, measured by equality of income distribution (GINI index), is highly significant $(\mathrm{p}<.001)$, but not in the predicted direction. Hypothesis 8 predicted that reputation assessments would be higher in countries with more developed institutional systems, as measured by the index of economic freedom. Although the model reports significant $(\mathrm{p}<.01)$ results, the direction is opposite to our expectations. Hypothesis 9 suggested a positive relationship between a country's human development level (proxied by education) and reputation assessments of firms operating in that country. Education was significant $(\mathrm{p}<.01)$, but again opposite the predicted direction.

In addition to direct effects, we investigated whether country-level factors 
moderate the effects of industry-level variables on reputation assessments. Hypothesis 10 argued that as a country's development level increases, the negative impact of operating in a service industry on firm reputations decreases. This hypothesis is tested through four development measures, separated into individual models to avoid multicollinearity issues. Models 5 and 8 testing economic (GDP) and human (education) development support Hypothesis 10 at the $p<.05$ level. Model 6 testing equality of income distribution (GINI Index) reports a significant result, but not in the expected direction and Model 7 testing institutional development does not find a significant result.

Hypothesis 11 argued that in more developed countries, the negative impact of operating in B2B industries on firm reputation would be lower. Models 9, 10, 11, and 12 test this hypothesis, Institutional development (Model 11) is significant $(\mathrm{p}<.05)$, but not in the predicted direction, while human development (education) (Model 12) is highly significant $(\mathrm{p}<.001)$ as expected. Finally, Models 13 through 16 test Hypothesis 12, which argued that as country development increases, the negative effects of operating in a controversial industry on firm reputation increase. Results highly support the hypothesis for the dimensions of economic $(\mathrm{p}<.01)$, institutional $(\mathrm{p}<.001)$, and human $(\mathrm{p}<.001)$ development.

We controlled for respondent gender, age, education, and income. The Model 1 results indicate that among respondents from 33 countries, females and people with higher income significantly evaluate firms more positively, and more educated people possess significantly lower opinions about firms. Models 2 and 3 show that in the U.S., gender and income are not determining factors of firm reputation assessments and older and more educated people have significantly more negative perceptions about firms. 
TABLE 1.4: Regression Analysis Predicting Corporate Reputation Perception

\begin{tabular}{|c|c|c|c|c|c|c|c|c|}
\hline Variable & Model 1 & Model 2 & Model 3 & Model 4 & Model 5 & Model 6 & Model 7 & Model 8 \\
\hline Intercept & $5.01(.05)^{* * *}$ & $5.15(.04)^{* * *}$ & $5.15(.04)^{* * *}$ & $5.04(.04)^{* * *}$ & $5.01(.04)^{* * *}$ & $5.01(.04)^{* * *}$ & $5.01(.04)^{* * *}$ & $5.01(.05)^{* * *}$ \\
\hline \multicolumn{9}{|l|}{ Level 1 - Individual } \\
\hline Gender & $0.06(.01)^{* * *}$ & $0.05(.03)+$ & $0.05(.03)+$ & $-0.00(.01)$ & $0.06(.01)^{* * *}$ & $0.06(.01)^{* * *}$ & $0.06(.01)^{* * *}$ & $0.06(.01)^{* * *}$ \\
\hline Age & $-0.02(.01)$ & $-0.05(.01)^{* * *}$ & $-0.05(.01)^{* * *}$ & $0.01(.00)^{*}$ & $-0.02(.01)$ & $-0.02(.01)$ & $-0.02(.01)$ & $-0.02(.01)$ \\
\hline Education & $-0.07(.01)^{* * *}$ & $-0.11(.03)^{* * *}$ & $-0.11(.03)^{* * *}$ & $0.03(.01)^{* *}$ & $-0.07(.01)^{* * *}$ & $-0.07(.01)^{* * *}$ & $-0.07(.01)^{* * *}$ & $-0.07(.01)^{* * *}$ \\
\hline Household Income & $0.03(.01)^{* *}$ & $0.02(.02)$ & $0.02(.02)$ & $0.01(.01)^{* *}$ & $0.03(.01)^{* *}$ & $0.03(.01)^{* *}$ & $0.03(.01)^{* *}$ & $0.03(.01)^{* *}$ \\
\hline Social Perf. (H2) & & & & $1.26(.01)^{* * *}$ & & & & \\
\hline \multicolumn{9}{|l|}{ Level 2 - Comp./Ind. } \\
\hline Return on Equity (H1) & $0.00(.01)$ & $-0.01(.09)$ & $-0.02(.08)$ & $0.00(.01)$ & $0.00(.01)$ & $0.00(.01)$ & $0.00(.01)$ & $0.00(.01)$ \\
\hline Social Concerns (H2) & & $-.03(.01)^{*}$ & $-.04(.01)^{* *}$ & & & & & \\
\hline Social Strengths (H2) & & $.03(.03)^{* *}$ & $.05(.01)^{* * *}$ & & & & & \\
\hline Revenue (H3) & $0.00(.00)$ & $-0.00(.00)$ & $-0.00(.00)$ & $0.00(.00)$ & $0.00(.00)$ & $0.00(.00)$ & $0.00(.00)$ & $0.00(.00)$ \\
\hline Manufacturing (H4) & $0.41(.06)^{* * *}$ & $0.11(.11)$ & $0.01(.10)$ & $0.36(.05)^{* * *}$ & $0.47(.08)^{* * *}$ & $0.43(.06)^{* * *}$ & $0.41(.06)^{* * *}$ & $0.40(.06)^{* * *}$ \\
\hline Bus.-to-Bus. (H5) & $-0.23(.06)^{* * *}$ & $-0.01(.15)$ & $-0.09(.13)$ & $-0.25(.06)^{* * *}$ & $-0.23(.06)^{* * *}$ & $-0.24(.06)^{* * *}$ & $-0.22(.06)^{* * *}$ & $-0.23(.06)^{* * *}$ \\
\hline Controversial Ind. (H6) & $-0.41(.07)^{* * *}$ & $-0.39(.18)^{*}$ & & $-0.36(.06)^{* * *}$ & $-0.41(.07)^{* * *}$ & $-0.41(.06)^{* * *}$ & $-0.41(.07)^{* * *}$ & $-0.41(.07)^{* * *}$ \\
\hline \multicolumn{9}{|l|}{ Level 3 - Country } \\
\hline GDP (H7) & $0.00(.00)$ & & & $0.00(.00)$ & $0.00(.00)$ & $0.00(.00)$ & $0.00(.00)$ & $0.00(.00)$ \\
\hline GINI Index (H7) & $0.02(.01)^{* * *}$ & & & $0.02(.01)^{* * *}$ & $0.02(.01)^{* * *}$ & $0.02(.01)^{* * *}$ & $0.02(.01)^{* * *}$ & $0.02(.01)^{* * *}$ \\
\hline IEF (H8) & $-0.01(.00)^{* *}$ & & & $-.01(.00)^{* *}$ & $-0.01(.00)^{* *}$ & $-0.01(.00)^{* *}$ & $-0.01(.00)^{* *}$ & $-0.01(.00)^{* *}$ \\
\hline Education (H9) & $-1.34(.42)^{* *}$ & & & $-1.43(.34)^{* * *}$ & $-1.35(.42)^{* *}$ & $-1.34(.41)^{* *}$ & $-1.34(.41)^{* *}$ & $-1.35(.42)^{* *}$ \\
\hline GDP*Manufact. (H10) & & & & & $-0.00(.00)^{*}$ & & & \\
\hline GINI*Manufact. (H10) & & & & & & $-0.01(.01)^{*}$ & & \\
\hline IEF*Manufact. (H10) & & & & & & & $-0.00(.01)$ & \\
\hline Educ*Manufact.. (H10) & & & & & & & & $1.20(.58)^{*}$ \\
\hline $\mathrm{X}^{2}$ Levels 1 and 2 & $8432.62 * * *$ & $1172.69 * * *$ & $1246.89 * * *$ & $15019.82 * * *$ & $8284.77 * * *$ & $8184.74 * * *$ & $8436.55 * * *$ & $8348.18 * * *$ \\
\hline$X^{2}$ Level 3 & $118.96^{* * *}$ & & & $117.65^{* * *}$ & $120.26^{* * *}$ & $120.73 * * *$ & $119.01 * * *$ & $119.68 * * *$ \\
\hline Deviance & 245,429 & 43,625 & 43631 & 100901 & 245,423 & 245,420 & 245,429 & 245,426 \\
\hline $\mathbf{N}$ - Level 1 & 71368 & 12417 & 12417 & 44074 & 71368 & 71368 & 71368 & 71368 \\
\hline $\mathbf{N}$ - Level 2 & 615 & 120 & 120 & 591 & 615 & 615 & 615 & 615 \\
\hline $\mathbf{N}-$ Level 3 & 33 & & & 33 & 33 & 33 & 33 & 33 \\
\hline
\end{tabular}

$* * * \mathrm{p}<.001 ; * * \mathrm{p}<.01 ; * \mathrm{p}<.05 ;+\mathrm{p}<.10 ;$ Regressions present beta coefficients (standard errors in parentheses). 
TABLE 1.5: Regression Analysis Predicting Corporate Reputation Perception

\begin{tabular}{|c|c|c|c|c|c|c|c|c|}
\hline Variable & Model 9 & Model 10 & Model 11 & Model 12 & Model 13 & Model 14 & Model 15 & Model 16 \\
\hline Intercept & $5.01(.05)^{* * *}$ & $5.01(.05)^{* * *}$ & $5.01(.05)^{* * *}$ & $5.01(.05)^{* * *}$ & $5.01(.05)^{* * *}$ & $5.01(.05)^{* * *}$ & $5.01(.05)^{* * *}$ & $5.01(.05)^{* * *}$ \\
\hline \multicolumn{9}{|l|}{ Level 1 - Individual } \\
\hline Gender & $0.06(.01)^{* * *}$ & $0.06(.01)^{* * *}$ & $0.06(.01)^{* * *}$ & $0.06(.01)^{* * *}$ & $0.06(.01)^{* * *}$ & $0.06(.01)^{* * *}$ & $0.06(.01)^{* * *}$ & $0.06(.01)^{* * *}$ \\
\hline Age & $-0.02(.01)$ & $-0.02(.01)$ & $-0.02(.01)$ & $-0.02(.01)$ & $-0.02(.01)$ & $-0.02(.01)$ & $-0.02(.01)$ & $-0.02(.01)$ \\
\hline Education & $-0.07(.01)^{* * *}$ & $-0.07(.01)^{* * *}$ & $-0.07(.01)^{* * *}$ & $-0.07(.01)^{* * *}$ & $-0.07(.01)^{* * *}$ & $-0.07(.01)^{* * *}$ & $-0.07(.01)^{* * *}$ & $-0.07(.01)^{* * *}$ \\
\hline Household Income & $0.03(.01)^{* *}$ & $0.03(.01)^{* *}$ & $0.03(.01)^{* *}$ & $0.03(.01)^{* *}$ & $0.03(.01)^{* *}$ & $0.03(.01)^{* *}$ & $0.03(.01)^{* *}$ & $0.03(.01)^{* *}$ \\
\hline \multicolumn{9}{|l|}{ Level 2 - Comp./Ind. } \\
\hline Return on Equity (H1) & $0.00(.01)$ & $0.00(.01)$ & $0.00(.01)$ & $0.00(.01)$ & $0.00(.01)$ & $0.00(.01)$ & $0.00(.01)$ & $0.00(.01)$ \\
\hline Revenue (H3) & $0.00(.00)$ & $0.00(.00)$ & $0.00(.00)$ & $0.00(.00)$ & $0.00(.00)$ & $0.00(.00)$ & $0.00(.00)$ & $0.00(.00)$ \\
\hline Manufacturing (H4) & $0.41(.06)^{* * *}$ & $0.41(.06)^{* * *}$ & $0.40(.06)^{* * *}$ & $0.40(.06)^{* * *}$ & $0.40(.06)^{* * *}$ & $0.41(.06)^{* * *}$ & $0.40(.06)^{* * *}$ & $0.41(.06)^{* * *}$ \\
\hline Bus.-to-Bus. (H5) & $-0.24(.06)^{* * *}$ & $-0.22(.06)^{* * *}$ & $-0.26(.06)^{* * *}$ & $-0.22(.05)^{* * *}$ & $-0.20(.07)^{* * *}$ & $-0.23(.06)^{* * *}$ & $-0.20(.06)^{* * *}$ & $-0.21(.06)^{* * *}$ \\
\hline Controversial Ind. (H6) & $-0.42(.07)^{* * *}$ & $-0.41(.07)^{* * *}$ & $-0.43(.07)^{* * *}$ & $-0.43(.07)^{* * *}$ & $-0.34(.08)^{* * *}$ & $-0.43(.07)^{* * *}$ & $-0.39(.07)^{* * *}$ & $-0.43(.06)^{* * *}$ \\
\hline \multicolumn{9}{|l|}{ Level 3 - Country } \\
\hline GDP (H7) & $0.00(.00)$ & $0.00(.00)$ & $0.00(.00)$ & $0.00(.00)$ & $0.00(.00)$ & $0.00(.00)$ & $0.00(.00)$ & $0.00(.00)$ \\
\hline GINI Index (H7) & $0.02(.01)^{* * *}$ & $0.02(.01)^{* * *}$ & $0.02(.01)^{* * *}$ & $0.02(.01)^{* * *}$ & $0.02(.01)^{* * *}$ & $0.02(.01)^{* * *}$ & $0.02(.01)^{* * *}$ & $0.02(.01)^{* * *}$ \\
\hline IEF (H8) & $-.01(.00)^{* *}$ & $-.01(.00)^{* *}$ & $-.01(.00)^{* *}$ & $-.01(.00)^{* *}$ & $-.01(.00)^{* *}$ & $-.01(.00)^{* *}$ & $-.01(.00)^{* *}$ & $-.01(.00)^{* *}$ \\
\hline Education (H9) & $-1.34(.42)^{* *}$ & $-1.35(.42)^{* *}$ & $-1.35(.42)^{* * *}$ & $-1.35(.42)^{* *}$ & $-1.35(.42)^{* *}$ & $-1.35(.42)^{* *}$ & $-1.35(.41)^{* *}$ & $-1.35(.41)^{* *}$ \\
\hline GDP*B2B (H11) & $0.00(.00)$ & & & & & & & \\
\hline GINI*B2B (H11) & & $-0.00(.01)$ & & & & & & \\
\hline $\mathrm{IEF} * \mathrm{~B} 2 \mathrm{~B}(\mathrm{H} 11)$ & & & $-0.01(.00)^{*}$ & & & & & \\
\hline Educ*B2B (H11) & & & & $1.31(.30)^{* * *}$ & & & & \\
\hline GDP*Controversy (H12) & & & & & $-0.00(.00)^{* *}$ & & & \\
\hline GINI*Controversy (H12) & & & & & & $0.01(.01)$ & & \\
\hline IEF*Controversy (H12) & & & & & & & $-0.02(.00)^{* * *}$ & \\
\hline Educ*Controversy (H12) & & & & & & & & $-1.52(.45)^{* * *}$ \\
\hline $\mathrm{X}^{2}$ Levels 1 and 2 & $8440.51 * * *$ & $8416.85^{* * *}$ & $8415.12 * * *$ & $8362.19^{* * *}$ & $8366.33^{* * *}$ & $8461.49 * * *$ & $8415.28 * * *$ & $8423.07 * * *$ \\
\hline$X^{2}$ Level 3 & $118.99^{* * *}$ & $118.91 * * *$ & $119.52 * * *$ & $119.88^{* * *}$ & $119.59^{* * *}$ & $119.07 * * *$ & $120.28 * * *$ & $119.86^{* * *}$ \\
\hline Deviance & 245,429 & 245,429 & 245,426 & 245,424 & 245,426 & 245,428 & 245,423 & 245,425 \\
\hline N - Level 1 & 71368 & 71368 & 44074 & 71368 & 71368 & 71368 & 71368 & 71368 \\
\hline $\mathbf{N}$ - Level 2 & 615 & 615 & 591 & 615 & 615 & 615 & 615 & 615 \\
\hline $\mathbf{N}$ - Level 3 & 33 & 33 & 33 & 33 & 33 & 33 & 33 & 33 \\
\hline
\end{tabular}

${ }^{* * *} \mathrm{p}<.001 ; * * \mathrm{p}<.01 ;{ }^{*} \mathrm{p}<.05 ;+\mathrm{p}<.10 ;$ Regressions present beta coefficients (standard errors in parentheses). 


\section{DISCUSSION AND CONCLUSIONS}

This study's purposes were twofold. First, we aimed to investigate the determinants of the general public's perceptions of firm reputations at different levels, including firm-level, industry-level, and country-level signals. Second, from a methodological perspective, this paper aimed to analyze the effects of interdependent predicting variables (individuals within companies/industries within countries) on a criterion variable. At the firm level, we studied the effects of financial performance, social performance, and firm size. At the industry level, industries were differentiated based on their output (manufacturing vs. service), customer (B2B vs. B2C), and reputation (controversial vs. non-controversial). At the country-level, direct effects of three aspects of country development including economic, institutional, and human development on corporate reputation were analyzed. In addition, we studied how country-level development moderates the effects of industry-level factors on firm reputation. Overall, although we found significant results for most of our direct-effect hypotheses as well as multiple moderating effects, surprisingly, our country-level results were consistently opposite to the direction we expected.

Looking at the firm-level results in more detail, the hierarchical linear model demonstrates support only for social performance. Consistent with past studies (Brammer \& Pavelin, 2006; Fombrun, 1998), results showed that the general public has more positive opinions about socially responsible firms. Social performance was operationalized two ways - by the social behavior of firms based on the opinions of experts who monitored social practices of firms, and based on the general public's perceptions of social performance. Both sets of results indicated that social performance 
has a highly significant influence on corporate reputation. Combining the financial and social performance results suggest that while financial performance has been found to impact firm reputation measures computed by financial analysts (e.g., MAC), social performance is more important to the general public.

We find strong evidence for industry effects on corporate reputation. First, we found strong evidence that manufacturing companies have more favorable reputations compared to service sector companies, consistent with Fombrun (1996) and Kim and Choi (2003). These results trace back to differences between services and products. Not only is controlling, improving, and maintaining high quality over time harder in services, but also evaluation of quality is more subjective. However, reputation has a strategic role in service industries, where consumers' evaluations of service quality are incomplete before purchasing the service (Wang, Lo \& Hui, 2003). Similarly, results demonstrated that firms in $\mathrm{B} 2 \mathrm{C}$ businesses have relatively more favorable reputations than firms in $\mathrm{B} 2 \mathrm{~B}$ industries. While $\mathrm{B} 2 \mathrm{C}$ companies have direct interaction with the general public, B2B firms are less engaged with end users. In addition, the higher complexity of B2B businesses and products/services deepens the information asymmetry between firms and stakeholders. In sum, the relatively higher information uncertainty in services compared to manufacturing and in $\mathrm{B} 2 \mathrm{~B}$ businesses compared to $\mathrm{B} 2 \mathrm{C}$ counterparts confirms the importance of communication in shaping general public perceptions, which is consistent with Fombrun and Shanley (1990) findings. Additionally, we found strong evidence that firms in controversial industries had lower reputation assessments. Consistent with Winn et al. (2008), results were highly significant, emphasizing the influence of industry reputation signals. Unlike firm-level factors, industry reputation signals the nature and 
identity of member firms. In other words, industry reputation conveys the common characteristics of member firms. When sufficient and reliable information about a firm is not available, the public generalizes industry reputations to member firms through stereotypical perceptions. Our analysis demonstrated that firms in controversial industries inherit the negative perceptions of the general public towards their industry.

At the country level, economic, institutional, and human development were examined. We found highly significant results suggesting that all three types of countrylevel development negatively relate to reputation assessments, opposite to our predictions. Although the direction was not as expected, highly significant outcomes show the importance of country-level factors, and calls for more research in this relatively neglected research area. Our country-level results were consistent with Deephouse et al.'s (2009) firm-level finding that corporate reputation is higher in countries with lower institutional development. We could think of three reasons for the unexpected negative direction of these findings. First, the structure of economies varies depending on their development level. In the process of industrialization, countries are changing their agriculture-based economies to become more industrial- and manufacturing-based in nature. More advanced countries have passed this stage and are converting their industrybased economies to become more knowledge- and service-oriented. Therefore, it is not surprising to see service sectors such as financial services, insurances, and telecommunication have a stronger role in more developed countries. Given our earlier result that service firms have lower reputations than manufacturing firms, people in more developed countries trust their companies less.

Second, in more developed countries, institutions are stronger, corruption is lower, 
government is more effective, and law enforcement is more serious (Hoskisson et al., 2000; Chen et al., 2009), while media, news agencies, and newspapers are stronger and people are more educated. Therefore, activities of large visible firms are better captured, scandals are reported, cover ups are more difficult, and consequently, people receive more information and stronger signals about firms. By contrast, in less developed countries, large companies have more bargaining power vis-à-vis law enforcement and media. Thus, people in less developed countries would evaluate corporations with higher reputations due to the differentiated signals they receive.

Third, expectations of firms differ between developed and less developed countries (Chen et al., 2009). Deephouse et al. (2009) argued that people in countries with lower institutional development levels compare private companies with less efficiently run state-owned companies. Therefore, they would more likely appreciate large private companies. On the other hand, people in countries with higher institutional development levels have post-materialist values (Inglehart \& Abramson, 1999), and therefore, evaluate corporations less positively (Deephouse et al., 2009). In sum, countrylevel reputation determinants shed light on new, and less studied mechanisms impacting corporate reputation.

In addition to investigating the direct effects of various reputation predictors in a hierarchical linear model, this study analyzed how country-level factors moderate the impact of industry-level factors on reputation assessments. Results confirm past studies showing the importance of communication on influencing public perception (Fombrun \& Shanley, 1990) by comparing business environments with different capability levels in disseminating information. However, we add to previous work by highlighting the 
importance of content and quality of disseminated information. While countries with advanced communication platforms help B2B businesses influencing public opinion in their favor, they also negatively affect firm reputations in controversial industries. We previously demonstrated that firms in manufacturing have more favorable reputations than firms in the service sector. However, our analyses indicated that in countries with higher education levels, operating in manufacturing industries has an even more favorable effect the firm's reputation, suggesting that information and signals sent by service firms are less convincing for more educated people and casting new doubts about the reliability and trustworthiness of service firms.

Similarly, country development affects the B2B-reputation assessment relationship. It was argued that due to larger information asymmetry, firms in B2B industries have lower reputations. Our cross-country analysis indicates that as country education level increases, the negative impact of operating in $\mathrm{B} 2 \mathrm{~B}$ industries decreases. This is mainly due to more effective and efficient communication between B2B firms and their stakeholders as both signal senders and receivers. Greater complexity of B2B output is one of the reasons for higher information asymmetry, which impacts firm reputations negatively. However, in more educated countries, stakeholders are more knowledgeable, which help B2B businesses reduce the information gap. Finally, the study shows that industry reputation has a stronger impact on firm reputation in more advanced countries. More specifically, firms operating in controversial industries such as the Tobacco industry suffer more from industry reputation in countries with higher economic, institutional, and human development levels. In developed countries, monitoring institutions such as standards and regulations, media, and activist groups are more 
developed and infrastructure is more available for them to reach their audiences. In addition, people are more educated, and consequently, demonstrate greater concern for environmental issues and human rights. In total, this study demonstrates that the business environment strongly affects firm reputation assessments both directly, and through its indirect effects on industry-level factors.

Our study findings also provide practical suggestions for managers. First, information asymmetry is a reason for low reputations. Results indicated that general public has more positive opinions if it is aware a firm is socially responsible. Therefore, effective communication with stakeholders can increase a firm's reputation. This is particularly important for firms in service sectors and B2B industries where information uncertainty is higher, and in controversial industries, where stereotype effects are stronger and the public is less able to differentiate a firm from its peers. Second, companies performing in multiple industries and/or countries or planning to diversify should realize that reputation is a context-dependent phenomenon. In other words, having a favorable reputation in one industry or one country does not guarantee a favorable reputation in a new setting. Each industry/country has its own characteristics and requires customized strategies. Finally, companies should be aware that reputation is dynamic and stems from the general public's expectations of a firm. Depending on their development level, societal expectations of firms differ. The generally lower reputations of firms in more advanced countries compared to less developed countries indicate that firms in developed countries have not adapted to society's evolving needs, values, and expectations.

We acknowledge study limitations provide opportunities for future research. First, 
we recognized the interdependence between firm-level and country-level variables, but we did not examine the effects of country-level factors on each of the firm-level factors in our model. It would be interesting to see how country-level factors moderate the firmlevel variable relationships with reputation. Second, corporate reputation is an aggregate of the general public's perceptions about different aspects of a company, of which we only studied three: financial performance, social performance, and firm size. Future studies can investigate the effects of other aspects such as quality of leadership, corporate governance, workplace, level of international expansion, and age. Third, this paper only studied three types of industries. There is a need for deeper investigation of industry characteristics and their effects on corporate reputation. Fourth, minimal studies have examined country-level determinants of corporate reputation. Although we analyzed country-level factors in 33 countries, we did not investigate each country individually, which could explain more about the mechanisms underlying corporate reputation. In addition, examining the effects of other country-level factors such as culture or media effectiveness/penetration, would be worthwhile. Fifth, social performance was tested only on the subsample of US firms due to lack of a worldwide measure of social performance. It would be interesting to extend this analysis into other countries. Finally, this is a crosssectional study of corporate reputation. Future work can research reasons for corporate reputation changes.

In summary, this study aimed to further the corporate reputation literature in two ways. Theoretically, there is a lack of studies analyzing industry- and country-level antecedents of corporate reputations, and we helped overcome this limitation by finding significant industry- and country-level effects, in addition to more commonly studied 
firm-level variables. Methodologically, this study contributes in terms of using multilevel analysis techniques to examine corporate reputation. Using multi-level analysis, this study recognizes the interdependence among the variables at different analysis levels and captures more accurate effects of higher level variables on our criterion variable. 


\section{ESSAY 2:}

\section{THE IMPACT OF STAKEHOLDER POWER ON CORPORATE REPUTATION:}

A CROSS-COUNTRY CORPORATE GOVERNANCE PERSPECTIVE

\section{INTRODUCTION}

Why do corporations exist? The role of the business corporation in society is one of the oldest and most passionately debated topics in the social sciences (Jensen, 2001; Sundaram \& Inkpen, 2004). Economists and strategy scholars characteristically offer utility- and efficiency-based explanations (see Williamson \& Winter, 1991). According to this perspective, the corporation is a legal fiction, or "nexus of contracts" designed to generate and distribute wealth to its economic participants (Coff, 1999; Jensen \& Meckling, 1976). Sociological researchers tend to be more divided (Fligstein, 2001). While Weber (2002: 13), for instance, acknowledged that corporations serve as engines for rationalization and economic prosperity, he also viewed capitalism pessimistically as a "monstrous cosmos" that promotes depersonalization, commodification, and a reduced sense of societal obligation (see also Weber, 1978: 636). From a power-based perspective, the corporation serves as a political contest where influential actors operating both within and outside organizational boundaries struggle for control in order to define the objectives of the firm and further their interests (Fligstein, 1987; Ocasio, 1994; Perrow, 1986; Pfeffer, 1981). Comparative corporate governance scholars stress how beliefs regarding the purpose and function of corporations differ across countries (Aguilera \& Jackson, 2003; Guillén, 2000; Hall \& Soskice, 2001).

We seek to contribute to this literature by exploring the connection between the contrasting views of the role of the corporation in society and corporate reputation. 
Defined as “a collective representation of a firm's past actions and results that describe the firm's ability to deliver valued outcomes to multiple stakeholders" (Fombrun \& Rindova, 1996: 3), corporate reputation is an important intangible asset and a critical source of differentiation and competitive advantage (Barney, 1991; Fombrun, 1996). Since its focus has been primarily on the firm, the reputation literature often implicitly treats the determinants of corporate reputation as being universal across countries (e.g., Love \& Kraatz, 2009). The impact of national institutions on corporate reputation assessment has received comparatively less attention and is not fully understood (Gardberg, 2006). Building on research in corporate governance, we explore how societal differences in the allocation of power amongst stakeholders influence beliefs about the role of the business corporation, and in turn which firms achieve superior reputations. Similar to reputation research, the field of corporate governance is intimately linked to the relationship between stakeholders and the firm. Davis (2005: 143) describes corporate governance as the "structures, processes and institutions within and around organizations that allocate power and resource control among participants". These participants include stakeholders such as shareholders, creditors, employees and customers, among others. Countries differ in the way that power is allocated across these groups, however, which is a reflection of each nation's legal systems and overall institutional framework (Fiss, 2008; Roe, 2003). Stakeholders whose rights are privileged over others enjoy greater influence in shaping firm behavior and widely-held beliefs about the role of the business corporation in society (Chen, Newburry, \& Park, 2009; Schneper \& Guillén, 2004). People use these expectations as criteria to evaluate corporate reputations (Deephouse, Li, \& Newburry, 2009). Therefore, the determination of 
corporate reputation will vary from country to country, depending on differences in national institutions.

Overall, we study how stakeholder power and interests affect organizational processes (corporate governance) and outcomes (corporate reputation). To accomplish this goal, we examine the general public's evaluation of firms in 33 countries covering a wide range of economic, socio-cultural, and legal differences. We intend to make several contributions. First, the variety of countries in the sample allows this study to demonstrate how the drivers of corporate reputation vary across countries. Second, this paper broadens the scope of reputation research by examining the assessments of the general public. While a few exceptions exist (e.g., Deephouse, Li \& Newburry, 2009), prior research has generally focused on the opinions of and/or used measures based on just one narrow constituency, such as financial analysts or top managers. Third, this study demonstrates the usefulness of the stakeholder-power perspective by examining the impact of stakeholders in determining the firm's role in society and the types of organizational practices that receive favor and legitimacy (Deephouse \& Carter, 2005). Finally, this paper demonstrates that despite economic and social consequences of globalization, corporate governance systems and the public's expectations of firms have not converged (Davis \& Marquis, 2005; Guillén, 2000; Weber, Davis \& Lounsbury, 2009). Managers of multinational corporations must thus take local conditions into consideration when expanding their businesses into other countries

Within the following section, we review past studies on corporate reputation and corporate governance. We then develop hypotheses predicting reputation assessments based on three aspects of firm performance, and how the impact of these performance 
dimensions may vary due to the legal rights and power of three important stakeholder groups - shareholders, creditors and labor. The differing degree that these three groups receive legal protection has long been a focal topic in comparative corporate governance research (see Aguilera \& Jackson, 2010; Armour, Deakin, Lele \& Simms, 2009; Deakin, 2005). Our theoretical approach parallels Fligstein and Choo's (2005) description of corporate governance as the result of corporate law, market regulation, and labor law. Likewise, Schneper and Guillén (2004) stress the importance of these three constituencies when evaluating how differences in stakeholder power affect organizational outcomes. We next present our theoretical model and empirical tests using a sample of 756 corporations from 33 countries. We conclude with a discussion of our results.

\section{LITERATURE REVIEW}

\section{Corporate Reputation}

Corporate reputation and its determinants have been studied by scholars emanating from a broad range of disciplines. These studies have shown that reputation assessments are associated with numerous important attributes, such as the quality of a firm's products (Podolny, 1993), financial performance (Gabbioneta, Ravasi, \& Mazzola, 2007), social responsibility (Schwaiger, 2004), esteem (Hall, 1992), and trust (Walsh, Mitchell, Jackson, \& Beatty, 2009), among other factors. While strategy and marketing scholars emphasized the factors determining corporate reputation and its heterogeneity among corporate audiences and stakeholders (Fombrun \& Shanley, 1990; Hall, 1993), sociologists and psychologists concentrated on the mechanisms through which corporate reputation is formed (Bromley, 2001; Staw \& Epstein, 2000). While comparative research is limited, some evidence suggests that the factors used in reputational 
assessment may vary dramatically across countries. Despite cultural similarities between Denmark, Norway and Sweden, for instance, Apéria and colleagues (2004) found significant differences in reputational assessments by inhabitants of those countries. Danish citizens provided higher reputational assessments of top tier domestic companies than Swedes and Norwegians. Additionally, while financial performance had the lowest weight amongst the corporate reputation determinants in Denmark and Norway, social responsibility was the least important factor in Sweden (Apéria et al., 2004). Based on their results, these researchers proposed that socio-cultural, legal, and other institutional differences served as an important cause of these variations. Likewise, Gardberg (2006) examined the cross-cultural construct equivalence of corporate reputation in six countries: Australia, Belgium, Greece, Italy, the Netherlands, and the U.K. Despite construct equivalency of corporate reputation across countries, she found differences in antecedents and consequences of reputation in those countries. For instance, profitability has a more salient role in forming firm reputations in Australia and the Netherlands, where a company could not have a good reputation if it was not profitable (Gardberg, 2006).

Institutional differences can influence both external observers who evaluate companies and organizational members who determine firm practices and strategies. Corporate reputation is formed based on the relationship and interaction between the firm and its observers in their shared institutional environment (Goode, 1978). Observers evaluate a firm based on its congruence to socially constructed standards and criteria that are context-specific rather than universal (Love \& Kraatz, 2009; Rao, 1994; Staw \& Epstein, 2000). Firms and observers are embedded in a cultural system (Rao, 1994) and thus form a mutual understanding about local standards, expectations, and beliefs about 
which business practices are legitimate and desirable (Deephouse \& Carter, 2005). Organizational reputation can be viewed as the shared cognitive representations of an organization held by its stakeholders (Fombrun, 1996; Grunig \& Hung, 2002). Thus, inhabitants of a country construct elaborate cognitive schema, or mental maps, which are influenced by shared socio-cultural and institutional settings and are different from those of people in other countries. One of the manifestations of these differences is found in people's perceptions of corporations and their evaluations of corporate reputation.

\section{Corporate Governance}

Corporate governance scholars frequently trace the origin of their field back to Berle and Means' (1932) classic book Private Property and the Modern Corporation (Davis, 2005). Since few investors were sufficiently large to fund the massive projects pursued by many U.S. corporations during the late $19^{\text {th }}$ and early $20^{\text {th }}$ century, shareholdings became disbursed. According to these authors, this lead to a system of socalled "managerial capitalism", where firms were owned by weak minority shareholders but controlled by powerful professional managers. While critics debate elements of this account such as the extent of unconstrained managerial power (see Davis, 2005; Mizruchi, 2004), this emphasis on the separation of share ownership and control underscores the competing demands imposed on the firm and its resources. While shareholders might want the firm to pursue financial returns and maximize profit, managers for instance may place a greater value in organizational growth, stability and empire building (Jensen \& Meckling, 1976).

Most corporate governance research to date has focused on threats to shareholder claims and interests (Davis, 2009; Lazonick \& O'Sullivan, 2000; Prahalad, 1994). In one 
frequently cited definition, for instance, economists Andrei Shleifer and Robert Vishny (1997: 737) describe corporate governance as "the ways in which suppliers of finance to corporations assure themselves of getting a return on their investment." This emphasis is at least partially attributable to the notion of shareholder primacy, within which shareholders are viewed for all practical purposes as the owners of the firm and the rights of all other stakeholders are treated as subordinate. Thus, the primary objective of the firm should be to maximize profitability and returns to stockholders (see Friedman, 1980; Jensen, 2001). This ideology appears to have first gained dominance in the United States and other market-based economies, but observers have also chronicled its uneven influence in other countries (Deakin, 2005; Fiss \& Zajac, 2004; Lazonick \& O'Sullivan, 2003; Roe, 2003; Yoshikawa, Tsui-Auch \& McGuire, 2007).

Some sociologists and legal scholars argue that shareholder primacy is more the result of political and normative influences rather than explicit legal statute (Blair \& Stout, 1999; Sundaram \& Inkpen, 2004). Deakin (2005) points out that even United States corporate law does not regard shareholders as undisputed owners of the firm. The shareholder primacy movement has instead gained dominance due to actions of a broad coalition of activists with common interests who were able to assert their legal rights (Davis \& Thompson, 1994). Despite the traditional emphasis in the corporate governance literature, recent research has dedicated increasing attention to the ways that other constituencies influence the firm and make claims on its resources (Fiss, 2008; Freeman, Wicks \& Parmar, 2004). O’Sullivan (2003), for instance, urges researchers to study more closely how labor power and preferences affect firm behavior. The comparative literature on corporate governance offers important insights on the various influences of the firm's 
diverse stakeholders (Schneper \& Guillén, 2004). Countries are often characterized as following either a shareholder- or stakeholder-centered model of corporate governance. The United States and the United Kingdom are most commonly offered as examples of the shareholder-centered model, which is characterized by liquid capital markets, disbursed stockholdings and well developed markets for corporate control. Since internal constraints on managers, such as boards of directors, are relatively weak, investors rely on market-based forces to discipline and control managers (Aguilera \& Jackson, 2003; Gedajlovic \& Shapiro, 1998; Guillén 2000). Accordingly, the shareholder-centered system is often viewed as a market-based economic system. The legal rights of shareholders tend to receive privilege, thus making this model consistent with the shareholder primacy perspective.

By comparison, the stakeholder-centered model exhibits concentrated shareholdings by powerful constituents such as banks or the state, strong boards with representation from regulatory, creditor and labor interests, but weak stock market constraints on managerial behavior. The stakeholder-centered corporate governance model is often referred to as a bank-based economic system. According to the stakeholder-centered model, the corporation tends to be viewed less as property and more as a public entity with a broad range of responsibilities to creditors, workers, the public and others (see Allen, 1992). Such values are upheld by broader legal rights and protections to these stakeholder groups (Aguilera \& Jackson, 2003; Roe, 2003). While Germany and Japan are the most frequently cited cases of the stakeholder-centered approach, it is important to note that both corporate governance models are ideal types and there is considerable diversity across countries. Even though the U.S. and U.K. 
systems are closely associated for instance, most comparative researchers agree that workers receive significantly weaker legal protection in the former (Schneper \& Guillén, 2004).

The study of national legal institutions has proven to be an especially fruitful way of exploring variations in corporate governance and stakeholder power. La Porta and colleagues (1998) tested the effect of legal origins on shareholder protections in 49 countries. They identified four legal origins for commercial laws: common law (England and British former colonies such as Australia, Canada, India, and the US), French civil law (Belgium, the Netherlands, Portugal, Spain, and countries under their colonial influence), German civil law (Austria, Greece, Hungary, Japan, Korea, and Switzerland), and Scandinavian civil law (four Nordic countries). They argued that shareholders seek power and control in the organization to influence decision-making and protect their interests. Common law countries were found to provide the best shareholder protection, whereas Scandinavian, German and French civil law provided progressively weaker protections. Consistent with their arguments, they found that ownership tends to be more concentrated in countries with weaker shareholder protections (i.e., civil law countries).

Political differences across countries are another source of corporate governance diversity. Vitols (2001) examined the political ideology of state elites in the 1930s and 1940s, particularly their views about state intervention in business affairs and the role of financial markets in the achievement of economic and social goals. Critical of market capitalism, German and Japanese state elites created a regulatory regime that favored banks over markets in the financial system whereas American state elites maintained a liberal approach in regulating financial markets. The bank-based system was regarded as 
a better fit by Japanese state elites who regarded financial systems as a "national resource" for promoting economic growth.

\section{STAKEHOLDER POWER, CORPORATE REPUTATION AND THE CORPORATE OBJECTIVE FUNCTION}

In an influential article, financial economist Michael Jensen (2001) proposed that corporate performance should be evaluated by the extent that firms achieve their fundamental goal, or corporate objective function. Jensen argued that the only economically justifiable objective for business corporations was shareholder value maximization. By contrast, many comparative corporate governance scholars argue that beliefs about corporate objectives are not so much universal and rationally determined as they are context-specific and socially constructed (Aguilera \& Jackson, 2010). Powerful stakeholders groups play a critical role in shaping beliefs about the types of corporate behaviors and goals deemed legitimate and favored by society (Fiss \& Zajac, 2004). Accordingly, we propose that societal members evaluate corporations based on these subjective expectations and that the firms that perform best according to these standards achieve superior reputations.

The notion that powerful societal elites help shape societal values and beliefs is not new. Mills (1956) suggested that society's "power elite" controlled public opinion in part through its influence over intellectuals, mass media, and educational institutions. From a Weberian perspective (1978), the state serves as a source of rational-legal or traditional authority. When a county's legal system favors one constituency over another, the claims of this group are deemed legitimate. Stakeholders with greater legal protections are also able to participate more directly in the governance of the firm 
(Schneper \& Guillén, 2004). Managers will communicate their organizations' actions, strategies and outcomes using language and rhetoric that are consistent with these stakeholders' preferences (Fiss \& Zajac, 2004), which further affects public opinion.

In our first three hypotheses, we examine the direct impacts of firms' financial performance (via stock market returns and financial performance stability) and social performance on reputational evaluations within society in order to disentangle the multiple impacts of firm performance on reputation. We suggest that these firm attributes are valued by a broad range of constituencies across countries. Most stakeholder groups tend to favor firms that are financially vigorous and act responsibly, even if they place a different priority on each of these objectives. In our final three hypotheses, we suggest that the comparative importance of financial and social performance to reputational assessment depends on the allocation of power and legal rights within society. In particular, we examine the rights and preferences of shareholders, creditors and labor since these stakeholders are most frequently cited for their varying levels of influence across countries and because of their comparatively direct claim on the firm's resources (see Schneper \& Guillén, 2004). We hypothesize moderating relationships based upon the protection of shareholder rights, creditor rights and labor rights, and how these protections might differentially impact different performance measures.

\section{Financial and Social Performance}

Financial performance information reflects a firm's success in past strategies, effectiveness in resource allocation, and fulfillment of its missions and goals. Although stakeholders place different expectations on the firm, strong financial performance is in part the consequence of satisfying these diverse objectives (Donaldson \& Preston, 1995; 
Waddock \& Graves, 1997; Walsh, Weber \& Margolis, 2003). To enhance their power and status, managers need legitimacy, trust, esteem, and admiration of shareholders, creditors, and other stakeholders that requires attention to financial outcomes. The relationship between financial performance and corporate reputation has been documented previously (Fombrun \& Shanley, 1990). Regardless of the country context, the business corporation is fundamentally a commercial endeavor. Shareholders, creditors, employees and other stakeholders all benefit albeit unequally from their relationships with firms that perform well financially.

While it follows that stakeholders will evaluate strong market performers favorably, it is important to consider the multifaceted nature of financial performance (Meyer, 1994). A firm's financial performance may appear dramatically different depending on the timeframe and type of measurement employed (see McGuire, Schneeweis, \& Hill, 1986). Shareholders are most likely to judge firms based on their stock market returns. However, the relevance of stock market performance to reputational assessment is not limited to shareholders. Strong stock market performance enhances a firm's prominence to creditors, potential employees and other stakeholders. Banks and other lenders for instance associate stock returns with a firm's ability to raise capital. According to Fligstein (1990, 2001), business discourse and beliefs in the U.S and many other countries have become dominated by a paradigm he terms as the finance conception of control. Fligstein and his proponents suggest this conception of control has evolved into a system where share price is considered the purest measure of a firm's value (Davis, 2009; Davis \& Stout, 1992). Accordingly, "firms are viewed as collections of assets earning different rates of return, not as producers of given goods" (Fligstein, 1990: 15). 
Another aspect of financial performance that might have an important impact on firm reputation involves the degree of financial stability (Chacar, Newburry, \& Vissa, 2010; McGahan \& Porter, 1999). While observers may laud a firm's recent market results, companies that have achieved sustained financial success are likely to be held in higher esteem. Firms with volatile earnings will be more likely to be viewed as risky. The general public and resource-providers are generally risk averse (Fombrun \& Shanley, 1990) and therefore favor more financially stable firms. Organization theory suggests that firms will be deemed more legitimate if their actions are consistent and predictable (Hannan \& Freeman, 1984; Suchman, 1995), which would likely lead to higher reputation assessments. Additionally, consistency and predictability lowers information asymmetry between a firm and its stakeholders. This allows stakeholders to have better knowledge about the true attributes of the firm. Gardberg and Newburry (2010) found that people with greater knowledge about a firm were less likely to punish the firm via boycott for negative attributes. Thus, while greater knowledge could include negative elements, to the extent that financial stability leads to greater knowledge, it may be correlated with higher reputation perceptions.

Based on these arguments, we propose the following hypotheses associated with financial performance:

Hypothesis 1 (H1): There is a positive relationship between stock market returns and corporate reputation.

Hypothesis 2 (H2): There is a positive relationship between financial performance stability and corporate reputation.

Corporate social performance (CSP) refers to the extent to which a firm's actions 
attend to the needs and interests of stakeholders beyond simply its investors (Waddock \& Graves, 1997). Examples include community spending, voluntary community engagement, transparency in both financial and social behavior, enactment of employee safety, health, and training policies, complying with equal employment opportunity, and adopting environmental standards. From an economic perspective, CSP reduces the uncertainty caused by information asymmetries between competing firms and their stakeholders (Rindova, Williamson, Petkova, \& Sever, 2005). To reduce uncertainty, stakeholders search for information that reveals the true attributes of competing firms. From this perspective, tangible organizational outputs such as strong financial results are specific attributes that lead to positive evaluations of organizational reputation (Love \& Kraatz, 2009; Rindova et al., 2005; Shapiro, 1982, 1983). Signaling theory suggests that socially responsible firms can help observers distinguish themselves from competing firms. As a result, observers learn more about the firms' other attributes (Spence, 1973).

From an institutional perspective, attitudes towards CSP are a collective perception (Fombrun, 1996). Observers evaluate firm behaviors as symbolic indicators of their conformity and fitness with society's norms and cultural beliefs (Love \& Kraatz, 2009). In a study of bandwagon effects of popular managerial fads (e.g., total quality management), Staw and Epstein (2000) found that while adoption provided no discernible economic gain, corporate reputations improved due to their conformity with beliefs about best practices. As countless observers have noted, firms across countries are confronted with growing normative pressures to act in a socially responsible manner (Campbell, 2007). Thus, we suggest:

Hypothesis 3 (H3): There is a positive relationship between corporate social 
performance and corporate reputation.

\section{Stakeholder Power}

Collective perceptions about the firm are influenced by information sent and received (Gardberg, 2006). Firms and other influential groups including the media, governmental and non-governmental agencies all participate in the production and dissemination of this information. However, personal assumptions, cognitive schema and societal expectations serve to filter and interpret this information. One of the underlying factors that affect both the information sent and received is the context and environment in which organizations operate and observers reside. Companies try to adapt to their unique environments resulting in variations in firm behavior across domains (Selznick, 1949). In other words, a firm's actions, strategies, goals, and even the type of information disclosed are chosen so as to conform to the formal and informal requirements of its environment. According to Trevino (1986: 612), “collective norms about what is and what is not appropriate behavior are shared and are used to guide behavior.... These help individuals judge both what is right and who is responsible in a particular situation". Consequently, reputational assessment and mechanisms through which observers trust, admire, and respect firms vary across countries.

Social elites possess significant influence on the type of information disseminated in a society as well as the establishment of shared norms and beliefs. Each country's institutional environment, including its legal system, serves to define property rights, governance structures and set expectations on how the firm and its constituencies ought to interact with one another (Campbell, 2007; Fligstein, 2001). A stakeholder power perspective thus suggests that differences in norms and collective beliefs are shaped 
largely by power dynamics, which tend to be highly institutionalized and resistant to substantial change (Davis \& Marquis, 2005). Following Schneper and Guillén (2004), we focus on the following three stakeholders: shareholders, creditors (commercial banks), and labor. We consider how power in the form of rights protections for these three key stakeholder groups interacts with specific performance measures (stock market returns, financial performance stability and social performance) to influence corporate reputation assessments within a society.

Shareholder rights protection. Fligstein (2001) contends that in market-oriented countries, owners of firms will try to capture economic rents by limiting direct government intervention and regulatory oversight. Capitalist interests prevent stateownership, and shareholders rights receive privilege since property rights and the concept of ownership are held as paramount. The dominance by capitalist elites creates a shareholding culture and engages all actors in the society (Davis, 2009). Consequently, firms, media, and third parties disseminate more information about share performance, and individuals are more motivated to follow or attend to this information. In sum, in societies where capitalists are the dominant power, stock performance is a more salient dimension of firm reputation than in countries where other social groups have dominant power. Therefore, we suggest that:

Hypothesis 4 (H4): In countries with strong shareholder rights protections, stock market returns have a relatively more positive influence on the public's assessment of corporate reputation than in markets where these protections are weaker.

Creditor rights protection. While creditors such as commercial banks also possess a financial stake in the corporation, their objectives and expectations are much 
different from shareholders. Unlike shareholders, creditors do not benefit from the residual claims of the corporation. The promised return to creditors is more or less fixed or contractually prescribed. Except in cases of corporate insolvency, a creditor's ability to influence management and exercise control over the firm is also much weaker than that of a shareholder (Aguilera \& Jackson, 2003). Corporate governance scholars tend to characterize bank-centered economies as more long-term oriented (Aguilera \& Jackson, 2003; Fligstein, 2001; Gedajlovic \& Shapiro, 1998). Banks in certain countries serve as major shareholders, but in these cases the banks tend to be more interested in developing long-term commercial ties with the firm rather than seeking gains from share appreciation (Fligstein, 2001; Schneper \& Guillén, 2004). For these reasons, creditors tend to favor stability and consistency in firms over maximizing share price.

Due to a lack of well-developed capital markets in bank-centered economies, banks are the major source of capital for firms. According to resource dependence theory, companies attend most to the demands of organizations that control their critical resources (Pfeffer, 1981). In bank-centered economies, firms are heavily dependent on banks for capital, an essential resource for their survival. This dependence gives banks an opportunity to control firms. Therefore, firms must manage these critical relationships by complying with bank goals and objectives. Additionally, unlike dispersed share ownership in market-based systems, in bank-centered economies, banks have large stakes in companies and have power to closely monitor and control companies. Assembling the prior arguments suggests that institutional pressures in bank-based financial systems tend to be more long-term oriented and favor more stable financial performance. Therefore, we hypothesize: 
Hypothesis 5 (H5): In countries with strong creditor protections, financial stability has a relatively more positive influence on the public's assessment of corporate reputation than in markets where these protections are weaker.

Labor rights protection. In societies where worker groups are relatively powerful, governments have a greater capacity for intervening directly in product and labor markets, and policy domains seek to protect workers and jobs to a greater degree (Fligstein, 2001). There are extensive work rules, welfare, unemployment, and health and safety benefits in these societies (Fligstein, 2001). State ownership is prevalent and the level of direct involvement of the state varies depending on the relative power of labor and firms (Fligstein, 2001). In labor disputes, the state frequently sides with worker groups over firms (Fligstein, 2001). Labor laws provide a mechanism for workers to influence organizational decision making. From a social movement perspective, workers can influence companies through collective actions (King, 2008). Labor laws provide capacity for development of formal organizations and interpersonal networks, which are instrumental in forming a mobilizing structure for collective actions (King, 2008). One of these mechanisms is freedom of association. Union rights allow labor to establish formal organizations to pursue their claims in a planned, organized, and powerful manner. In addition, formal labor unions not only lower starting costs, but also strengthen the interpersonal networks and interaction among workers and assist them in developing similar interests and identities (King, 2008). Another mechanism is representation rights. Strong representation rights provide labor with legal rights to information, consultation, and codetermination in key decisions (Aguilera \& Jackson, 2003). Employee participation in decision making changes the shareholder supremacy model to a more 
stakeholder approach by bringing interests of other stakeholders, particularly the longterm needs of society, into consideration. In other words, the presence of employees in decision making may cause companies to take more responsibility toward society through good governance, human rights, and the environmental consequences of their activities. To the extent that the employee promotes community and labor interests, we can expect that firms will face greater pressures to pursue social responsibility. Therefore, we propose:

Hypothesis 6 (H6): In countries with strong labor rights protections, corporate social performance has a relatively more positive influence on the public's assessment of corporate reputation than in markets where these protections are weaker.

\section{METHODS}

\section{Setting and Data}

The unit of analysis in our study is the firm. We used a sample of corporate reputation data collected by the Reputation Institute as part of their 2009 RepTrack Pulse study (Reputation Institute, 2009). The Reputation Institute conducted a cross-country survey examining the general public's reputational assessments of the 600 largest companies in the world (based on revenue) along with 750 additional companies to balance the sample in terms of industry and country comparisons. Since the general public is likely to evaluate foreign and domestic companies differently (Newburry, Gardberg \& Belkin, 2006), we excluded reputational assessments of subsidiaries of foreign companies. Thus, each country was evaluated only by members of the general public from its home country. After further elimination due to lack of data, our final sample size became 756 companies from 33 countries. All explanatory and control 
variables were lagged one year.

\section{Dependent Variable}

The Reputation Institute administered a multi-item online survey measuring the perceptions of individuals from the general public on different aspects of corporate reputation. While prior research on corporate reputation tends to rely on the perceptions of a narrowly defined group (such as shareholders, managers, or market analysts), this measure is notable since it is derived from broader public attitudes. More than 115,000 respondents from 33 countries who have at least minimal familiarity with a focal company were selected to participate in the study. In order to be selected, a respondent was required to answer 3 out of 4 screening questions about the company (Asher, 2004). In addition, respondents were chosen to represent the general population of their countries based on gender and age. Surveys were conducted in the local language to prevent biases associated with an English-only questionnaire (Harzing, 2005). Questionnaires were translated and back translated by professionals fluent in English and the local language to ensure accuracy. The four items composing the index are (1) "good overall reputation”, (2) “a company I have a good feeling about”, (3) "a company that I trust", and (4) "a company that I admire and respect" (Reputation Institute, 2009). Prior research findings suggest that items measuring general perceptions have greater face validity across cultures than more specific and culturally derived items (Scandura, Williams, \& Hamilton, 2001). Respondents evaluated each item on a 7-point scale, where "1" indicates "strongly disagree" and "7" indicates "strongly agree". Respondents also had the option to indicate "not sure". The scale Chronbach Alpha is 0.988. Since interpretation of items can vary across cultures (Gardberg, 2006), their factor structure 
was evaluated in each country and found to be equivalent. LISREL analyses confirmed the unidimensionality, convergent validity, and fit of the scale items. A company's reputation score is calculated using the average of the scores of all respondents evaluating a particular company within a country, and then converted to a $0-100$ scale for ease of interpretation.

\section{Independent Variables}

Firm financial data was gathered from the Bloomberg (2010) database. Stock market returns are commonly considered the firm financial performance measure most closely associated with the shareholder value paradigm (Fligstein, 1990). Thus, we measured financial performance by using each firm's three-year cumulative total return. Cumulative total returns account for both stock price changes and disbursements to shareholders by assuming that cash dividends are reinvested on the ex-date (Bloomberg, 2010). Results were materially the same in supplemental tests using one- and five-year total return measures. To construct our measure of financial stability $(\mathrm{H} 2)$, we adopted a standard proxy of financial risk by calculating the variance of each firm's return on assets (ROA) from 2000 to 2008 (Thomsen \& Rose, 2004). We multiplied this score by “-1" so that higher scores represent greater stability.

An ideal corporate social performance measure would be based on the direct observation of the firm and its various human, environmental and societal relationships (Wood, 2007). To our knowledge, however, no adequate measure of this nature exists for a sample of firms across a large number of countries. We thus focused on each firm's social reporting and participation in key voluntary CSR initiatives, i.e., U.N. Global Compact (UNGC) and the Global Reporting Initiative (GRI). Business ethicists often 
contend that transparency and stakeholder engagement are essential elements of strong social performance (Scherer \& Palazzo, 2008). Since our focus in this paper is on public perceptions of the firm, CSR reporting and participation in voluntary initiatives are particularly relevant since they provide a highly visible signal of the firm's espoused commitment to CSR. We collected data from three sources, namely, UNGC, GRI, and Bloomberg, and combined them to create our own measure of social performance reporting. UNGC and GRI are probably the most often noted global voluntary initiatives for their role in setting CSR engagement and reporting standards (see, e.g., Hess, 2008; Runhaar \& Lafferty, 2009). The UNGC framework includes 10 principles in the areas of human rights, labor, environment, and anti-corruption. Similar to UNGC, GRI requires companies to report on the impact of their activities in the areas of environment, human rights, society, and product responsibility. We also examined transparency and disclosure data from the Bloomberg database. Bloomberg reviews environmental, social, and governance (ESG) disclosures of companies (e.g., code of ethics, health and safety policy, human right policy, equal employment policy, fair remuneration policy, among others) and assigns an ESG Disclosure score to them. Combining the above information, we constructed a binary variable that equals " 1 " if the company participates in UNGC or GRI, or if its Bloomberg ESG Disclosure score is better than $75 \%$ of the companies in the sample. Since UNGC, GRI and the Bloomberg ESG disclosure scores include a strong labor component, firms must demonstrate a strong commitment to labor to achieve a positive score in our measure.

We measured the strength of shareholder rights $(\mathrm{H} 4)$ using the "antidirector rights index" originally developed by La Porta, Lopez-de-Silanes, Shleifer and Vishny 
(1998). This index reflects the level of minority shareholder rights protection against expropriation by corporate insiders. A country's score can theoretically range from zero to six based on the presence or absence of six representative shareholder rights provisions, such as the ability for shareholders to vote cumulatively for board members and the existence of a legal mechanism for shareholders to challenge actions by management. (See Armour, Deakin, Lele \& Simms, 2009 for a recent discussion.) Djankov, La Porta, Lopez-de-Silanes, and Shleifer (2008) updated the original index and expanded coverage from 49 to 72 countries. We use the revised index in our analysis.

To evaluate the effects of creditor rights (H5), we adopted Barth, Caprio, and Levine's (2008) four-point Bank Ownership index. Banks have a more limited influence on the national economy and corporate governance in countries which scored "1" where "banks may not acquire any equity investment in a nonfinancial firm" or " 2 " where "banks can only acquire less than $100 \%$ of the equity in a nonfinancial firm". On the other hand, banks have a more central role in a national economy and corporate governance in countries which scored "3", meaning "banks may own $100 \%$ of the equity in a nonfinancial firm, but ownership is limited based on a bank's equity capital" or "4" meaning "banks may own $100 \%$ of the equity in any nonfinancial firm".

Our labor rights (H6) measure was based on Botero, Djandov, La Porta, Lopezde-Silanes, and Shleifer (2004), which investigated the regulation of labor markets in 85 countries from three broad areas: employment, collective relations, and social security laws. For each of the areas, they examined the formal legal statutes governing labor markets and constructed an index within which higher values correspond to more legal protection for employees in that area. We aggregated these three indices to measure labor 
rights protection in this study.

\section{Control Variables}

We controlled for country-, industry-, and firm-level factors that might have effects on individual perceptions about corporations. At the country level, we controlled for cultural, political, and economic factors. Word of mouth, the availability of multiple options and the possibility of comparing them, autonomy to make decisions, and national

pride are factors that influence individuals' perceptions about local firms (Fombrun, 1996;

Fombrun \& Shanley, 1990; Gardberg, 2001). Therefore, we controlled for the level of trust, national pride, autonomy, and freedom of choice index scores from the World Value Survey 2009 (World Value Survey, 2009). We also controlled for level of democracy (Polity IV database; Marshall, Gurr \& Jaggers, 2010) and government accountability in each country (World Bank's World Governance Indicator). Furthermore, we controlled for economic development (GDP per capita), economic globalization, which leads to presence of foreign firms and participation of local firms in the global economy (FDI/GDP), and market capitalization.

Past studies show that industry reputation influences perceptions of companies (Winn, MacDonald, \& Ziestsma, 2008). Companies in our sample cover 25 industries and we controlled for industry effects by defining dummy variables for each industry (telecom is the excluded variable). In addition, past studies suggest that firm visibility and history affect corporate reputation (Fombrun \& Shanley, 1990) and therefore, we controlled for company size (Revenue) and age.

\section{Estimation Method}

Since our dependent variable (RepTrack Pulse scores) is an index ranging from 0 
to 100 , ordinary least squares regression is not appropriate (OLS). Under conditions where the dependent variable is censored, OLS produces parameter estimates that are inconsistent (Long, 2005). Therefore, we used the Tobit regression model (Tobin, 1958) which is designed to produce consistent parameter estimates in cases of limited, or censored dependent variables (see also Amemiya, 1984).

\section{RESULTS}

Table 2.1 provides descriptive statistics and correlations for our measures. It shows that some of the country-level controls have moderate levels of correlation (between 0.35 and 0.65 ) and two correlations are above the commonly used cut-off of 0.7 (Tabachnick \& Fidell, 2007). High correlations are reported between democracy and government accountability as well as economic development and market capitalization. Collinearity diagnosis indicated that the mean variance inflation factor (VIF) is 2.98 and all individual scores are below 4.00, which is below the commonly used threshold of 10 (see Hair, Anderson, Tatham, \& Black, 1998), except for the above mentioned four variables. In order to better understand the effect of these correlations on our results, we ran our analyses two times. In the first run, we included all variables, and in the second we excluded democracy and market capitalization. Excluding these two measures, there were no individual VIFs above 4.00 and no evidence that multicollinearity was a problem. Results of these two runs were highly consistent with the results reported below, with the exception that the significance level for H6 was slightly over marginal significance $(\mathrm{p}=.14)$. Results were also robust when we attempted model specifications with alternative or fewer country-level controls. 
Table 2.1: Descriptive Statistics and Correlations

\begin{tabular}{|c|c|c|c|c|c|c|c|c|c|c|c|c|c|c|}
\hline Variable & Mean & S.D. & Min & $\operatorname{Max}$ & $\overline{1}$ & 2 & 3 & 4 & 5 & $\overline{6}$ & 7 & 8 & 9 & $\overline{10}$ \\
\hline 1 Corporate Reputation & 65.43 & 10.67 & 14.00 & 91.34 & & & & & & & & & & \\
\hline 2 Trusting People & 1.65 & 0.12 & 1.30 & 1.94 & 0.05 & & & & & & & & & \\
\hline 3 National Pride & 1.63 & 0.30 & 1.16 & 2.30 & $-0.13 *$ & $-0.10 *$ & & & & & & & & \\
\hline 4 Autonomy Index & 0.79 & 0.19 & 0.33 & 1.18 & $-0.22 *$ & $-0.41^{*}$ & $0.61 *$ & & & & & & & \\
\hline 5 Freedom of Choice & 7.07 & 0.59 & 5.67 & 7.74 & 0.04 & $-0.14 *$ & $-0.58 *$ & $*-0.25 *$ & & & & & & \\
\hline 6 Democracy & 8.35 & 4.29 & -7.00 & 10.00 & $-0.32 *$ & $0.28 *$ & $-0.25 *$ & * $-0.13 *$ & $0.09 *$ & & & & & \\
\hline 7 Gov. Accountability & 0.85 & 0.83 & -1.68 & 1.59 & $-0.42 *$ & $0.11 *$ & $-0.18^{*}$ & $* \quad-0.04$ & $0.19^{*}$ & $0.92 *$ & & & & \\
\hline 8 Globalization & 6.28 & 4.52 & -2.45 & 25.59 & $-0.19 *$ & -0.01 & $0.14^{*}$ & * $-0.13 *$ & 0.03 & $0.07 *$ & $0.26^{*}$ & & & \\
\hline 9 Economic Development & 4643.37 & 5413.47 & 170.86 & 48706.88 & 0.06 & $-0.12 *$ & $-0.39 *$ & $* \quad-0.02$ & $0.46^{*}$ & $0.09 *$ & 0.06 & $-0.27 *$ & & \\
\hline 10 Market Capitalization & 333644.00 & 437855.70 & 4913.75 & 1173810.00 & $0.09 *$ & $-0.12 *$ & $-0.45^{*}$ & k -0.07 & $0.51 *$ & $0.12 *$ & $0.09 *$ & $-0.26^{*}$ & $0.94^{*}$ & \\
\hline 11 Company Size (Sales) & 29309.37 & 43843.85 & -58601.00 & 458361.00 & $-0.14^{*}$ & 0.05 & $0.09 *$ & $0.14^{*}$ & 0.00 & $0.12 *$ & $0.13 *$ & 0.01 & $0.19^{*}$ & $0.18^{*}$ \\
\hline 12 Company Age & -0.22 & 54.99 & -61.14 & 473.86 & -0.01 & -0.05 & -0.04 & 0.03 & 0.04 & $0.21 *$ & $0.22 *$ & 0.03 & $0.10^{*}$ & $0.08 *$ \\
\hline 13 Shareholder Rights & 0.00 & 1.13 & -2.57 & 1.43 & $-0.15^{*}$ & $0.30 *$ & $-0.08 *$ & $-0.11 *$ & $-0.16^{*}$ & $0.50 *$ & $0.43 *$ & $0.16^{*}$ & $-0.26^{*}$ & $-0.25 *$ \\
\hline 14 Creditor Rights & 0.00 & 0.85 & -1.61 & 1.39 & $-0.29 *$ & $0.35 *$ & $=-0.01$ & $-0.22 *$ & 0.04 & $0.46^{*}$ & $0.48 *$ & $0.28 *$ & $-0.40 *$ & $-0.40 *$ \\
\hline 15 Labor Rights & 0.00 & 0.37 & -0.39 & 0.75 & $-0.16^{*}$ & -0.02 & $0.53^{*}$ & $0.23^{*}$ & $-0.41 *$ & $-0.08 *$ & -0.05 & $0.16^{*}$ & $-0.52 *$ & $-0.58 *$ \\
\hline 16 Stock Market Returns & -0.07 & 64.44 & -92.56 & 760.58 & $0.19 *$ & $-0.08^{*}$ & $0.11^{*}$ & 0.05 & 0.02 & $-0.34 *$ & $-0.29 *$ & -0.02 & -0.05 & -0.06 \\
\hline 17 Financial Stability & -0.18 & 88.05 & -1109.19 & 26.92 & $0.08 *$ & $0.08 *$ & 0.06 & $5 \quad 0.02$ & -0.05 & -0.04 & -0.05 & 0.00 & 0.00 & -0.01 \\
\hline 18 Corp. Social Performance & 0.00 & 0.50 & -0.53 & 0.47 & $-0.11 *$ & $0.11 *$ & $0.13^{*}$ & $0.08^{*}$ & $-0.15^{*}$ & $0.26^{*}$ & $0.28 *$ & $0.09 *$ & -0.07 & $-0.09 *$ \\
\hline
\end{tabular}

\begin{tabular}{lrrrrrrr}
\hline \multicolumn{1}{c}{ Variable } & $\mathbf{1 1}$ & $\mathbf{1 2}$ & $\mathbf{1 3}$ & $\mathbf{1 4}$ & $\mathbf{1 5}$ & $\mathbf{1 6}$ & $\mathbf{1 7}$ \\
\hline 12 Company Age & 0.05 & & & & & & \\
13 Shareholder Rights & 0.00 & 0.04 & & & & & \\
14 Creditor Rights & -0.01 & 0.01 & $0.54^{*}$ & & & & \\
15 Labor Rights & 0.02 & 0.00 & $-0.20^{*}$ & $0.08^{*}$ & & & \\
16 Stock Market Returns & 0.00 & $-0.11^{*}$ & $-0.16^{*}$ & $-0.15^{*}$ & 0.04 & & \\
17 Financial Stability & $0.10^{*}$ & $0.09^{*}$ & -0.02 & -0.06 & 0.01 & $0.07^{*}$ & \\
18 Corp. Social Performance & $0.24^{*}$ & $0.14^{*}$ & $0.20^{*}$ & $0.20^{*}$ & $0.17^{*}$ & $-0.09^{*}$ & 0.03 \\
\hline \multicolumn{1}{c}{$\boldsymbol{*}<<0.05$} & & & & & & &
\end{tabular}


Table 2.2 presents Tobit regression results for corporate reputation and includes six models. All models include our full sample of 756 firms from 25 industries across 33 countries. Each model also demonstrates a highly significant likelihood ratio $(\mathrm{p}<0.001)$ suggesting a good fit. Model 1 includes just control variables and serves as a baseline. Model 2 incorporates the direct effect variables, namely financial performance, financial stability, and corporate social performance. The results provide positive and significant support for the effects of financial performance $(\mathrm{p}<0.01)$, financial stability $(\mathrm{p}<0.05)$, and corporate social performance $(\mathrm{p}<0.01)$ on corporate reputation, thus supporting H1- H3.

Models $3-5$ report the results for our hypothesized interaction effects. Model 3 adds the interaction between shareholder rights protection and financial performance, with a significant positive coefficient $(\mathrm{p}<0.05)$, implying greater importance of financial performance in countries where the legal system provides more protection to shareholders. Thus, we find support for H4. Model 4 adds the hypothesized interaction between creditor rights protection and financial stability to Model 2 to test H5. The result is significant, but not in the expected direction. Therefore, H5 was not supported. Testing H6, Model 5 adds the interaction between labor rights protection and social performance and finds a significant effect $(\mathrm{p}<.05)$. Thus, we find support for H6.

Model 6 presents our full model with all controls, direct effects and all three interactions. This model reports results that are similar to our previous models, further demonstrating the robustness of the findings. Overall, all three of our direct effect hypotheses and two of our interaction hypotheses were supported, with our third interaction variable (creditor rights) being significant in the opposite direction to our expectations. 
Table 2.2: Tobit Regression Results for Corporate Reputation

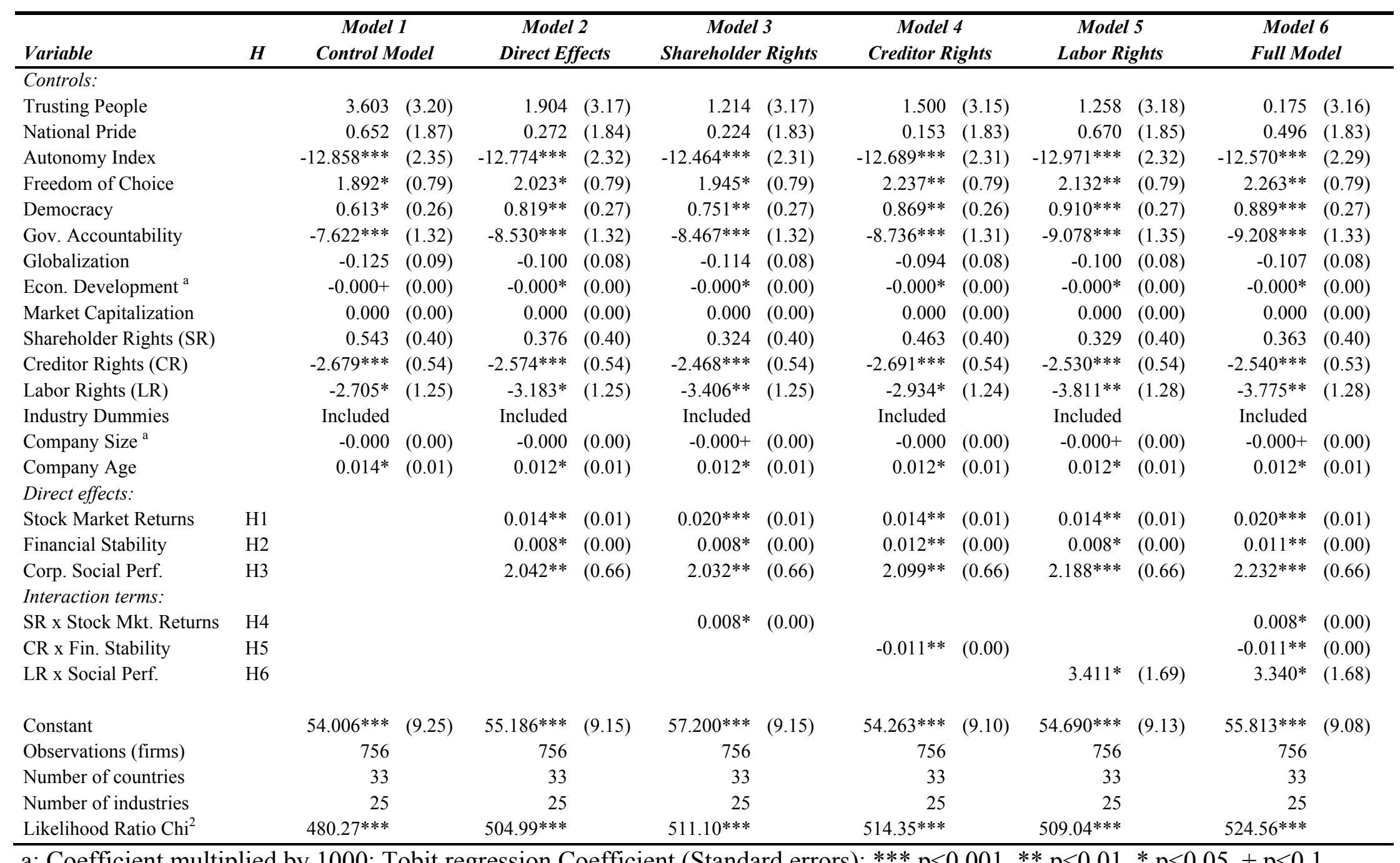




\section{DISCUSSION AND CONCLUSIONS}

Drawing on insights from the corporate governance and stakeholder power literatures, this study investigated differences in the reputational assessments of corporations across countries. The results are consistent with the image of the firm as a political contest where powerful actors help generate and foster national beliefs about the role of the business corporation in society (Fligstein, 2001; Perrow. 1986). These beliefs in turn assist in determining the types of firms that enjoy superior reputations. Consistent with past studies, the results demonstrate the positive impact of both financial performance (Fombrun \& Shanley, 1990; Gabbioneta et al., 2007) and social performance (Brammer \& Pavelin, 2006; Schwaiger, 2004) on corporate reputation. The results also demonstrated that the diversity of reputed firms across countries can be linked to national differences in stakeholder power and corporate governance practices. The analysis showed that in countries where shareholder rights are privileged, stock market return has a greater weight in forming public perceptions about companies. In addition, in countries where labor rights are more protected, corporate social performance has an increased role in determining corporate reputation. Contrary to our expectations, we also found that when creditors have greater power, the influence of financial stability on reputation assessment becomes weaker.

Examining our individual results, this study shows that both short-term stock market returns and financial stability positively influence a public's perception of firms. Stock price is a simple and easy to communicate signal (see, e.g., Spence, 1973) that reflects important information and expectations about the firm. On the other hand, financial stability may be regarded by certain audiences as a more reliable indication of 
an effective business model and better overall fit between resources and strategies.

Therefore, these expectations about future firm performance create trust and admiration in the eyes of observers and lead them to form positive opinions about firms.

Similar to financial performance, strong corporate social performance provides signals that make the general public more aware of the favorable attributes of the firm. The general public expects firms to be aligned with society's normative values and cultural beliefs (Love \& Kraatz, 2009) and act responsibly toward its stakeholders. Given the difficulties of measuring social performance in a global setting, we developed a new measure focusing on transparency and engagement, two aspects of corporate social responsibility highly relevant to the drivers of positive corporate reputation. Our results show that greater transparency and engagement by firms contributes to more favorable evaluations from society. Overall, our direct effect results demonstrate three distinct avenues by which firm performance influences firm reputation. While financial and social performance have been examined in past research (e.g., Fombrun \& Shanley, 1990; Gabbioneta et al., 2007), we extend previous research by distinguishing two important types of financial performance along with examining these financial performance types alongside social performance to better appreciate the individual contribution of each.

Confirming stakeholder power arguments (e.g., Schneper \& Guillén, 2004), our results demonstrated that the diversity of reputed firms across countries can be linked to differences in powerful stakeholders and corporate governance systems. The analysis showed that in countries where shareholder rights are more protected, stock market returns have more weight in influencing the public's perceptions about companies. In other words, in societies where the policy domain is designed to favor shareholders, 
shareholder wealth maximization plays an even greater role in determining corporate reputation. This finding provides important insights about the relationship between financial performance and reputation, which has generally examined the impact of financial performance in single country settings (Fombrun \& Shanley, 1990).

We achieved unexpected results for countries where bank/creditor rights are strongly protected. We argued that in societies where creditor rights are strong, financial stability would have a relatively more positive influence on the public's assessment of corporate reputation than in markets where these protections are weaker. However, our results showed that financial stability over time was significantly negatively related to corporate reputation assessments in countries where creditor rights are more protected. One potential explanation for this result involves our use of the world's largest companies for our sample. These firms are more likely to possess the political and financial resources necessary to shield themselves during economic downturns. Creditors might prefer customers with these types of resources to be more dynamic and aggressive in growing their businesses. By contrast, creditors might view financial stability to be more critical for smaller, less established firms.

Finally, the results supported our prediction about societies where labor rights receive privilege. We argued that in societies with stronger labor rights protection, a firm's social performance would have an important influence on the general public's perception of the firm. Results confirmed that social performance disclosure has a direct positive effect on the public's perceptions when employees can influence or participate in firm decision making processes. This is consistent with Apéria et al.'s (2004) study on reputations of companies in the Scandinavian countries of Denmark, Norway, and 
Sweden, where they found that over 90 percent of the general public in those countries expect companies to be socially responsible. In contrast, Maignan and Ralston (2002) argue that in countries where the state has traditionally been responsible for the social welfare of society, the firm's role in corporate social responsibility is narrowly defined and limited to good working conditions for employees (Weaver, 2001), while in countries where businesses have a significant role in the development of cities and communities, they have been assigned substantial responsibility toward the societies (Vogel, 1992).

Our study is limited in several important ways. Although most of our countrylevel variables such as cultural, political, legal, and economic variables and the dependent variable (perception of corporate reputation) are fairly persistent, longitudinal analysis could add to the strength of our arguments and results. In addition, this paper studies the world largest companies, which are more visible and have established reputations. Future research should investigate the effects of institutional context on reputation formation in smaller firms as well as start-up companies. This paper also highlights the need for more comprehensive social performance measures to compare firms at the global level.

In addition to the contributions noted earlier, this study contributes to several streams of research. First, this paper is among the few studies that examine corporate reputation in a wide range of countries from both developed and developing economies. Through the use of this cross-country setting, we are able to generate important new insights into how national institutional differences affect the performance-reputation relationship. Second, this paper contributes to the field of corporate governance by extending the relevance of this literature to a new study domain, the area of corporate reputation. Our paper reaffirms the utility of conceptualizing national corporate 
governance systems by stakeholder influence. Countries must not be segregated too quickly into dichotomies or other simplified categorization schemes (e.g., shareholderversus stakeholder-centered models). Our analysis underscores how the use of more finegrained measures of stakeholder power can produce more nuanced insights. Third, our study contributes to the debate on convergence and the global diffusion of business practices (Davis \& Marquis, 2005; Guillén, 2001; Weber, Davis \& Lounsbury, 2009). Corporate governance and other practices are unlikely to converge in the foreseeable future since the very concept of the firm differs significantly across countries. Managers of multinational corporations must take power dynamics into account when operating in different countries in order to achieve legitimacy and strong reputations. Finally, this study examines reputation using a measure based on the assessments of the general population of a country. This differs significantly from studies that examine measures based on a specific segment of elite evaluators, such as financial analysts. By taking this approach, the study is able to better capture the effects of stakeholder power on society. This paper began by raising the question of "why firms exist". Our theoretical arguments and empirical evidence suggest that an important related question is "who decides why corporations exist?" While researchers might assign images to the firm that liken them to a "political contest", "bundle of resources", or "nexus of contracts", the most important conceptions of the firm are probably those held by its stakeholders. For many shareholders, the firm may truly approximate a stream of expected future cash flows signified by its share price. Banks may be more likely to regard business corporations as ongoing customers for a variety of financial products and services. Workers might view the corporation as the basis for their livelihood and more closely 
identify with its social performance. The image that prevails ultimately depends on the respective power and influence of each stakeholder. Corporate reputation has roots in national beliefs about the role of the business corporation in society, which are constructed in accordance with the interests and beliefs of powerful stakeholders. Building on a stakeholder-power approach to corporate governance, within this manuscript, we investigated whether societal-level power of shareholders, creditors, and workers interacts with particular firm performance measures to influence reputation assessments of the general public. Using a sample of 756 of the largest companies in the world from 33 countries, our results demonstrated positive impacts of stock market returns, financial stability, and corporate social performance on corporate reputations. In addition, we provided evidence that the diversity of reputed firms across countries can be linked to national differences in stakeholder power and corporate governance practices. By doing so, we made significant contributions to both the reputation and the corporate governance literatures. 


\section{ESSAY 3:}

\section{NO SUBSTITUTE FOR EXPERIENCE? THE IMPACT OF CORPORATE REPUTATION ON STOCK MARKET REACTIONS TO MERGERS AND ACQUISITIONS}

\section{INTRODUCTION}

The topic of intangible assets has attracted considerable attention among scholars in organizational and strategy research (see Barney, 1991; Deephouse \& Carter, 2005; Dierickx \& Cool, 1989; Fombrun, 1996; Pfarrer, Polluck \& Rindova, 2010; Rindova, Williamson \& Petkova, 2010). The Resource-based View (RBV) proposes that rare, socially complex, and difficult to imitate intangible assets significantly contribute to performance differences among organizations (Amit \& Schoemaker, 1993; Barney, 1991; Peteraf, 1993; Rao, 1994). Most research in this area has focused on the effects of intangible assets on overall firm performance (Deephouse, 2000; Fombrun \& Shanley, 1990; Roberts \& Dowling, 2002). By comparison, the impact of intangible assets on specific strategic actions remains poorly understood (Pfarrer et al., 2010). Therefore, the objective of this study is to advance this literature by responding to the following three questions: (1) Do intangible assets have a significant impact on organizational outcomes? (2) What is the specific impact of intangible assets on an organizational outcome? (3) Do intangible assets have combined impact on an organizational outcome? We intend to answer the above questions in the context of mergers and acquisitions (hereafter referred to simply as acquisition). In other words, we plan to investigate the effect of intangible assets on market reaction to acquisition announcements. In order to answer the first question, we focus on three intangible assets -- acquisition experience corporate 
reputation and business approach toward societal responsibilities - to examine whether they have a significant impact on the market's assessment of acquisition announcements. In the second step, we study the nature of the relationships between each of the three intangible assets and the market's expectation about acquisition success. To answer the third question, we analyze the impact of corporate reputation on the relationship between acquisition experience and market reaction to acquisition announcements.

This study contributes to the strategy literature and advances our understanding of intangible assets in four ways. First, confirming the RBV perspective (Amit \& Schoemaker, 1993; Barney, 1991), this paper empirically shows that both action-specific factual and general perceptual intangible assets have a significant impact on strategic actions and organizational outcomes. Second, the results report that the impacts of intangible assets could go beyond the simple linear relation and might be in contrast to general opinions depending on the context of organizational practice (Haleblian \& Finkelstein, 1999). Third, the study demonstrates that companies can take advantage of "economies of scale" benefits of action-specific factual intangible assets and of "economies of scope" benefits of general perceptual intangible assets. Finally, Capron and Shen (2007) indicated that most of acquisition research studied only public targets. This research contributes by including both publically and privately held targets as well as disclosed and undisclosed deals.

The study is organized in following structure. First, we review the literature on acquisitions and corporate reputation. Following, we develop theoretical arguments and propose our hypotheses. Next we describe our method and measures. We then present the results. In the final section, we discuss the findings, implications for managers, and 
suggestions for future research.

\section{LITERATURE REVIEW}

\section{Mergers and Acquisitions}

Acquisition is a complex strategic action where a company (acquirer) acquires

another company (target). It's a non-routine event that significantly impacts functions and procedures in many parts of an organization (Oler, Harrison \& Allen, 2008). Acquiring companies have different motivations for buying target firms. There is a large body of literature studying acquisition motives. The wide range of acquisition motivations can be categorized into three main groups: economic motives (short-term), strategic motives (long-term), and managerial self-interests (see Brouthers, van Hastenburg \& van den Ven, 1998; Haleblian, Devers, McNamara, Carpenter \& Davison, 2009).

One of the main reasons for acquisitions is to enhance economic performance. Acquisitions can help an acquiring company enhance its economic performance through revenue generation, cost reduction, and risk-spreading. An acquiring firm generates new revenues by gaining access to new markets for its products through acquisition of a company operating in other locations (Dunning, 1998). Similarly, an acquiring company can enter into a new product market by pursuing a diversified acquisition by purchasing a target firm in a different industry (Rumelt, 1982). Diversified acquisition also creates new revenues when acquiring and target firms can combine their knowledge and technologies to develop new products. Particularly, managers view horizontal acquisitions as a strategy to redeploy resources and transfer competencies and knowledge to generate economies of scope (Haleblian et al., 2009). Karim and Mitchell (2000) reported that acquirers not only combine their resources in the areas of their strength, but also extend 
their scope into new areas. An acquiring company can also produce revenue by acquiring an underperforming firm. In addition to generating new revenue, firms can improve their performance by reducing their costs. One strategy to reduce costs is to benefit from economies of scale through integrating value chain activities in acquiring and target companies. Combined supply orders, integrated operations, joint marketing and sales activities, and elimination of redundant support activities such as accounting, procurement, and human resources functions can significantly lower costs of the combined company. Furthermore, past studies have shown that an acquisition lowers cost through resource reconfiguration. Restructuring of assets and resources can increase efficiency of operations in the combined company. Similarly, acquisitions can reduce transaction costs. Acquiring and target companies have their own network of suppliers, contractors, and distributors. Bringing their social capital together lowers transaction costs not only with external partners, but also within their organizations. Particularly, in related acquisitions - in terms of resources and products - managers can apply their "dominant logics" (Prahalad \& Bettis, 1986) in the new combined business and benefit from a diminishing need to learn about the business functions and processes in the target company business (Hitt, Harrison \& Ireland, 2001).

Companies also pursue acquisitions to pursue their strategic and long-term goals. Gaining market power and reducing their dependence on other organizations are among proactive strategic motivations for acquisitions. Brouthers et al. (1998) interviewed Dutch managers engaged in acquisition activities and found that market power was the most important motive for pursuing acquisitions. Acquiring a rival company results in fewer companies in an industry and not only elevates entry barriers for new entrants, but also 
increases pricing power of the firm (Oler et al., 2008). Kim and Singal (1993) studied airline mergers in 1980s and showed that ticket price in routes served by merging firms increased compared to other routes. Companies also pursue acquisitions to limit their dependence on other organizations (Pfeffer, 1972). Particularly, acquisitions of raw material suppliers, product and process technology providers, and knowledge-based companies through vertical integration are common forms of reducing dependence on external organizations. In addition to proactive strategic motivations for acquisition, there are external factors that influence corporate strategies. From an institutional perspective, DiMaggio and Powell (1983) argued that firms tend to behave similarly under isomorphic pressures. Mimetic pressure arguments explain that under conditions of uncertainty, firms tend to imitate behavior of successful and leading organizations in their field. Stearns and Allan (1996) studying merger waves explained the role of imitation in merger waves. They argued that fringe players "initiate the innovations that enable them to execute mergers. Merger waves occur when these actors become increasingly successful and their innovations are imitated through-out the business community" (Stearns \& Allan, 1996: 699). Similarly, network ties and board interlock influence managers' decisions on pursuing acquisitions (Haunschild, 1993).

Acquisition decisions are made by top managers. In addition to short-term and long-term goals, human factors are involved in acquisition decisions. Acquisition decisions are complex and multidimensional decisions that are not made solely on a techno-economic basis (Hayward \& Hambrick, 1997). Managers make decisions based on their premises, biases, and limitations (March \& Simon, 1958). Therefore, managers' backgrounds, self-images, and assumptions influence acquisition decisions (Hambrick \& 
Mason, 1984). Recent studies in the management and finance area show that manager's self-interests (i.e., compensation, power, and prestige) are strong motivations in pursuing acquisitions (see Haleblian et al., 2009). These studies reported that CEO's postacquisition compensation generally increased, irrespective of acquisition performance (e.g., Grinstein \& Hribar, 2004; Harford \& Li, 2007). In addition, managing larger firms provides managers with more discretion and power (Hambrick \& Finkelstein, 1987) as well as prestige (Brouthers et al., 1998). Besides self-interests, CEO’s hubris exaggerated self-confidence - motivates and impacts acquisition decisions (Hayward \& Hambrick, 1997; Hiller \& Hambrick, 2005).

With all the motivations for pursuing acquisitions and the growing number of acquisition activities, the literature suggests that most acquisitions fail (Barkema $\&$ Schijven, 2008). King and his colleagues (2004) employed a meta-analysis technique to review empirical articles about mergers and acquisitions in accounting, finance, economics, and management journals and found robust results indicating that acquisitions had not led to positive changes in acquiring firms' performance. Scholars studying the effect of acquisitions on firm value report similar results. These studies demonstrated that acquisitions did not enhance acquiring firms' value in the short-term (Asquith, 1983; Jarrell \& Poulsen, 1989) and the long-term (Agrawal, Jaffe, \& Mandelker, 1992; Loderer \& Martin, 1992). Because acquiring firms pay acquisition premiums for target companies, research showed that acquisitions generally have positive impacts on the acquired company’s value (Datta, Piches \& Narayanan, 1992; Malatesta, 1983).

Due to the impact of various factors on acquisition performance, scholars face challenges in operationalizing this concept. Therefore, there is a wide range of acquisition 
performance measures in the literature. Zollo and Meier (2007) reviewed empirical M\&A articles published in top finance and management journals between 1970 and 2006 and reported 12 different measures for acquisition performance including subjective and objective measures, measures with short and long time horizons, and operationalizations at different organizational levels. The most notable measures are market-based measures (short- and long-term abnormal stock returns), accounting-based measures (e.g., return on assets), survival analysis, and managers' perceptions and analysis. Zollo and Meier (2007) indicated that the largest group of research studies in their sample (41\%) used the shortterm window event study method. This method measures the stock market reaction to the acquisition around the acquisition announcement date. Stock market reactions to M\&A announcements (short window studies) gauge "...the collective cognitive heuristic, the overall market "sentiment", about how a given typology of acquisition ... should perform." (Zollo and Meier, 2007: 24). In other words, cumulative abnormal changes to the acquiring (or acquired) firm's stock price around the acquisition announcement date are calculated and interpreted as a capital market's unbiased expectation of future benefits of an acquisition based on all available information (Brown \& Warner, 1985). The desirable property of shorter windows is that the market reaction is less likely to be contaminated by other extraneous events (Oler et al., 2008). Adoption of a short window event study method is based on the semi-strong version of the efficient-market hypothesis (EMH; Fama, 1970; McWilliams \& Siegel, 1997), which asserts financial markets are informationally efficient and stock prices not only reflect all publically available information, but also instantly change based on new public information. However, in recent studies, scholars criticized the interpretations of short-term event studies 
(Bromiley, Govekar \& Markus, 1989; Oler et al., 2008; Zajac \& Westphal, 2004). Mainly, the literature suggests that instead of interpreting short-term event study results of acquisition announcements as 'value' or 'wealth' created by the event, it should rather be interpreted as stock market assessment of expected value the event would create (Capron \& Pistre, 2002; Kumar, 2005; Shen \& Canella, 2003). Therefore, following Haleblian et al.'s (2009: 493) suggestion, we labeled the cumulative abnormal returns (CAR) in a short-window event study as "short-term market response to acquisition announcements".

Based on all publicly available information, a stock market reacts to an acquisition announcement by demonstrating its perception and evaluation of the expected future benefits of the acquisition. An acquisition is a complex and multi-dimensional event that influences multiple areas of the firm and can have deep and fundamental changes in firm operations. Consequently, prediction of its future outcome is difficult and requires taking multiple factors into consideration (Oler et al., 2008). Future success of an acquisition depends on the realization of synergy between acquiring and target organizations (Haspeslagh \& Jemison, 1991; Hitt et al., 2001; Larsson \& Finkelstein, 1999). According to Barkema and Schijven (2008), the realization of synergy depends on two main groups of activities: careful target selection (Harrison, Hitt, Hoskisson, \& Ireland, 1991; Ramaswamy, 1997) and effective post-acquisition integration (Chatterjee, Lubatkin, Schweiger, \& Weber, 1992; Datta, 1991). In the target selection category, issues such as strategic and organizational fit between acquiring and target firm, information about potential target firms, and due diligence (Buono \& Bowditch, 1989; Haspeslagh \& Jemison, 1991) can send signals to the market about the likelihood of synergy realization in a combined firm. On the other hand, future success of an 
acquisition depends on the firm's capabilities in future procedural (e.g., administrative, operations, management), physical (e.g., product lines, technologies, and other resources), and social integration (e.g., employees) (Shrivastava, 1986). In addition to target selection assessment and firm integration capability speculation, characteristics of an acquisition deal (e.g., premium, payment method) influence stock market reaction (Haleblian et al., 2009). Particularly, acquiring managers use acquisition premium, which is the additional value an acquiring firm intends to pay for each share of a target firm, to signal that the target firm's stock price inadequately reflects the firm's value and they can make more value (Hayward \& Hambrick, 1997). However, a large premium can negatively impact the acquiring firm's shareholder return (Sirower, 1997) and ultimately acquisition performance. Similarly, payment methods (i.e., cash, stock, and combined) send distinct signals to the market. Managers tend to finance acquisitions by cash if they believe their stock is undervalued and by stock if its overvalued (King et al., 2004). Therefore, a cash-financed acquisition signals that managers have strong expectations about combined firm performance (King et al., 2004). In sum, perceptions of the market about three major groups of issues influence short-term market reaction to acquisition announcements: selected target characteristics, likelihood of successful integration, and acquisition deal characteristics.

\section{Corporate Reputation and Consequences}

Corporate reputation is a multidisciplinary concept. Scholars in economics, management, strategy, sociology, psychology, and marketing have studied corporate reputation. Application of corporate reputation in different disciplines is one of the sources of multiple definitions for corporate reputation. In their review of the 
organizational reputation literature, Lange, Lee and Dai (2011) concluded that corporate reputation is a multidimensional concept and the pluralism in its definition is the reflection of its theoretical pluralism. They defined corporate reputation along three dimensions: "Being Known" (extent of awareness and knowledge about an organization), "Being Known for Something" (level of confidence in prediction of future behavior of an organization), and "Generalized Favorability" (extent of favorable or unfavorable judgment about an organization as a whole). They argued that despite overlaps among these dimensions, they are distinct based on two characteristics: judgment vs. impression and particular attribute vs. generalized picture. While "Being Known" is a generalized impression about an organization, "Being Know for Something" and "Generalized Favorability" are, respectfully, judgments about a particular attribute of an organization and an organization as a whole. While Lange et al. (2011) defined three dimensions of corporate reputation, Love and Kraatz (2009) took a more divergent approach and elaborated three distinct perspectives of reputation, i.e., organizational character, symbolic conformity, and technical efficacy. They emphasized that each of these perspectives are distinct in the evaluative logic that corporate audiences use to assess corporate reputation. The "Organizational Character" approach suggests that audiences of an organization perceive it as an exchange partner that they might have transactions with. Therefore, they want to learn about the "true" attributes of the organization. For this purpose, they tend to evaluate the organization based on its actions and the decisions it makes. They expect an organization with favorable reputation to possess desirable character traits such as trustworthiness, credibility, and reliability (Davies, Chun, da Silva \& Roper, 2001; Fombrun, 1996). Unlike the "Organizational Character" perspective 
where reputation assessment criteria are universal (e.g., trustworthiness), in the "Symbolic Conformity" approach, organizational audiences evaluate an organization based on its conformity with context-specific and socially constructed standards and norms (Rao, 1994; Staw \& Epstein, 2000). Love and Kraatz (2009) indicated that this approach considers organizations and evaluators embedded within larger cultural systems (Rao, 1994). Therefore, they develop a mutual understanding about desirable and undesirable practices. Consequently, cultural fitness, conformity with social expectations, and adoption of socially desirable practices are the main criteria for audiences to assign approval and esteem to an organization. Consistent with this approach, Staw and Epstein (2000) showed that adoption of popular management practices (e.g., total quality management) that have positive value in society resulted in enhanced reputation, even though they did not improve financial performance. Different from the two previous approaches, an organization's audiences in the "Technical Efficacy" perspective have a more utilitarian approach in evaluating the organization's reputation. In other words, evaluators assess organization reputation based on its tangible outputs such as superior quality of products and services, and superior financial performance (Shapiro, 1983). As stakeholders of an organization have different interests in the organization, they might have different reputational assessments about the organization. For instance, while stock price is the primary interest of shareholders, financial stability is the central objective to creditors, and product quality and safety the main concern of customers. Therefore, depending on firm performance in these areas, it may have different reputational assessments. Love and Kraatz (2009) reported that downsizing negatively impacts corporate reputation. However, stock market reactions to downsizing varied depending 
on firm performance, where downsizers with superior financial performance received less reputation damage. To address multiple stakeholders' perceptions, Rindova and her colleagues (2005) studied components of reputation and how these components shape stakeholders' perceptions as well as their behavior toward the organization. They argued that corporate reputation has two components: perceived quality and prominence. Perceived quality represents an economic perspective of reputation, which argues that a firm's past actions work as signals reflecting the "true" attributes of the firm and influence stakeholders' perceptions about a particular attribute of the firm (Clark \& Montgomery, 1998; Weigelt \& Camerer, 1988). Depending on the interest and information that stakeholders attend to, they might have different perceptions about different attributes of the organization. On the other hand, the prominence component of reputation corresponds to an institutional perspective of reputation that is concerned with collective awareness and recognition of an organization among its stakeholders. An organization gains this recognition through interaction and information exchange with other entities in its organizational field (Fombrun, 1996; Rao, 1994; Rindova \& Fombrun, 1999). Furthermore, these two components of reputation determine consequences of an organization's reputation by influencing stakeholders' behavior. For example, customers are willing to pay price premiums to a firm that is perceived to produce superior quality products (Shapiro, 1983). Similarly, employees would like to work for prominent companies that are recognized and respected in society (Newburry, 2010).

Scholars from different disciplines have done a considerable amount of research on the consequences of reputation. These studies can be grouped into three main categories. One stream of research investigated the effect of corporate reputation on 
supportive behavior of stakeholders (i.e., customers, job applicants, and investors) in competitive markets (i.e., product, labor, and capital market) (Doh, Howton, Howton \& Siegel, 2009; Newburry, 2010; Walsh, Mitchell, Jackson \& Beatty, 2009). Walsh et al. (2009) showed that good reputation not only helps firms in retaining their customers (customer loyalty), but also it attracts new customers through word of mouth. In addition, customers are more willing to pay price premiums to reputed companies (Shapiro, 1983). Benjamin and Podolny (1999) demonstrated that wineries with high-status affiliations could charge price premiums for their reputation. Similar to product markets, research has reported positive impacts of good reputations in labor markets. Turban and Cable (2003), studying the effect of organization reputation on employment, showed that companies with better reputations both attract more job applicants and are able to select higher-quality ones. Likewise, based on a person-organization fit argument (Chatman, 1989), Newburry (2010) showed that individuals are more willing to work for companies with better reputations. Reputation also impacts investors' investment choices (Helm, 2007; Shefrin, 2001). MacGregor and colleagues (2000) reported that an IPO's reputation is a basis for investors' buying decisions. In addition to initial investment decisions, Helm (2007) showed that firm reputation significantly impacts investor satisfaction and loyalty.

The second strand of consequences of reputation studies examined the impact of corporate reputation on everyday operations and overall business of firms. These studies analyzed the impact of reputation on financial performance (Deephouse, 2000; Fombrun \& Shanley, 1990), sustained financial performance (Roberts \& Dowling, 2002), employee satisfaction and retention (Fombrun, 1996), and internal operations and 
supplier relationship management (Alloza, 2008), among others. The third area of reputation consequences research concentrates on the investigation of the impacts of reputation on the firm's strategic actions and organizational outcomes. Despite a large body of studies on reputation consequences, this area has been less studied and remains poorly understood (Pfarrer et al., 2010). Deephouse and Carter (2005), studying organizational practices, investigated the relationship between reputation and isomorphism. They showed that organizations with higher reputation can deviate from conforming behaviors. While deviation from conforming behaviors sounds questionable and could negatively impact companies with middle status, high-status companies are more secure in exhibiting non-conforming behavior (Phillips \& Zuckerman, 2001). Stakeholders may even judge non-conforming behaviors positively by giving them “idiosyncratic credits" (Ashforth \& Gibbs, 1990; Hollander, 1958; Phillips \& Zuckerman, 2001). In another study in this group, Saxton and Dollinger (2004) examined acquisitions and found that favorable reputation of a target company significantly impacts the acquirer's satisfaction. In this paper, we intend to expand this area of research by examining how the reputation of a company influences stock market reactions to its strategic decisions regarding acquiring another company.

\section{HYPOTHESES DEVELOPMENT}

In this study, we intend to investigate the impact of intangible assets on market reaction to acquisition announcements..For this purpose, we selected an intangible asset specifically related to the strategic action, namely, acquirer's acquisition experience, and two other general intangible assets, i.e., acquirer's reputation and social responsibility approach. In addition to direct effects, we examine the combined impact of acquisition 
experience and reputation on market response to acquisition announcement.

\section{Acquisition Experience}

An acquisition announcement brings about a stock market reaction to an acquiring company's stock price. Market reaction demonstrates market expectations about the future success of an acquisition based on all available information (Fama, 1970; McWilliams \& Siegel, 1997). One of the factors that impacts stock market expectations about success of an acquisition is the acquiring company's acquisition experience. A large body of literature studied the impact of learning and acquisition experience on acquisition success but reported mixed results (Barkema \& Schijven, 2008). While some studies found a positive relationship between acquisition experience and acquisition performance (Fowler \& Schmidt, 1989), others found no significant relationship (Hayward, 2002; Zollo \& Singh, 2004) or a U-shaped relationship (Haleblian \& Finkelstein, 1999; Zollo \& Reuer, 2006). Although there is no consensus on the impact of acquisition experience on acquisition performance in the literature, acquisition experience is an extra piece of information that the stock market can use to lower information uncertainty (Spence, 1973) and influence stock market expectation about the success of the acquisition.

As mentioned earlier, three groups of information shape stock market expectation about acquisition success: deal characteristics, target company selection, and successful integration (factors influencing synergy realization). Determination of acquisition deal characteristics such as acquisition premium, payment method, and acquisition type is highly dependent on the top management team and governance structure of an acquiring company. Acquiring companies with more acquisition experience develop learning skills 
in the valuation of target companies as well as incorporate mechanisms and structures for effective decision making. For instance, Hayward and Hambrick (1997) showed that a vigilant board of directors could restrain a CEO from decisions influenced by hubris. In addition, experienced acquirers incur lower transaction costs by accumulating more knowledge about payment method choice as well as developing more stable and efficient relationships with banks and other intermediary financial institutions that send positive signals to the stock market.

Similarly, acquisition experience is valuable in the process of analyzing potential target companies. Particularly, prior literature indicated that information gathering about potential targets, due diligence, and evaluation of strategic and organizational fit are essential steps in acquisition success (Datta, 1991; Galpin \& Herndon, 2007; Hitt et al., 2001). Through past experience, acquirers learn about the type of information they need and more efficient ways to acquire this information. Furthermore, they create expertise in due diligence processes and assessment of strategic and organizational fit.

The third area that affects stock market evaluation of the future outcome of an acquisition is the acquirer's capacity in integrating target companies. Previous acquisition experience helps acquiring companies to develop routines for future acquisitions (Szulanski, 1996). Organizational routines are repetitive organizational activities that guide organizational decisions (Nelson \& Winter, 1982). Firms gain expertise and competence in a routine by accumulating experience in it (Haleblian, Kim \& Rajagopalan, 2006). Routines are important in acquisitions and specifically in integration processes where there is a high level of uncertainty. As an acquirer pursues more acquisitions, these routines become more developed, accessible, transparent, and immediate (Hayward, 
2002). These routines can become a source of competitive advantage and play a critical role in organizational decision making (March, 1999). Routines are more effective in similar organizational activities. Particularly, they are effective sources for successful procedural integration (i.e., combination of administrative systems and rules), which has similar building blocks across acquisitions (Shrivastava, 1986). In addition, routines are imperative for speed of integration, which positively impacts acquisition success (Homburg \& Bucerius, 2006). Similary, Ashkenas, DeMonaco and Francis (1998) and Hitt, Harrison, Ireland and Best (1998) showed that organizations with prior acquisition experience are better at improving effectiveness and efficiency of integration processes.

However, there are fundamental requirements for past experience to lead to organizational learning and ultimately success. It's important to note that experience effects are not always positive. Specially, transfer of past experience to the settings where past lessons do not apply is not positive (Barkema \& Schijven, 2008). Haleblian and Finkelstein (1999) showed that generalization of past experience in dissimilar situations does not lead to positive outcomes. In particular, acquisitions are complex projects that involve different areas of organization and consist of many interdependent subactivities (Hitt et al., 2001). Furthermore, acquisitions are different from each other and the acquisition process should be customized to each deal (Barkema \& Schijven, 2008; Galpin \& Herndon, 2007). Therefore, acquiring companies face high levels of causal ambiguity due to the complexity and heterogeneity of acquisitions (Lippman \& Rumelt, 1992; Zollo \& Singh, 2004). Haleblian and Finkelstein (1999) demonstrated that there are differences in application of past acquisition experience between novice (i.e., acquirers with limited acquisition experience) and expert (i.e., acquirers with extensive acquisition 
experience) acquirers. While novices realize more obvious and surface information, experts capture both surface and underlying features (Novick, 1988). Furthermore, novice, compared to expert, acquirers make more inappropriate generalizations of past acquisition experiences (Haleblian \& Finkelstein, 1999). In other words, the information and knowledge a novice acquirer gains in its first acquisition experience is very superficial. It uses this information as the base for the second acquisition (e.g., inappropriate generalization) without realizing the underlying differences between the acquisitions, resulting in lower performance (Haleblian \& Finkelstein, 1999). By pursuing more acquisitions, the novice acquirer gains acquisition expertise and knowledge about underlying dissimilarities between acquisitions and consequently makes less inappropriate generalizations and more appropriate generalizations (Haleblian \& Finkelstein, 1999). Building on this past research, we expect stock markets to react negatively to acquisition announcements of novice acquirers and positively to those of expert acquirers. Therefore, we suggest following hypothesis:

Hypothesis 1 (H1): There is a U-shape relationship between acquiring company acquisition experience and stock market reaction to its acquisition announcement.

\section{Corporate Reputation}

A corporate acquisition is a complex event involving multiple interconnected areas of an organization in various ways (Oler et al., 2008). Although acquisitions include some routines and similar activities, they are distinct from each other, and furthermore, most of them fail (Barkema \& Schijven, 2008). The common characteristic of all acquisitions is the high level of uncertainty in every step of the pre- and post-acquisition processes. Acquiring company's managers face uncertainty due to information 
asymmetry between them and potential target organizations. Uncertainty about reactions of managers and shareholders of a target company influences an acquiring company's choice of acquisition type, premium, and payment method. Uncertainty also negatively impacts employees of both acquiring and target companies, making them anxious about integration processes, new procedures, lay-offs, and most importantly, working with employees in the other organization with different organizational cultures, norms, and value systems. The impact of uncertainty goes beyond internal stakeholders and affects outside stakeholders, as well. Suppliers worry about new policies and requirements, new transactions, and new competitions. Similarly, distribution channels face uncertainty about how acquisitions may change their established relationships with acquiring and acquired companies. Customers are also uncertain about short-term and long-term consequences of an acquisition and how the acquisition may affect their relationship with combining organizations as well as the quality and price of products and services. For instance, the merger of Continental Airlines and United Air Lines took more than a year to consolidate their different ticket reservation systems, online portals, and frequent flyer program activities such as earning and redeeming mileage, upgrades, and elite status, among others, all of which creates questions and confusion in customers not only about the short-term consequences of the merger, but also how it will affect the quality and price of the joint United Airlines in the future.

All these uncertainties impact the stock market expectation about the future of an acquisition. Therefore, corporate reputation that can lower information uncertainty would be very valuable to stakeholders and particularly the stock market (Benjamin \& Podolny, 1999; Spence, 1973; Weigelt \& Camerer, 1988). Rindova et al. (2005) compared how 
reputation lowers information uncertainty by signaling the "true" attributes of an organization from economic and institutional perspectives. From an economic perspective, reputation is formed based on past actions, choices, and decisions made by an organization. In other words, past behavior of an organization informing its reputation reveals its "true" attributes, which are very specific rather than general, such as product quality, innovativeness, and social responsiveness (Lange et al., 2011). From an institutional perspective, "true" attributes of an organization are unveiled through interaction and information exchange among diverse actors in the organizational field (Rindova et al., 2005). Particularly, institutional intermediaries and high-status actors have important roles in publicizing the "true" attributes of an organization by their superior ability to access and disseminate information (Rindova et al., 2005).

All in all, two main components of reputation, namely perceived quality and prominence (Rindova et al., 2005), provide stakeholders with valuable information about acquiring and target companies. Favorable reputation of an acquiring company positively influences deal characteristics and target selection process. Potential target managers and shareholder would prefer to be acquired by a company known for its good reputation. In addition, good reputation can facilitate integration processes and minimizes conflicts. Specifically, reputation plays a critical role in managerial and sociocultural integration. Good reputation gives an acquiring company legitimacy to mobilize organizations toward integration, combining cultures, managerial systems, and organizational structures (Vaara \& Monin, 2010). Favorable reputation provides the target company's employees with information that lowers uncertainty and increases their confidence to accept the change. Furthermore, good reputation reduces transaction costs within two organizations 
as well as between combined companies and other resource and service providers outside the organization (Bergh, Ketchen, Boyd \& Bergh, 2010). Reputation reflecting the trustworthiness and credibility of an acquiring company can become a discriminating factor for target company employees and outside stakeholders (Williamson, 1996). Trustworthiness reduces transaction costs by lowering the likelihood of an acquiring firm's opportunistic behavior. Companies with good reputation willingly relinquish shortterm benefits of opportunistic behavior for long-term benefits of favorable reputation (Chiles \& McMackin, 1996). Therefore, good reputation facilitates a target company’s employees renewing and redefining their relationship and interactions, including contracts with the acquiring company, incurring less transaction costs.

Also, good acquiring company reputation impacts its relationship with potential outside partners. Suppliers and service providers incur transaction costs due to bounded rationality, opportunism, and risks in search for partners, negotiation processes, and enforcing contracts, and a strong reputation of the acquiring company reduces these costs (Bergh et al., 2010; Chiles \& McMackin, 1996). In sum, favorable reputation of an acquiring company has a positive impact on deal characteristics, target selection, and integration processes, and consequently, on the expectations of the stock market about future benefits of the acquisition. Therefore, we propose the following hypothesis: Hypothesis 2 (H2): There is a positive relationship between acquiring company reputation and market reaction to its acquisition announcement.

\section{Impact of Acquirer's Reputation on its Acquisition Experience}

Corporate reputation adds a new dimension to an already complex acquisition process for acquirers. On the one hand, it impacts stock market opinions by revealing 
more information about the attributes of acquirer, and on the other hand, it influences the acquirer's top management by increasing the complexity of decision making. Reputed companies are more covered by media and more information about their activities is disseminated (Wartick, 1992). Strategic actions of these more visible companies attract more attention, especially when it comes to debating strategies such as acquisitions, of which the majority have been shown to fail (Barkema \& Schijven, 2008). Under these circumstances, other characteristics of the acquirer and particularly its acquisition experience become more important.

A highly positive reputation may not only be not positive for a novice acquirer, but may also be detrimental for three main reasons. First, one of the factors that results in negative acquisition performance is top management team hubris, defined as exaggerated self-confidence (Hayward \& Hambrick, 1997). Hayward and Hambrick (1997) identified three sources of CEO hubris: recent organizational success, media praise, and selfimportance. An acquirer's high reputation reflects its superior quality and prominence (Rindova et al, 2005). Media praise the top management team and organizational actors attribute their organization's success to them. Therefore, the top management team gains more confidence and develops greater expectations about their abilities (Brockner, 1988; Hiller \& Hambrick, 2005; Jacobs, Berscheid, \& Walster, 1971). These greater expectations about their ability combined with their lack of acquisition experience lead novice acquirers with high reputations to overlook the dissimilarities between acquisitions and neglect to take necessary actions, consequently leading them to potentially acquire target companies that are beyond their capabilities to integrate.

Second, companies with high reputation, which attract more attention and are 
more covered by media, are more cautious and constrained in their actions in order to protect their good reputation (Chiles \& McMackin, 1996). Post-acquisition processes include activities such as cutting costs and duplicated activities that are not necessarily favored by stakeholders. Unlike expert acquirers, novice acquirers with high reputations do not have sufficient acquisition experience to realize solutions that can facilitate postacquisition processes without harming the acquirer's high reputation. In other words, high reputation intensifies the negative impact of lack of acquisition experience for novice acquirers. Finally, attracting more attention, reputed companies not only are under isomorphic pressure to pursue strategies that are adopted by their peers (Deephouse, 1996), but they also are under higher expectations to perform better than their peers with lower reputations (Rindova et al., 2005). These institutional pressures negatively influence acquirers with less acquisition experience in the selection of target companies and implementing acquisition activities, especially when there is no strong and economically justifiable motivation.

In sum, reputation magnifies the importance of acquisition experience. For novice acquirers, in particular, it intensifies the negative effect of lack of sufficient acquisition experience on the expected outcome of acquisition. However, for expert acquirers that could realize both surface and underlying similarities as well as dissimilarities between acquisitions, high reputation amplifies the positive value of acquisition expertise. Extended acquisition experience creates organizational knowledge that lowers top management hubris, prevents inappropriate generalization, and supports appropriate discrimination. Having extended acquisition experience, expert acquirers are not only free from institutional isomorphic pressure, but they also have expertise in adopting 
effective post-acquisition activities without harming their reputation, thus allowing them to augment reputation with acquisition expertise. Therefore, we predict that acquirer reputation intensifies acquisition experience, negatively for novice acquirers and positively for expert ones. According, we suggest following hypothesis:

Hypothesis 3 (H3): The reputation of the acquiring company magnifies the relationship between acquisition experience and market reaction to acquisition announcement.

\section{Acquirer's Social Responsibility Approach}

Market reaction to an organization's action varies according to the nature and complexity of that action. In particular, an acquisition is characterized as a non-routine practice that impacts multiple areas of an acquiring company. Although acquisitions comprise similar steps such as due diligence and integration, they are different in content depending on acquisition type (e.g., diversification or cross-border acquisition), target company type (e.g., start-up, joint venture, subsidiary, private, or public company), acquisition attitude (e.g., friendly or hostile), and acquisition form (e.g., disclosed or undisclosed) among other factors. These complexities increase the uncertainty about the future outcome of the acquisition. In addition, the stock market is bounded to consider all the factors in the pre- and post-acquisition periods that might influence the future success of an acquisition. Therefore, the stock market uses heuristic models formed based on the accumulated knowledge from past acquisition practices in order to estimate the future value of a focal acquisition announcement (Zollo \& Meier, 2007). Furthermore, the fact that the majority of acquisitions fail (Barkema \& Schijven, 2008) or do not result in a positive change in the acquirer's performance (King et al, 2004) causes the stock market to take a conservative approach to estimating the future value of an announced 
acquisition. In these circumstances, past actions revealing the "true" attributes of an acquiring firm, partially reduce information uncertainty and impact stock market expectations about the ability of a firm to create value from an acquisition. Past actions are a reflection of the firm's philosophy about the role of firm in society and choice of its primary stakeholder. This philosophy is one of the factors that could augur an acquisition's outcome. In other words, this philosophy is the grounds for critical decisions that an acquiring firm needs to make after the acquisition to develop strategies for integrating the companies and creating synergy. Companies believing in their responsibility toward society would pursue different strategies from companies that recognize interests of society after their own financial interests. Socially responsible companies consider their legal, ethical, and philanthropic responsibilities in addition to economic responsibility in their decisions (Carroll, 1979). In practice, "corporate social responsibility (CSR) is continuing commitment by business to behave ethically and contribute to economic development while improving the quality of life of the workforce and their families as well as of the local community and society at large" (The World Business Council for Sustainable Development, 1998: 3). Therefore, these companies feel responsible regarding the impact of their activities, strategies, and decisions on employees, community, and the environment. A CSR mindset prevents a company from pursuing strategies that could create economic value for the company at the expense of society. Particularly, a CSR mindset impacts acquisition outcomes. Acquisitions are evaluated based on the capability of the acquirer to create short-term economic benefits through increasing revenues and cutting costs. The stock market expects acquirers with more favorable CSR reputations and records of higher transparency, human rights, and 
environmental standards to take more lenient approaches in post-acquisition integration processes to meet societal expectations. This in turn would prevent legitimate but less socially-favored strategies such as significant workforce reduction. On the other hand, market-savvy acquirers are more willing to utilize all legitimate capacities for cost reduction and revenue generation. Having a shareholder primacy mindset, these companies pursue strategies that put shareholders' interests above other stakeholders. In other words, the impact of a potential firm strategy on shareholders' wealth is the main criterion to adopt a strategy. Past behavior of these companies such as investment choice, lay-offs, and product and market positioning signals their approach to the stock market. Therefore, the stock market is more confident that market-savvy acquirers are more aggressive in creating value out of the acquisition, while it perceives acquirers with higher CSR reputations as less efficient in cost reduction and revenue generation. Consequently, they will produce less cash flow after an acquisition compared to acquirers with lower CSR reputation. Accordingly, we suggest following hypothesis:

Hypothesis 4 (H4): The stock market reacts more negatively to acquisition announcements of socially responsible companies.

\section{METHODS}

\section{Sample}

The sample consists of 296 acquisitions (both disclosed and undisclosed) conducted by the 87 largest (by revenue) US companies from 23 industries including both financial and non-financial sectors in 2010. The list of acquirers was identified based on the companies evaluated by the Reputation Institute as part of their 2009 RepTrack Pulse study (Reputation Institute, 2009). The acquisition includes both public 
and private target companies. Acquisition, acquirer, and target company data are collected using Securities Data Corporation's (SDC Platinum) Merger \& Acquisition database. All explanatory and control variables are lagged one year.

\section{Dependent Variable}

Market reaction to $M \& A$ announcement. We used a short-window event study, the most frequently used method in the acquisition literature (Zollo \& Meier, 2007), to measure market expectation about the future of an announced acquisition. This method estimates the cumulative abnormal security returns (CAR) of an acquirer company in a short window around the acquisition announcement date. CARs are calculated in three steps: (1) estimating the expected (if announcement had not been made) acquirer's security return for each day in the specified window, (2) calculating the abnormal return by subtracting the expected return from the actual market return on each day in the study window, and (3) aggregating abnormal returns in the study window. We used a shortterm window of 5 days prior to the announcement to 1 day after the announcement. The advantage of a short-term window is that it minimizes noises from other confounding variables (Haleblian et al., 2009). We included 5 days prior to the announcement in the study window to allow for information leaks prior to official announcements. We used SDC Platinum to collect data on the acquirer and acquisition date and used the EVENTUS software package, which acquires stock market data directly from the Center for Research in Securities Pricing (CRSP) US stock databases, to calculate CAR for each event.

\section{Independent Variables}

Acquisition experience (H1). Following Barkema and Schijven (2008) and Fowler 
and Schmidt (1989), we measured an acquirer's acquisition experience by counting the number of its acquisitions in the previous 4 years $(2006-2009)$. We collected acquisition experience data through SDC Platinum.

Corporate reputation (H2). Acquirer reputation is obtained from the Reputation Institute's 2009 RepTrack Pulse study (Reputation Institute, 2009). The Reputation Institute administered a multi-item online survey to measure perceptions of individuals from the general public about the reputation of a company. Past qualitative studies showed the content validity of this measure in the US (Ponzi, Fombrun \& Gardberg, 2011). Unlike other reputation measures, which are based on opinions of a narrowly defined group such as business analysts, the Reputation Institute's measure is notable since it is derived from broader public attitudes. However, individuals were required to demonstrate some knowledge about a company to participate in the survey. For this purpose, they needed to answer 3 out of 4 screening questions (Asher, 2004). Moreover, respondents were selected to represent the general population by gender and age. The RepTrack Pulse reputation index comprised four items: (1) "good overall reputation", (2) "a company I have a good feeling about", (3) "a company that I trust", and (4) "a company that I admire and respect" (Reputation Institute, 2009). All four items were on a 7-point Likert scale, where "1" indicates "strongly disagree" and "7" indicates "strongly agree". Respondents also had the option to indicate "not sure". The Chronbach Alpha for this scale is 0.988 . Unidimensionality, convergent validity, and fit of the scale items were confirmed by LISREL. An acquirer's reputation is calculated by creating an average of the scores of all respondents who evaluated the acquirer and then converted to a $0-100$ scale for ease of interpretation. 
Social responsibility (H3). We used KLD Research \& Analytics (KLD) data to measure an acquirer's approach toward society. KLD creates profile of company performance based on Environmental, Social, and Governance (ESG) factors. KLD measures the number of strengths of and concerns about a firm's performance in the following categories: community, corporate governance, diversity, employee relations, environment, human rights, and products. To construct our measure, we calculated the total strengths of a company and subtracted its total concerns. Acquirers with higher scores demonstrated more involvement in societal responsibilities.

\section{Control Variables}

Numerous factors impact market reaction to an acquisition announcement. In order to rule out the impact of other factors, we control for five variables that have been shown in past studies to influence expectations about the future outcome of an acquisition. Acquirer size is one of these factors (Haleblian et al., 2009), which was measured as the natural logarithm of an acquirer's book value in twelve month prior to the acquisition announcement. Larger acquirers possess more assets and resources that facilitate integration with target companies and increase post-acquisition asset productivity (Healy, Palepu \& Ruback, 1992). Another factor that affects expectations about the future of an acquisition is Acquirer profitability (Capron \& Shen, 2007), which was measured as the ratio of an acquirer's net income to its total assets in the year prior to the acquisition announcement. Acquirers with poor performance might be motivated to pursue acquisitions to hide their poor performance (Capron \& Shen, 2007). On the other hand, acquirers with superior performance are more likely to be able to succeed in postacquisition processes. Acquirer industry also can influence expectations about future 
acquisition performance (Bergh, 1997). Industry characteristics such regulations, technology, and capital structure of businesses in an industry could influence attractiveness and expected success of acquisitions as a strategic choice (Haleblian et al., 2006). Particularly, businesses in financial industries have more resources (including capital resources) to undertake acquisitions. Therefore, we controlled for acquirers in financial sectors. Another factor that influences stock market reaction to an acquisition announcement is availability of information about a target company. While there is less information available about private companies, the market has good information access regarding public targets. Availability of information lowers information asymmetries and increases confidence in the market about the outcome of an acquisition. Accordingly, we controlled for Target type using a dummy variable, valued "1" for public and "0" for private targets. Finally, we controlled for acquirer and target relatedness, which was measured as a dummy variable with a value of " 1 " for acquirer and target companies with similar 3-digit SIC codes. By acquiring from the same or a similar industry, an acquirer can appropriately generalize their knowledge (Haleblian \& Finkelstein, 1999). In addition, post-acquisition processes and the success of integration of companies depend on the level of relatedness of acquiring and target companies (Bragado, 1992; Haspeslagh \& Jemison, 1991; Homburg \& Bucerius, 2006).

\section{RESULTS}

We tested our hypotheses using Ordinary Least Squares (OLS) estimation method. Table 1 reports the descriptive statistics and correlations between variables. There are seven correlations at a moderate level, but no correlation is reported above 0.50 , well below the common used cut-off of 0.70 (Tabachnick \& Fidell, 2007). Collinearity 
diagnosis indicates that the mean variance inflation factor (VIF) is 1.72 and the highest individual score is 2.18 , which is far below the commonly used threshold of 10 (see Hair, Anderson, Tatham, \& Black, 1998). Therefore, no multicollinearity problem is diagnosed.

Table 1: Descriptive Statistics and Correlations

\begin{tabular}{|c|c|c|c|c|c|c|}
\hline Variable & Mean & S.D. & Min & $\operatorname{Max}$ & 1 & 2 \\
\hline 1 Std. CAR $[-5,+1]$ & -0.14 & 0.99 & -5.72 & 2.80 & & \\
\hline 2 Acquirer size & 2.88 & 1.00 & -0.11 & 4.91 & -0.04 & \\
\hline 3 Acquirer profitability & 0.08 & 0.06 & -0.07 & 0.28 & -0.01 & $0.11 *$ \\
\hline 4 Acquirer industry & 0.11 & 0.32 & 0 & 1 & -0.07 & $0.28^{*}$ \\
\hline 5 Target type: Public & 0.17 & 0.37 & 0 & 1 & 0.10 & -0.06 \\
\hline 6 Relatedness & 0.56 & 0.50 & 0 & 1 & -0.07 & 0.11 \\
\hline 7 Acq. experience & 23.66 & 19.17 & 0 & 71 & -0.08 & $0.27 *$ \\
\hline 8 Acquirer reputation & 70.31 & 8.53 & 30.28 & 84.07 & $-0.14 *$ & 0.03 \\
\hline 9 CSR reputation & 2.02 & 5.32 & -10 & 14 & $-0.14 *$ & -0.10 \\
\hline
\end{tabular}

\begin{tabular}{llrrrrc}
\hline \multicolumn{1}{c}{ Variable } & \multicolumn{1}{c}{3} & \multicolumn{1}{c}{4} & 5 & 6 & 7 & 8 \\
\hline 4 Acquirer industry & $-0.43^{*}$ & & & & & \\
5 Target type: Public & -0.07 & -0.01 & & & & \\
6 Relatedness & $0.26^{*}$ & $-0.21^{*}$ & -0.01 & & & \\
7 Acq. experience & $0.30^{*}$ & 0.07 & -0.07 & $0.36^{*}$ & & \\
8 Acquirer reputation & $0.46^{*}$ & $-0.42^{*}$ & -0.01 & $0.22^{*}$ & $0.16^{*}$ & \\
9 CSR reputation & $0.44^{*}$ & $-0.11^{*}$ & -0.02 & $0.33^{*}$ & $0.37^{*}$ & $0.47^{*}$ \\
\hline$* \mathrm{p}<0.05$ & & & & & &
\end{tabular}

Table 2 presents OLS regression results for market reaction (CAR) to acquisition announcements and includes six models. All models test the full sample of 296 events. 
Table 2: Regression Results for Market Reaction to M\&A Announcement

\begin{tabular}{|c|c|c|c|c|c|c|c|c|c|c|c|c|c|}
\hline Variable & $H$ & $\begin{array}{r}\text { Model } \\
\text { Control } \\
\end{array}$ & 1 & $\begin{array}{r}\text { Model } \\
\text { H1 } \\
\end{array}$ & 2 & $\begin{array}{r}\text { Model } \\
\mathrm{H} 2 \\
\end{array}$ & 3 & $\begin{array}{r}\text { Model } \\
\text { H3 } \\
\end{array}$ & 4 & $\begin{array}{r}\text { Model } \\
\text { H4 } \\
\end{array}$ & 5 & $\begin{array}{r}\text { Model } \\
\text { Full } \\
\end{array}$ & 6 \\
\hline Constant & & -0.037 & $(0.20)$ & -0.202 & $(0.21)$ & -0.175 & $(0.20)$ & $-0.452 *$ & $(0.23)$ & -0.039 & $(0.19)$ & $-0.405+$ & $(0.23)$ \\
\hline Acquirer size & & 0.001 & $(0.06)$ & 0.022 & $(0.06)$ & 0.017 & $(0.06)$ & 0.098 & $(0.07)$ & -0.042 & $(0.07)$ & 0.071 & $(0.08)$ \\
\hline Acquirer profitability & & -0.317 & $(1.14)$ & -0.838 & $(1.21)$ & 0.813 & $(1.18)$ & 0.016 & $(1.31)$ & 1.120 & $(1.27)$ & 0.386 & $(1.37)$ \\
\hline Acquirer industry (Financial) & & -0.291 & $(0.22)$ & $-0.469 *$ & $(0.24)$ & $-0.493 *$ & $(0.23)$ & $-0.638 * *$ & $(0.25)$ & -0.169 & $(0.22)$ & $-0.560 *$ & $(0.26)$ \\
\hline Target type: Public & & $0.269+$ & $(0.16)$ & $0.276+$ & $(0.15)$ & $0.280+$ & $(0.15)$ & 0.240 & $(0.15)$ & $0.274+$ & $(0.15)$ & 0.245 & $(0.15)$ \\
\hline Acq. \& target relatedness & & -0.162 & $(0.12)$ & -0.192 & $(0.13)$ & -0.131 & $(0.12)$ & -0.105 & $(0.13)$ & -0.070 & $(0.13)$ & -0.080 & $(0.13)$ \\
\hline Acquisition experience & $\mathrm{H} 1$ & & & $-0.009 *$ & $(0.00)$ & & & -0.007 & $(0.00)$ & & & -0.006 & $(0.00)$ \\
\hline Acquisition experience sq. & $\mathrm{H} 1$ & & & $0.001 * *$ & $(0.00)$ & & & $0.000 *$ & $(0.00)$ & & & $0.000^{*}$ & $(0.00)$ \\
\hline Acquirer reputation & $\mathrm{H} 2$ & & & & & $-0.025 * *$ & $(0.01)$ & $-0.043 * * *$ & $(0.01)$ & & & $-0.038 * *$ & $(0.01)$ \\
\hline Reputation x Experience & $\mathrm{H} 3$ & & & & & & & $-0.001+$ & $(0.00)$ & & & -0.001 & $(0.00)$ \\
\hline Reputation x Experience sq. & $\mathrm{H} 3$ & & & & & & & $0.000 *$ & $(0.00)$ & & & $0.000 *$ & $(0.00)$ \\
\hline CSR reputation & $\mathrm{H} 4$ & & & & & & & & & $-0.032 *$ & $(0.01)$ & -0.014 & $(0.02)$ \\
\hline No. of acquisitions & & 296 & & 296 & & 296 & & 296 & & 296 & & 296 & \\
\hline R-squared & & 0.023 & & 0.050 & & 0.057 & & 0.088 & & 0.042 & & 0.091 & \\
\hline Adj. R-squared & & 0.006 & & 0.026 & & 0.037 & & 0.056 & & 0.023 & & 0.056 & \\
\hline
\end{tabular}

*** $\mathrm{p}<0.001,{ }^{* *} \mathrm{p}<0.01,{ }^{*} \mathrm{p}<0.05,+\mathrm{p}<0.1$; Standard errors in parentheses 
Model 1 only consists of control variables and is the baseline model. All other five show significantly stronger explanatory power than the baseline model. Model 2 tests $\mathrm{H} 1$, which suggests a U-shaped relationship between acquirer acquisition experience and market response to its acquisition announcement. In order to test H1 in Model 2, acquirer acquisition experience and the square value of its acquisition experience are added to baseline model. The significant negative coefficient of acquisition experience $(p<0.05)$ and the significant positive coefficient of square of acquisition experience $(\mathrm{p}<0.01)$ support H1. Further investigation demonstrates that the inflection point is experience of 38 acquisitions in previous 4 years. In other words, the market reacts negatively to acquisition experience until a firm reaches 38 acquisitions and then begins a positive trend. Figure 1 depicts this curvilinear relationship.

Figure 1: Impact of acquirer's acquisition experience on market reaction to acquisition announcement

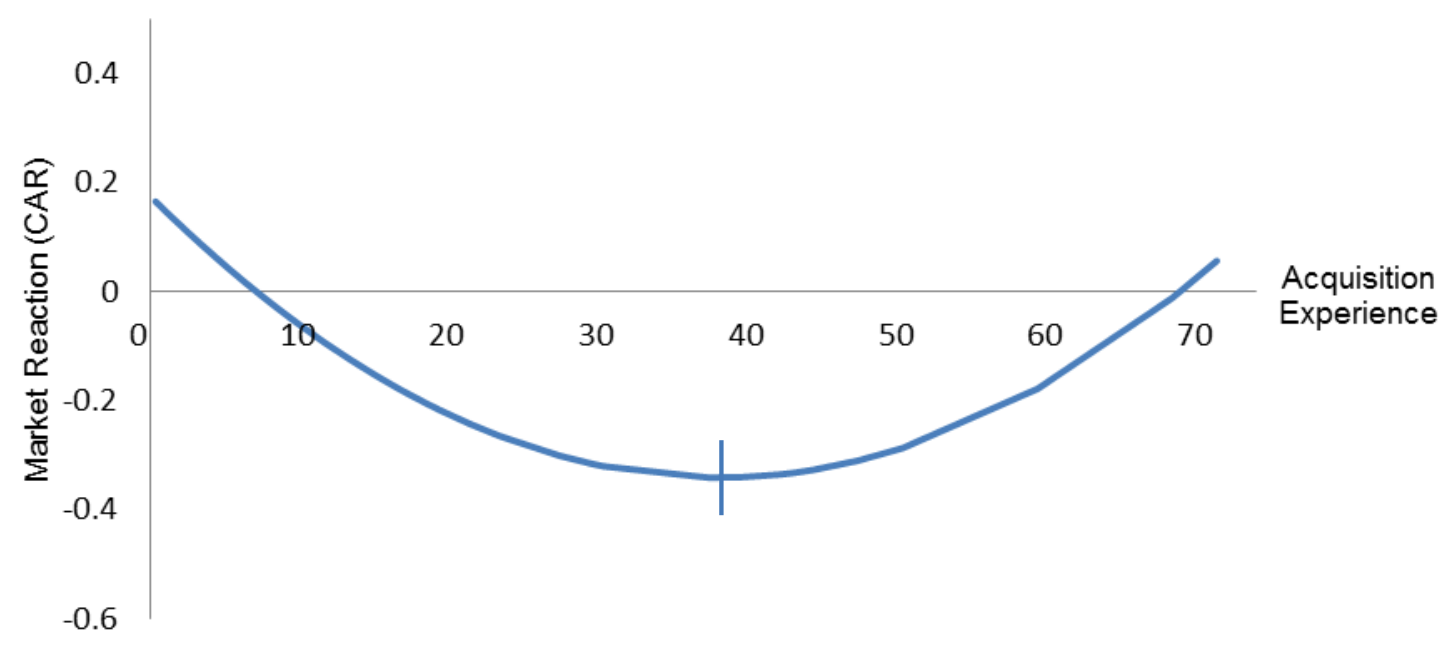
Acquisition Experience

$\mathrm{H} 2$ hypothesizes a positive relationship between acquirer reputation and market reaction to its acquisition announcement. Model 3 incorporates acquirer reputation in the 
baseline model to test $\mathrm{H} 2$. Although the result reports a significant coefficient $(\mathrm{p}<0.01)$, the direction is opposite to what we expected. Therefore, $\mathrm{H} 2$ is not supported.

Model 4 tests the interaction effect of acquirer acquisition experience and reputation proposed in $\mathrm{H} 3$. $\mathrm{H} 3$ suggests that acquirer reputation magnifies the impact of acquisition experience on market reaction. To test $\mathrm{H} 3$, in addition to acquirer reputation, acquisition experience, and square value of acquisition experience, interaction terms between reputation and acquisition experience as well as reputation and square value of acquisition experience are included in the model. The marginally significant and negative $(p<0.10)$ coefficient of interaction between reputation and acquisition experience accompanied with a positive and significant $(\mathrm{p}<0.05)$ coefficient of interaction between reputation and square value of acquisition experience confirm the magnifying effect of reputation on acquisition experience and support H3. Figure 2 illustrates the magnifying role of reputation by depicting the impact of acquisition experience on market reaction at three levels of acquirer reputation - plus one standard deviation, mean level, and minus one standard deviation (Aiken \& West, 1991, pp. 68-69). Further probing shows that the inflection points for acquirers with high, medium, and low reputations are 33, 34, and 111 prior acquisitions, respectively. This shows that higher reputation decreases the turning point, indicating that for more reputed acquirers, less acquisition experience is required to reach an inflection point. In other words, each acquisition experience counts more for more reputed acquirers. Moreover, Figure 2 demonstrates that from low to high reputation, the U-shaped curves become deeper (i.e., the absolute value of the slope for any specific acquisition experience value grows going from the low to the high reputation curve). Thus, the relationship between acquisition experience and market reaction 
becomes more intense and sensitive, confirming $\mathrm{H} 3$.

Figure 2: Impact of acquirer's acquisition experience on market reaction to acquisition announcement at different level of acquirer's reputation

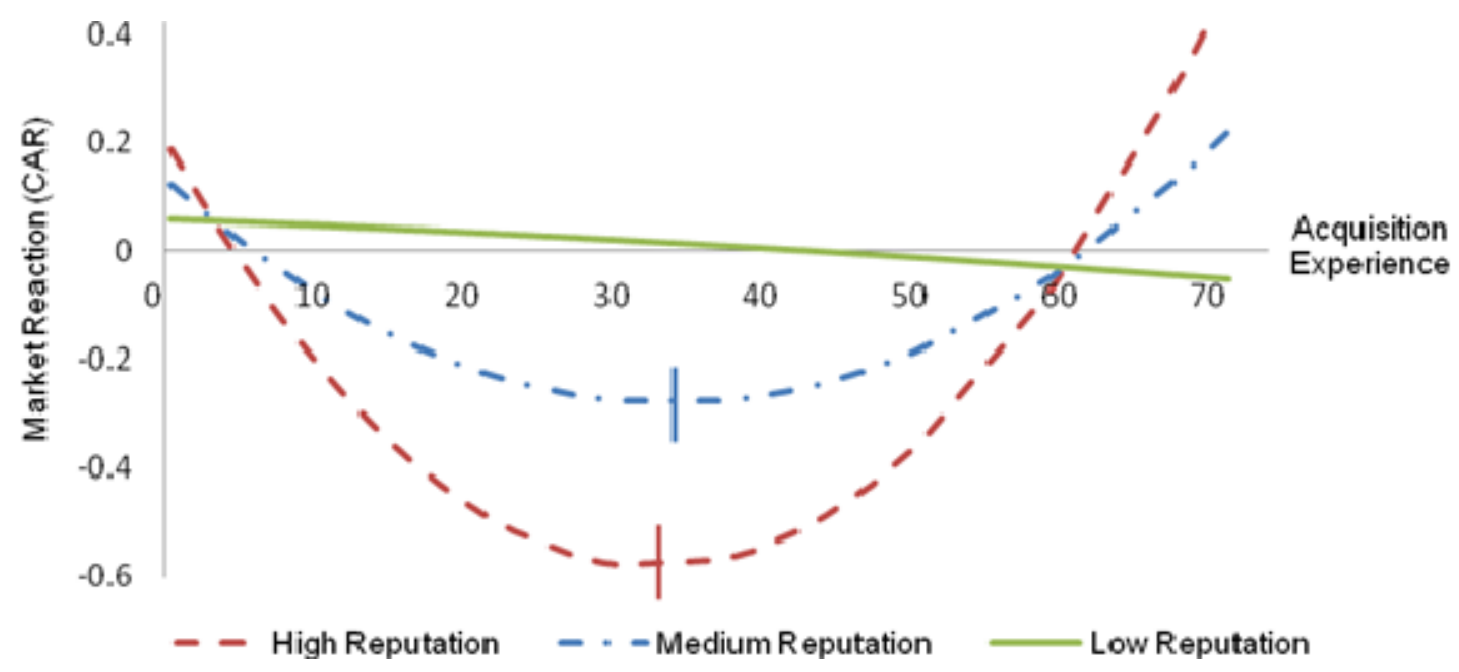

To test H4, CSR reputation of the acquirer is added to the baseline model in Model 5. The negative and significant $(\mathrm{p}<0.05)$ coefficient of CSR reputation confirms the negative relationship between CSR reputation and market expectation about the future of an acquisition and therefore, supports $\mathrm{H} 4$.

\section{DISCUSSION AND CONCLUSIONS}

In this study, we intended to take our understanding about the impact of intangible assets on strategic actions and organizational outcomes to a new level. To accomplish this goal, we investigated the outcome of acquirer acquisition experience, reputation, and business ideology on stock market expectations about success of an acquisition attempt. We found that both action-specific factual and general perceptual intangible assets not only have significant direct impacts, but also have significant combined effects on stock 
market expectations. In particular, our results showed that acquirer acquisition experience has a U-shaped relationship with market expectation about the success of an acquisition. In other words, the market does not expect that acquirers without sufficient experience can benefit from their acquisition experience. Opposite to our expectation, our analysis reported that acquirer reputation has a negative relationship with market expectations about the future outcome of an acquisition. Moreover, our investigation demonstrated that reputation magnifies the importance of acquisition experience. Finally, an acquirer's beliefs about its role in society also impacts market reaction to its acquisition. More specifically, the market expects acquirers with better records of socially responsible behavior to be less successful in creating value out of acquisitions.

In the first hypothesis, we investigated the effect of acquisition experience on market expectation about the outcome of an acquisition. There is a rich body of literature on the impact of acquisition experience on success of an acquisition. However, the findings are not consistent and there is no consensus about the effect of acquisition experience (Barkema \& Schijven, 2008). Some studies reported no relationship (Hayward, 2002; Zollo \& Singh, 2004), while others showed positive (Fowler \& Schmidt, 1989) or U-shaped relationships (Haleblian \& Finkelstein, 1999; Zollo \& Reuer, 2006). Our analysis demonstrated a U-shaped impact of acquisition experience. This finding confirms critics of traditional organizational learning assumptions that assume experience effects are always positive and equate experience with learning (Barkema \& Schijven, 2008). On the other hand, it is consistent with Haleblian and Finkelstein's (1999) categorization of novice and expert acquirers. Unlike expert acquirers who have extensive acquisition experience, novice acquirers only realize surface information about 
a target company without understanding the underlying factors (Haleblian \& Finkelstein, 1999). Consequently, without realizing similarities and dissimilarities between past and future acquisitions, they conduct more inappropriate generalizations and less appropriate discrimination (Haleblian \& Finkelstein, 1999). Our analysis showed that, in general, acquirers with more than 38 prior acquisitions in the past four years can gain the market's confidence about their ability to benefit from their past acquisition experiences.

Further, we tested the relationship between another intangible asset, corporate reputation, and expectation about the outcome of an acquisition. Contrary to our expectation, results showed that acquirer reputation has a negative relation with evaluations of future value creation of an acquisition. In other words, the market has lower expectations about the ability of acquisitions conducted by more reputed acquirers to improve their overall market performance. To probe more on this finding, we re-ran the analysis using Fortune's Most Admire Companies score and found similar results. Also, results reported that on average, the market has lower perceptions about acquisition outcomes of acquirers listed in Fortune's Most Admire Companies compared to those are not recognized in the list.

These consistent findings can be explained from three perspectives. First, the effect of reputation should be analyzed depending on its context. In this case, an acquisition is not considered as a successful strategy. The majority of acquisitions fail (Barkema \& Schijven, 2008), did not result in positive performance for acquirers (King et al., 2004), or could not enhance value of acquiring firms neither in the short-term (Asquith, 1983; Jarrell \& Poulsen, 1989) nor in the long-term (Agrawal et al., 1992; Loderer \& Martin, 1992). In this circumstance, conformity with a practice that is 
perceived as generally not successful by a reputed acquirer, which attracts more attention and is held to higher standards of what type of strategies and behaviors it pursues, tends to be subject to greater market evaluation penalties. Second, past studies showed that reputation has a positive impact on a firm's financial performance (Fombrun \& Shanley, 1990). A company's reputation is already accounted for in its stock price (Fama, 1970). In other words, " $\$ \mathrm{X}$ " of stock price of a reputed firm is the realization of its favored reputation. In order for the market to show a positive response to an acquisition announcement, at least the " $\$ X$ " effect of reputation in the acquirer's stock price should not diminish more than the expected future gain of the acquisition. However, in acquisition announcements, the stock market is skeptical of whether an acquisition can contribute to the reputation of already reputed companies, particularly when there is not sufficient information about private targets or undisclosed deals. The third way to explain the negative relationship between reputation and market reaction to an acquisition is through acquirer motivation to conduct an acquisition. Particularly, companies with lower reputations try more aggressively to acquire reputed targets to improve their reputations in addition to other motivations, while already reputed acquirers have more economic motives for acquisitions.

In sum, our results showed that while reputation does not have a direct positive impact on stock market evaluations, it can have a positive effect combined with acquisition experience. The analysis demonstrated that reputation magnifies the relationship between acquisition experience and expectation of acquisition outcome. More specifically, the U-shaped relationship between acquisition experience and acquisition outcome becomes deeper and more intense as the reputation level increases 
from low to medium to high (see Figure 2). In addition, an acquisition attempt counts more for a more reputed company which is demonstrated by the number of acquisition attempts required to reach the inflection point in Figure 2. Finally, we found that an acquirer's approach toward its societal responsibility determines market evaluation of its acquisition. The market expects acquirers with stronger beliefs in its responsibility toward society, higher standards for their social and environmental activities, and better records of social performance to be less willing to adopt legitimate but less sociallyfavored strategies in creating value out of acquisitions. Therefore, acquirers with higher social performance are expected to be less successful in acquisitions.

Our findings also suggest implications for managers of acquiring firms. We found that intangible assets have significant impacts on organizational strategies and outcomes. Managers can enjoy "economies of scale" benefits by utilizing their action-specific intangible assets and "economies of scope" benefits by applying their general intangible assets into different strategic actions. However, the impact of intangible assets might not be simple and consistent with general beliefs. In particular and for acquisition practices, the findings refuted simple positive relationships between acquisition experience, reputation, and social performance and expected acquisition outcome. On the other hand, results showed a U-shaped relationship between acquisition success and acquisition experience and negative relations with reputation and social performance. Furthermore, managers of less experienced acquirers should be aware of negative impacts of inappropriate generalization and discrimination. They should go beyond surface information and realize the underlying similarities and differences between acquisitions. Within our sample, the market does not expect managers to benefit from acquisition 
experience prior to conducting 38 acquisitions in 4 years prior to the new acquisition. Practically speaking, since few companies are able to pursue acquisitions at that rate, for most firms, acquisition experience is not directly valued by the market. Moreover, although reputation is a valuable intangible asset, managers should realize that it could work to their disadvantage if they do not have sufficient acquisition experience. However, if they are experienced acquirers, reputation would amplify the positive impact of their acquisition experience. Finally, although it has been shown that socially responsible firms are more respected (Love \& Kraatz, 2009), managers of these companies should be aware of potential negative consequences when they adopt strategies that are mainly evaluated based on their economic success, such as acquisitions.

Our study is limited in several important ways. First, our study investigated only acquisition announcements in 2010. A longitudinal analysis would add to the strength of our arguments and results. Second, we tried to include all disclosed and undisclosed acquisitions in 2010. Therefore, we lost the flexibility to control for some deal characteristics such as payment method as well as some target company characteristics such as target size and profitability prior to an acquisition. Third, our sample includes only the largest companies with established reputations. There is an opportunity for future research to examine the importance of intangible assets for smaller firms. Finally, our study was limited only to the US market's reaction to acquisition announcements. However, markets in other countries might show different reactions. Particularly, the U.S. is known as a more shareholder-centered country (Aguilera \& Jackson, 2003). Therefore, it would be interesting to test the arguments of this study in more stakeholder-centered countries. 
To conclude, this study contributes to the strategy literature by demonstrating the effect of intangible assets on strategic actions and organizational outcomes. Analyzing 296 acquisition announcements in 2010, we found that acquirer acquisition experience has a U-shaped relationship with market evaluation of acquisition success, while reputation and social performance both have negative relationships. Furthermore, we demonstrated that reputation magnifies the impact of acquisition experience, making it more negative for novice acquirers and more positive for expert ones. By doing so, we tried to deepen our understanding of the strategic importance of intangible assets. 


\section{REFERENCES}

Aaker, J. 1997. Dimensions of brand personality. Journal of Marketing Research, 34: 347-356.

Agrawal, A., Jaffe, J., \& Mandelker, G. 1992. The post-merger performance of acquiring firms: A reexamination of an anomaly. Journal of Finance, 47: 1605-1621.

Aguilera, R., \& Jackson, G. 2003. The Cross-National Diversity of Corporate Governance: Dimensions and Determinants. Academy of Management Review, 28(3): 447-465.

Aguilera, R., \& Jackson, G. 2010. Comparative and international corporate governance. Academy of Management Annals, 4(1): 485-556.

Aiken, L., \& West, S. 1991. Multiple Regression: Testing and Interpreting Interactions. Newbury Park, CA: Sage.

Akerlof, G. 1970. The market for 'lemons': quality uncertainty and the market mechanism. Quarterly Journal of Economics, 84(3): 488-500.

Allen, W. 1992. Our schizophrenic conception of the business corporation. Cardozo Law Review, 261: 621-681.

Alloza, A. 2008. Brand engagement and brand experience at BBVA, the transformation of a 150 years old company. Corporate Reputation Review, 11: 371-379 .

Amemiya, T. 1984. Tobit models: A survey. Journal of Econometrics, 24(1-2): 3-61.

Amit, R., \& Schoemaker, P. 1993. Strategic assets and organizational rents. Strategic Management Journal, 14: 33-45.

Apéria, T., Simcic-Brønn, P., \& Schultz, M. 2004. A Reputation Analysis of the Most Visible Companies in the Scandinavian Countries. Corporate Reputation Review, 7(3): 218-230.

Armour, J., Deakin, S. Lele, P. \& Siems, M.M. 2009. How do legal rules evolve? Evidence from a cross-country comparison on shareholder, creditor and worker protection. Cambridge, U.K.: Centre for Business Research, University of Cambridge.

Asher, H. 2004. Polling and the Public (6th ed.). Washington DC: CQ Press.

Ashforth, B., \& Gibbs, B. 1990. 'The double-edge of organizational legitimation. 
Organization Science, 1: 177-194.

Ashkenas, R., DeMonaco, L., \& Francis, S. 1998. Making the deal real: How GE Capital integrates acquisitions. Harvard Business Review, 76: 165-178.

Asquith, P. 1983. Merger bids, uncertainty, and stockholder returns. Journal of Financial Economics, 11: 51-83.

Backhaus, K., \& Voeth, M. 2004. Handbuch Industrieguetermarketing: StrategienInstrumente- Anwendungen, 1st edn, Wiesbaden: Gabler.

Balmer , J . 2001. Corporate identity, corporate branding and corporate marketing, seeing through the fog. European Journal of Marketing, 35(3/4): 248 - 29.

Barich, H., \& Kotler, P. 1991. A framework for marketing image management. Sloan Management Review, 32(2): 94-104.

Barkema, H., \& Schijven, M. 2008. How do firms learn to make acquisitions? A review of past research and an agenda for the future. Journal of Management, 34: 594-634.

Barnett, M., \& Hoffman, A. 2008. Beyond Corporate Reputation: Managing Reputational Interdependence. Corporate Reputation Review, 11: 1-9.

Barnett, M., Jermier, J., \& Lafferty, B. 2006. Corporate reputation: The definitional landscape. Corporate Reputation Review, 9: 26-38.

Barney, J. 1991. Firm resources and sustained competitive advantage. Journal of Management, 17(1): 99-120.

Barth, J., Caprio, G., \& Levine, R. 2008. Bank regulations are changing: For better or for worse? World Bank Policy Research Working Paper 2725.

Behrend, T., Baker, B., \& Thomson, L. 2009. Effects of pro-environmental recruiting messages: The Role of Organizational Reputation. Journal of Business and Psychology, 24(3): 341-350.

Benjamin, B., \& Podolny, J. 1999. Status, quality, and social order in the California wine industry. Administrative Science Quarterly, 44: 563-589.

Bennett, R., \& Kottasz , R . 2000. Practitioner perceptions of corporate reputation: An empirical investigation. Corporate Communications: An International Journal, 5(4): 224 -234 . 
Bergh, D. 1997. Predicting divestiture of unrelated acquisitions: an integrative model of ex ante conditions. Strategic Management Journal, 18(9): 715-731.

Bergh, D., Ketchen, D. Jr., Boyd, B., \& Bergh, J. 2010. New frontiers of the reputationperformance relationship: Insights from multiple theories. Journal of Management, 36: 620-632.

Berle, A., Jr., \& Means, G. C. 1932. The modern corporation and private property. New York, NY: Macmillan.

Blair, M.M., \& Stout, L.A. 1999. A team production theory of corporate law. Virginia Law Review, 85(2): 247-328.

Bloomberg Database. 2010. Available: Bloomberg.

Boddewyn, J., Halbrich, B., \& Perry, C. 1986. Service Multinationals: Conceptualization, Measurement and Theory. Journal of International Business Studies, 17(3): 41-57.

Botero, J., Djankov, S., La Porta, R., Lopez-de-Silanes, F., \& Shleifer, A. 2004. The regulation of labor. Quarterly Journal of Economics, 119: 1339-1382.

Boulding, W., \& Kirmani, A. 1993. A consumer-side experimental examination of signaling theory. Journal of Consumer Research, 20(1): 111-23.

Bragado, J. 1992. Setting the correct speed for postmerger integration. M\&A Europe, 5: 24-31.

Brammer, S., \& Pavelin, S. 2006. Corporate reputation and social performance: The importance of fit. Journal of Management Studies, 43: 435-455.

Brockner, J. 1988. Self-esteem at work. Lexington, MA: Lexington Books.

Bromiley, P., Govekar, M., \& Markus, A. 1989. On Using Event-Study Methodology in Strategic Management Research. In R. Burton, J. Forsyth, \& B. Obel (eds.), Organizational Responses to the New Business Conditions: An Empirical Perspective: 24-40. Amsterdam, The Netherlands: Elsevier Science.

Bromley, D. 2001. Relationships between personal and corporate reputation. European Journal of Marketing, 35(3/4): 316-334.

Brouthers, K, van Hastenburg, P, \& van den Ven, J. 1998. If Most Mergers Fail Why Are They so Popular? Long Range Planning, 31: 347-353. 
Brown, S., \& Warner, J. 1985. Using daily stock returns: The case of event studies. Journal of Financial Economics, 14: 3-31.

Brown, T., \& Dacin, A. 1997. The company and product: corporate associations and consumer product responses. Journal of Marketing, 61: 68-84.

Buono, A., \& Bowditch, J. 1989. The Human Side of Mergers and Acquisitions, San Francisco, CA: Josey-Bass.

Campbell, J. L. 2007. Why would corporations behave in socially responsible ways? An institutional theory of corporate social responsibility. Academy of Management Review, 32(3): 946-967.

Capron, L., \& Pistre, N. 2002. When Do Acquirers Earn Abnormal Returns? Strategic Management Journal, 23: 781-794.

Capron, L., \& Shen, J. 2007. Acquisitions of private vs. public firms: Private information, target selection, and acquirer returns. Strategic Management Journal, 28: 891-911.

Carroll, A. 1979. A three-dimensional conceptual model of corporate performance. Academy of Management Review, 4(4): 17.

Caves, R.E., \& Porter, M.E. 1977. From entry barriers to mobility barriers. Quarterly Journal of Economics, 91: 421-34.

Chacar, A., Newburry, W., \& Vissa, B. 2010. Bringing Institutions into Performance Persistence Research: Exploring the Impact of the Product, Financial and Labor Market Institutions. Journal of International Business Studies, 41(7): 1119-1140.

Chatman, J. 1989. Improving interactional organizational research: A model of personorganization fit. Academy of Management Review, 14(3): 333-349.

Chatterjee, S., Lubatkin, M., Schweiger, D., \& Weber, Y. 1992. Cultural differences and shareholder value in related mergers: Linking equity and human capital. Strategic Management Journal, 13: 319-334.

Chen, D., Newburry, W., \& Park, S. 2009. Improving sustainability: An international evolutionary framework. Journal of International Management, 15(3): 317-327.

Chiles, T., \& McMackin, J. 1996. Integrating variable risk preferences, trust, and transaction cost economics. Academy of Management Review, 21: 73-99.

Clark, B., \& Montgomery, D. 1998. Deterrence, reputations, and competitive cognition. 
Management Science, 44: 62-82.

Coff, R.W. 1999. When competitive advantage doesn't lead to performance: The resource-based view and stakeholder bargaining power. Organization Science, 10(2): 119-133.

Craig, S., \& Douglas, S. 2000. International marketing research. New York, NY: Wiley.

Darby, M., \& Karni, E. 1973. Free Competition and the Optimal Amount of Fraud. Journal of Law and Economics, 16(1): 67-88.

Datta, D. 1991. Organizational fit and acquisition performance: Effects of postacquisition integration. Strategic Management Journal, 12: 281-297.

Datta, D., Pinches, G., \& Narayanan, V. 1992. Factors influencing wealth creation from mergers and acquisitions-A meta-analysis. Strategic Management Journal, 13: 67-84.

Davies, G., Chun, R., da Silva, R., \& Roper, S. 2001. The personification metaphor as a measurement approach for corporate reputation. Corporate Reputation Review, 4: 113127.

Davies, G., Chun, R., Da Silva, R., \& Roper, S. 2003. Corporate Reputation and Competitiveness. London and New York: Routledge.

Davis, G, \& Marquis, C. 2005. The globalization of stock markets and convergence in corporate governance. In R. Swedberg, \& V. Nee (eds.), The Economic Sociology of Capitalism: 352-390. Princeton, NJ: Princeton University Press.

Davis, G. 2005. New directions in corporate governance. Annual Review of Sociology, 31: 143-152.

Davis, G. 2009. Managed by the Markets: How Finance Re-Shaped America. Oxford, U.K.: Oxford University Press.

Davis, G., \& Stout, S. 1992. Organization Theory and the Market of Corporate Control: A Dynamic Analysis of the Characteristics of Large Takeover Targets, 1980-1990. Administrative Science Quarterly. 37(4): 604-633.

Davis, G., \& Thompson, T. 1994. A social movement perspective on corporate control. Administrative Science Quarterly, 39: 141-173.

Deakin, S. 2005. The coming transformation of shareholder value. Corporate Governance: An International Review, 13(1):11-18. 
Deephouse, D. 1996. Does isomorphism legitimate? Academy of Management Journal, 39: 1024-1039.

Deephouse, D. 2000. Media reputation as a strategic resource: An integration of mass communication and resource-based theories. Journal of Management, 26: 1091-1112.

Deephouse, D., \& Carter, S. 2005. An examination of differences between organizational legitimacy and organizational reputation. Journal of Management Studies, 42: 329-360.

Deephouse, D., Li, L., \& Newburry, W. 2009. Institutional and national culture effects on corporate reputation. Academy of Management Proceedings. 2009 Annual Meeting Proceedings.

Dierickx, I., \& Cool, K. 1989. Asset stock accumulation and sustainable competitive advantage. Management Science, 35: 1504-1511.

DiMaggio, P., \& Powell, W. 1983. The iron cage revisited: Institutional isomorphism and collective rationality in organizational fields. American Sociological Review, 48: 147-160.

Djankov, S., La Porta, R., Lopez-de-Silanes, F., \& Shleifer, A. 2008. The law and economics of self-dealing. Journal of Financial Economics, 88: 430-465.

Doh, J., Howton, S., Howton, S., \& Siegel, D. 2009. Does the market respond to endorsement of social responsibility? The role of institutions, information, and legitimacy. Journal of Management, 36: 1461-1485.

Donaldson, T., \& Preston, L. 1995. The Stakeholder Theory of the Corporation: Concepts, Evidence, and Implications. Academy of Management Review, 20 (1): 65-91.

Dowling, G. 1986. Managing your corporate images. Industrial Marketing Management, 15(2): 109-115.

Dunning, J. 1998. Location and the multinational enterprise: a neglected factor? Journal of International Business Studies, 29(1): 45-66.

Fama, E. 1970. Efficient Capital Markets: A Review of Theory and Empirical Work. Journal of Finance, 25: 383-397.

Fiss, P. 2008. Institutions and Corporate Governance. In R. Greenwood, C. Oliver, K. Sahlin, \& R. Sudda (eds.), Handbook of Organizational Institutionalism: 389-410. London, UK: Sage Publications.

Fiss, P., \& Zajac, E. 2004. The diffusion of ideas over contested terrain: The 
(non)adoption of a shareholder value orientation among German firms. Administrative Science Quarterly, 49(4): 501-534.

Fligstein, N. 1987. The intraorganizational power struggle: Rise of finance personnel to top leadership in large corporations, 1919-1979. American Sociological Review, 52(1): 44-58.

Fligstein, N. 1996. Markets as Politics: A Political-Cultural Approach to Market Institutions. American Sociological Review, 61: 656-673.

Fligstein, N. 1990. The Transformation of Corporate Control. Cambridge, MA: Harvard University Press.

Fligstein, N. 2001. The Architecture of Markets. Princeton, NJ: Princeton University Press.

Fligstein, N., \& Choo, J. 2005. Law and Corporate Governance. Annual Review of Law and Social Science, 1: 61-84.

Fombrun, C. 1996. Reputation: Realizing value from the corporate image. Boston, MA: Harvard Business School Press.

Fombrun, C. 1998. Corporate reputation. In N. Nicholson (ed.), Blackwell Encyclopedic Dictionary of Organizational Behavior, Malden: Blackwell Publishers.

Fombrun, C., \& Rindova, V. 1996. Who's tops and who decides? The social construction of corporate reputations. New York University, Stern School of Business, Working Paper.

Fombrun, C., \& Shanley, M. 1990. What's in a name? Reputation building and corporate strategy. Academy of Management Journal, 33: 233-56.

Fombrun, C., \& Van Riel, C. 1997. The reputational landscape. Corporate Reputation Review, 1(1/2): 5-13.

Fombrun, C., \& van Riel, C. 2004. Fame and Fortune: How Successful Companies Build Winning Reputation. New Jersey: Pearson Education.

Fowler, K., \& Schmidt, D. 1989. Determinants of tender offer post-acquisition financial performance. Strategic Management Journal, 10: 339-350.

Freeman, R. 1984. Strategic Management: A Stakeholder Approach. Boston, MA: Pitman Press. 
Freeman, R., Wicks, A., \& Parmar, B. 2004. Stakeholder theory and 'The corporate objective revisited.' Organization Science, 15(3): 364-369.

Friedman, M. 1970. The social responsibility of business is to increase profits. New York Times Magazine, September 13: 32-33, 122, 124, 126.

Fryxell, G., \& Wang, J. 1994. The Fortune Corporate Reputation Index: Reputation For What? Journal of Management, 20: 1-14.

Gabbioneta, C., Ravasi, D., \& Mazzola, P. 2007. Exploring the Drivers of Corporate Reputation: A Study of Italian Securities Analysts. Corporate Reputation Review, 10(2): 99-123.

Galpin, T., \& Herndon, M. 2007. The complete guide to mergers and acquisitions: Process tools to support M\&A integration at every level. San Francisco, CA: John Wiley.

Gardberg, N. \& Newburry, W. 2010. Who boycotts whom? A social identity perspective on consumer boycotts. Business \& Society, published online - March 11. doi: 10.1177/0007650309352507.

Gardberg, N. 2006. Reputatie, reputation, réputation, reputazione, ruf: A cross-cultural qualitative analysis of construct and instrument Equivalence. Corporate Reputation Review, 9(1): 39-61.

Gedajlovic, E., \& Shapiro, D. 1998. Management and ownership effects: Evidence from five countries. Strategic Management Journal, 19: 533-553.

Goldberg, A., Cohen, G., \& Fiegenbaum, A. 2003. Reputation building: Small business strategies for successful venture development. Journal of Small Business Management, 41(2): $168-187$.

Goode, W. 1978. The Celebration of Heroes: Prestige as a Social Control System. Berkeley, CA: University of California Press.

Gotsi, M., \& Wilson, A. 2001. Corporate reputation: Seeking a definition. Corporate Communications: An International Journal, 6(1): 24 - 30.

Grinstein, Y., \& Hribar, P. 2004. CEO compensation and incentives: Evidence from M\&A bonuses. Journal of Financial Economics, 73: 119-143.

Grunig, J., \& Hung, C. 2002. The effect of relationships on reputation and reputation on relationships: A cognitive, behavioural study. Paper presented at the PRSA Educator's 
Academy 5th Annual International, Interdisciplinary Public Relations Research Conference, Miami, FL.

Grunig, J.M. 1993. Image and substance: from symbolic to behavioural relationships. Public Relations Review, 19(2): 121-139.

Guillén, M. 2000. Corporate Governance and Globalization: Is There Convergence across Countries? Advances in Comparative International Management, 13: 175-204.

Hair, J., Anderson, R., Tatham, R., \& Black, W. 1998. Multivariate data analysis with readings. Englewood Cliffs, NJ: Prentice-Hall.

Haleblian, J., \& Finkelstein, S. 1999. The influence of organizational acquisition experience on acquisition performance: A behavioral learning perspective. Administrative Science Quarterly, 44: 29-56.

Haleblian, J., Devers, C., McNamara, G., Carpenter, M., \& Davison, R. 2009. Taking stock of what we know about mergers and acquisitions: A review and research agenda. Journal of Management, 35: 469-502.

Haleblian, J., Kim, J., \& Rajagopalan, N. 2006. The influence of acquisition experience and performance on acquisition behavior: Evidence from the US commercial banking industry. Academy of Management Journal, 49: 357-370.

Hall, J., \& Soskice, D. (eds.) 2001. Varieties of Capitalism. Oxford, UK: Oxford University Press.

Hall, R. 1992. The strategic analysis of intangible resources. Strategic Management Journal, 13: 135-144.

Hall, R. 1993. A framework linking intangible resources and capabilities to sustainable advantage. Strategic Management Journal, 14(8): 607-618.

Hambrick, D., \& Finkelstein, S. 1987. Managerial discretion-A bridge between polar views of organizational outcomes. Research in Organizational Behavior, 9: 369-406.

Hambrick, D., \& Mason, P. 1984. Upper echelons: The organization as a reflection of its top managers. Academy of Management Review, 9: 195-206.

Hannan, J., \& Freeman, J. 1984. Structural inertia and organizational change. American Sociological Review, 49: 149-64.

Harford, J., \& Li, K. 2007. Decoupling CEO wealth and firm performance: The case of 
acquiring CEOs. Journal of Finance, 62: 917-949.

Harrison, J., Hitt, M., Hoskisson, R., \& Ireland, R. 1991. Synergies and post-acquisition performance: Differences versus similarities in resource allocations. Journal of Management, 17: 173-190.

Harzing, A. 2005. Does the use of English-language questionnaires in cross-national research obscure national differences? International Journal of Cross Cultural Management, 5(2): 213-24.

Haspeslagh, P., \& Jemison, D. 1991. Managing acquisitions: Creating value through corporate renewal. New York, NY: Free Press.

Haunschild, P. 1993. Interorganizational imitation: The impact of interlocks on corporate acquisition activity. Administrative Science Quarterly, 38: 564-592.

Hayward, M. 2002. When do firms learn from their acquisition experience? Evidence from 1990-1995. Strategic Management Journal, 23: 21-39.

Hayward, M., \& Hambrick, D. 1997. Explaining the premiums paid for large acquisitions: Evidence of CEO hubris. Administrative Science Quarterly, 42: 103-127.

Healy, P., Palepu, K., \& Ruback, R. 1992. Does corporate performance improve after mergers. Journal of Financial Economics, 31: 135-175.

Helm, S. 2007. The role of corporate reputation in determining investor satisfaction and loyalty. Corporate Reputation Review, 10: 22-37.

Hess, D. 2008. The Three Pillars of Corporate Social Reporting as New Governance Regulation: Disclosure, Dialogue and Development. Business Ethics Quarterly, 18: 447482.

Hiller, N., \& Hambrick, D. 2005. Conceptualizing executive hubris: The role of (hyper)core self-evaluations in strategic decision-making. Strategic Management Journal, 26: 297-319.

Hitt, M., Harrison, J., \& Ireland, R. 2001. Mergers and acquisitions: A guide to creating value for stakeholders. New York, NY: Oxford University Press.

Hitt, M., Harrison, J., Ireland, R., \& Best, A. 1998. Attributes of successful and unsuccessful acquisitions of US firms. British Journal of Management, 9: 91-114.

Hollander, E. 1958. Conformity, status, and idiosyncrasy credit. Psychological Review, 
65: 117-127.

Homburg, C., \& Bucerius, M. 2006. Is speed of integration really a success factor of mergers and acquisitions? An analysis of the role of internal and external relatedness. Strategic Management Journal, 27(4): 347-367.

Hoskisson, R., Eden, L., Lau, C., \& Wright, M., 2000. Strategy in emerging economies. Academy of Management Journal, 43: 249-67.

Inglehart, R., \& Abramson, P. 1999. Measuring postmaterialism. The American Political Science Review, 93(3): 665-677.

Jacobs, L., Berscheid, E., \& Walster, E. 1971. Self-esteem and attraction. Journal of Personality and Social Psychology, 17: 84-91.

Jarrell, G., \& Poulsen, A. 1989. The returns to acquiring firms in tender offers: Evidence from 3 decades. Financial Management, 18(3): 12-19.

Jensen, M. 2001. Value maximization, stakeholder theory, and the corporate objective function. European Financial Management Review, 14(3), 47-63.

Jensen, M., \& Meckling, W. 1976. Theory of the firm: Managerial behavior, agency costs and ownership structure. Journal of Financial Economics, 3(4): 305-360.

Karim, S., \& Mitchell, W. 2000. Path-dependent and path-breaking change:

Reconfiguring business resources following acquisitions in the US medical sector, 19781995. Strategic Management Journal, 21: 1061-1081.

Kim, E., \& Singal, V. 1993. Mergers and market power: Evidence from the airline industry. American Economic Review, 83: 549-569.

Kim, J., \& Choi, C. 2003. Reputation and product tampering in service industries. Service Industries Journal, 23: 3-11.

King, B. 2008. A social movement perspective of stakeholder collective action and influence. Business \& Society, 47(1): 21-49.

King, D., Dalton, D., Daily, C., \& Covin, J. 2004. Meta-analyses of post-acquisition performance: Indications of unidentified moderators. Strategic Management Journal, 25: 187-200.

Kotler, P., \& Keller, K. 2006. Marketing Management (12th Ed). Upper Saddle River, NJ: Prentice Hall. 
Kumar, M. 2005. The Value From Acquiring and Divesting a Joint Venture: A Real Options Approach. Strategic Management Journal, 26: 321-31.

La Porta, R., Lopez-de-Silanes, F., Shleifer, A., \& Vishny, R. 1998. Law and Finance. Journal of Political Economy, 106(6):1113-1155.

Lange, D., Lee, P., \& Dai, Y. 2011. Organizational Reputation: A Review. Journal of Management, 37(1): 153-185.

Larsson, R., \& Finkelstein, S. 1999. Integrating strategic, organizational, and human resource perspectives on mergers and acquisitions: A case survey of synergy realization. Organization Science, 10: 1-26.

Lazonick, W., \& O’Sullivan, M. 2000. Maximizing Shareholder Value: A New Ideology for Corporate Governance. Economy and Society, 29(1): 13-35.

Lewis, S. 2001. Measuring corporate reputation. Corporate Communications: An International Journal, 6: 374-384.

Lippman, S., \& Rumelt, R. 1982. Uncertain imitability: An analysis of interfirm differences in efficiency under competition. Bell Journal of Economics, 13: 418-438.

Loderer, C., \& Martin, K. 1992. Postacquisition performance of acquiring firms. Financial Management, 21(3): 69-79.

Long, J. S. 2005. Regression Models for Categorical and Limited Dependent Variables. Thousand Oaks, CA: Sage Publications.

Love, E., \& Kraatz, M. 2009. Character, conformity, or the bottom line? How and why downsizing affected corporate reputation. Academy of Management Journal, 52: 314-335.

MacGregor, D., Slovic, P., Dreman, D., \& Berry, M. 2000. Imagery, affect, and financial judgment. The Journal of Psychology and Financial Markets, 1: 104-110.

Maheswaran, D. 1994. Country of origin as a stereotype: Effects of consumer expertise and attribute strength on product evaluations. Journal of Consumer Research, 21: 354365.

Maignan, I., \& Ralston, D. 2002. Corporate Social Responsibility in Europe and the US: Insights from Businesses' Self-Representations. Journal of International Business Studies, 33(3): 497-514.

Malatesta, P. 1983. The wealth effect of merger activity and the objective functions of 
merging firms. Journal of Financial Economics, 11: 155-181.

March, J. 1999. The pursuit of organizational intelligence. Oxford, UK: Blackwell.

March, J., \& Simon, H. 1958. Organizations. New York, NY: McGraw-Hill.

Marshall, M., Gurr, T., \& Jaggers, K. 2010. POLITY IV Project: Political Regime Characteristics and Transitions, 1800-2009. Center for Systemic Peace.

McGahan, A., \& Porter, M. 1999. The persistence of shocks to profitability. Review of Economics and Statistics, 81(1): 143-153.

McGuire J, Schneeweis T, \& Hill, J. 1986. An analysis of alternative measures of strategic performance. In, R. Lamb, \& P. Shrivastava (Ed.), Advances in Strategic Management, 4: 107-153. Greenwich, CT: JAI Press.

McGuire, J., Sundgren, A., \& Schneweiss, T. 1988. Corporate social responsibility and Firm financial performance. Academy of Management Journal, 31: 854-877.

McWilliams, A., \& Siegel, D. 1997. Event studies in management research: theoretical and empirical issues. Academy of Management Journal, 40, 626-57.

Meyer, M. 1994. Measuring performance in economic organizations. In N. Smeker, \& R. Swedberg (Eds), Handbook of Economic Sociology, Princeton, NJ: Princeton University Press.

Milgrom, P., \& Roberts, J. 1986. Price and advertising signals of new product quality. Journal of Political Economy, 94: 796-821.

Miller, T., \& Triana, M. 2009. Demographic Diversity in the Boardroom: Mediators of the Board Diversity-Firm Performance Relationship. Journal of Management Studies, 46(5): 755-786.

Mills, C. 1956. The Power Elite. Oxford, UK: Oxford University Press.

Mitchell, R, Agle, B, \& Wood, D. 1997. Toward a theory of stakeholder identification and salience: Defining the principle of who and what really counts. Academy of Management Review, 22: 853-886.

Mizruchi, M. 2004. Berle and Means revisited: The governance and power of large U.S. corporations. Theory and Society, 33(5): 579-617.

Nelson, P. 1970. Information and Consumer Behavior. Journal of Political Economy, 
78(2): 311-329.

Nelson, R., \& Winter, S. 1982. An Evolutionary Theory of Economic Change. Cambridge, MA: Harvard University Press.

Newburry, W. 2010. Reputation and supportive behavior: Moderating impacts of foreignness, industry and local exposure. Corporate Reputation Review, 12(4): 388-405.

Newburry, W., Gardberg, N., \& Belkin, L. 2006. Organizational attractiveness is in the eye of the beholder: The interaction of demographic characteristics with foreignness. Journal of International Business Studies, 37(5): 666-686.

North, D., 1990, Institutions, Institutional Change and Economic Performance, Cambridge, UK: Cambridge University Press.

Novick, L. 1988. Analogical transfer, problem similarity, and expertise. Journal of Experimental Psychology: Learning, Memory, and Cognition, 14(3): 510-520.

O'Sullivan, M. 2003. The political economy of comparative corporate governance. Review of International Political Economy, 10: 23-73.

Ocasio, W. 1994. Political dynamics and the circulation of power: CEO succession in US industrial firms, 1960-1990. Administrative Science Quarterly, 39(2): 285-312.

Oler, D., Harrison, J., \& Allen, M. 2008. The Danger of Misinterpreting Short-Window Event Study Findings in Strategic Management Research: An Empirical Illustration Using Horizontal Acquisitions. Strategic Organization, 6: 151-184.

Perrow, C. 1986. Complex Organizations. New York, NY: Random House.

Peteraf, M. 1993. The cornerstones of competitive advantage: a resource-based view. Strategic Management Journal, 14: 179-191.

Pfarrer, M., Pollock, T., \& Rindova, V. 2010. A tale of two assets: The effects of firm reputation and celebrity on earnings surprises and investors' reactions. Academy of Management Journal, 53: 1131-1152.

Pfeffer, J. 1972. Merger as a response to organizational interdependence. Administrative Science Quarterly, 17: 382-394.

Pfeffer, J. 1981. Power in Organizations. Marshfield, MA: Pitman.

Pfeffer, J., \& Salancik, G. 1978. The external control of organizations. A resource 
dependence perspective. New York, NY: Harper Row.

Phillips, D., \& Zuckerman, E. 2001. Middle-status conformity: theoretical restatement and empirical demonstration in two markets. American Journal of Sociology, 107: 379429.

Podolny, J. 1993. A status-based model of market competition. American Journal of Sociology, 98: 829-872.

Ponzi, L., Fombrun, C., \& Gardberg, N. 2011. RepTrak TM Pulse: Conceptualizing and Validating a Short-Form Measure of Corporate Reputation. Corporate Reputation Review, 14(1): 15-35.

Prahalad, C.K. 1994. Corporate governance or corporate value added?: Rethinking the primacy of shareholder value. The Bank of America Journal of Applied Corporate Finance, 6(4): 40-50.

Prahalad, C.K., \& Bettis, R. 1986. The dominant logic: a new linkage between diversity and performance. Strategic Management Journal, 7(6): 485-501.

Ramaswamy, K. 1997. The performance impact of strategic similarity in horizontal mergers: Evidence from the US banking industry. Academy of Management Journal, 40: 697-715.

Rao, H. 1994. The social construction of reputation: Certification contests, legitimation, and the survival of organizations in the American automobile industry: 1895-1912. Strategic Management Journal, 15: 29-44.

Rao, H., Davis, G., \& Ward, A. 2000. Embeddedness, social identity and mobility: Why firms leave the NASDAQ and join the New York Stock Exchange. Administrative Science Quarterly, 45: 268-295.

Raudenbush, S., Bryk, A., Cheong, Y.F., Congdon, R., \& du Toit, M. 2004. HLM6: Hierarchical linear and nonlinear modeling. Lincolnwood, IL: Scientific Software. Reputation Institute. 2007. Global RepTrak ${ }^{\mathrm{TM}}$ Pulse 2007: Summary of Results. New York, NY: Reputation Institute.

Reputation Institute. 2009. 2009 Global Reputation Pulse. New York, NY: Reputation Institute.

Rindova, V., \& Fombrun, C. 1999. Constructing competitive advantage: The role of firm- 
constituent interactions. Strategic Management Journal, 20: 691-710.

Rindova, V., Williamson, I., \& Petkova, A. 2010. Reputation as an intangible asset: Reflections on theory and methods in two empirical studies of business school reputations. Journal of Management, 36: 610-619.

Rindova, V., Williamson, I., Petkova, A., \& Sever, J. 2005. Being good or being known: An empirical examination of the dimensions, antecedents, and consequences of organizational reputation. Academy of Management Journal, 48: 1033-1049.

Roberts, P., \& Dowling, G. 2002. Corporate reputation and sustained superior financial performance. Strategic Management Journal, 23(12): 1141 - 1158.

Roe, M. 2003. Political Determinants of Corporate Governance: Political Context, Corporate Impact. New York, NY: Oxford University Press.

Rumelt, R. 1982. Diversification strategy and profitability. Strategic Management Journal, 3: 359-369.

Runhaar, H., \& Lafferty, H. 2009. Governing Corporate Social Responsibility: An Assessment of the Contribution of the UN Global Compact to CSR Strategies in the Telecommunications Industry. Journal of Business Ethics, 84(4): 479-495.

Sanders, G., \& Boivie, S. 2004. Sorting things out: Valuation of new firms in uncertain markets. Strategic Management Journal, 25: 167-186.

Saxton, T., \& Dollinger, M. 2004. Target reputation and appropriability: Picking and deploying resources in acquisitions. Journal of Management, 30: 123-147.

Scandura, T., Williams, E., \& Hamilton, B. 2001. Measuring invariance using confirmatory factor analysis and item response theory. In C. Schriesheim, \& L. Neider, (Eds.), Equivalence in measurement: 99-130. Greenwich, CT: Information Age.

Scherer, A., \& Palazzo, G. 2007. Toward a political conception of corporate responsibility: Business and society seen from a Habermasian perspective. Academy of Management Review, 32: 1096-1120.

Schneper, W., \& Guillén, M. 2004. Stakeholders rights and corporate governance: A cross-national study of hostile takeovers. Administrative Science Quarterly, 49(2): 263295.

Schwaiger, M. 2004. Components and parameters of corporate reputation - an empirical 
study. Schmalenbach Business Review, 56: 46-71.

Selznick, P. 1949. TVA and the Grass Roots. Berkeley, CA: University of California Press.

Shaphiro, S. 1987. The social control of impersonal trust. American Journal of Sociology, 93: 623-58.

Shapiro, C. 1982. Consumer information, product quality, and seller reputation. Bell Journal of Economics, 13: 20-35.

Shapiro, C. 1983. Premiums for high quality products as returns to reputation. Quarterly Journal of Economics, 98: 659-679.

Shefrin, H. 2001. Do investors expect higher returns from safer stocks than from riskier stocks? The Journal of Psychology and Financial Markets, 2: 176-181.

Shen, W., \& Canella, A. Jr. 2003. Will Succession Planning Increase Shareholder Wealth? Evidence from Investor Reactions to Relay CEO Successions. Strategic Management Journal, 24: 191-198.

Shleifer, A., \& Vishny, R. 1997. A Survey of Corporate Governance. Journal of Finance, 52: 737-783.

Shrivastava, P. 1986. Post-merger integration. Journal of Business Strategy, 7(1): 65-76.

Sirower, M. 1997. The Synergy Trap: How Companies Lose the Acquisition Game. New York, NY: The Free Press.

Spence, M. 1973. Job market signaling. Quarterly Journal of Economics, 87(3): 355-374.

Staw, B., \& Epstein, L. 2000. What bandwagons bring: Effects of popular management techniques on corporate performance, reputation, and CEO pay. Administrative Science Quarterly, 45: 523-556.

Stearns, L., \& Allan, K. 1996. Economic behavior in institutional environments: The corporate merger wave of the 1980s. American Sociological Review, 61: 699-718.

Suchman, M. 1995. Managing Legitimacy: Strategic and Institutional Approaches. Academy of Management Journal, 20(3): 571-610.

Sundaram, A., \& Inkpen, A. 2004. The corporate objective revisited. Organization Science, 15(3): 350-363. 
Szulanski, G. 1996. Exploring internal stickiness: Impediments to the transfer of best practice within the firm. Strategic Management Journal, 17: 27-42.

Tabachnick, B, \& Fidell, L. 2007. Using Multivariate Statistics. Boston, MA: Pearson.

Thomsen, S, \& Rose, C. 2004. Foundation ownership and financial performance: Do companies need owners? European Journal of Law and Economics, 18: 343-364.

Tobin, J. 1958. Estimation of relationships for limited dependent variables. Econometrica, 26: 24-36.

Trevino, L. 1986. Ethical decision making in organizations: A person-situation interactionist model. Academy of Management Review, 17: 647-676.

Turban, D., \& Cable, D. 2003. Firm reputation and applicant pool characteristics. Journal of Organizational Behavior, 24: 733-751.

Turban, D., \& Greening, D. 1997. Corporate social performance and organizational attractiveness to prospective employees. Academy of Management Journal, 40: 658-763.

UNDP. 2009. Human Development Report 2009 - Overcoming barriers: Human mobility and development. United Nations.

Vaara, E., \& Monin, P. 2010. A recursive perspective on discursive legitimation and organizational action in mergers and acquisitions. Organization Science, 21(1): 3-22.

Vitols, S. 2001. The origins of bank-based and market-based financial systems: Germany, Japan, and the United States. In W. Streeck, \& K. Yamamura (Eds.), The origins of nonliberal capitalism: Germany and Japan in comparison. Ithaca, NY: Cornell University Press.

Vogel, D. 1992. The Globalization of Business Ethics: Why America Remains Distinctive. California Management Review, Fall: 30-49.

Waddock, S., \& Graves, S. 1997. The corporate social performance - financial performance link. Strategic Management Journal, 18(4): 303-319.

Walsh, G., Mitchell, V., Jackson, P., \& Beatty, S. 2009. Examining the antecedents and consequences of corporate reputation: A customer perspective. British Journal of Management, 20: 187-203.

Walsh, J., Weber, K., \& Margolis, J. 2003. Social Issues and Management: Our Lost Cause Found. Journal of Management, 29(6): 859-881. 
Wang, Y., Lo, H., \& Hui, Y. 2003. The antecedents of service quality and product quality and their influence on bank reputation: evidence from the banking industry in China. Managing Service Quality, 13: 72-83.

Wartick, S. 1992. The relationship between intense media exposure and change in corporate reputation. Business \& Society, 31: 33-49.

Weaver, G. 2001. Ethics Programs in Global Businesses: Culture's Role in Managing Ethics. Journal of Business Ethics, 30(1): 3-15.

Weber, K., Davis, G., \& Lounsbury, M. 2009. Policy as myth and ceremony? The global spread of stock exchanges, 1980-2005. Academy of Management Journal, 52(6): 13191347.

Weber, M. 1978. Economy and Society. Berkeley, CA: University of California Press.

Weber, M. 2002. The Protestant Ethics and the Spirit of Capitalism and Other Writings, ed. and tr. Peter Baehr \& Gordon Wells, New York, NY: Penguin.

Weigelt, K., \& Camerer, C. 1988. Reputation and corporate strategy: a review of recent theory and applications. Strategic Management Journal, 9: 443-454.

Weiner, B. 1985. An attributional theory of achievement motivation and emotion. Psychological Review, 92: 548-573.

Williamson, O. \& Winter, S. (eds.) 1991. The Nature of the Firm: Origins, Evolution, and Development, Oxford, UK: Oxford University Press.

Williamson, O. 1996. The mechanisms of governance. New York, NY: Oxford University Press.

Williamson, O., 1975, Markets and Hierarchies: Analysis and Antitrust Implications, New York, NY: Free Press.

Winn, M., MacDonald, P., \& Ziestsma, C. 2008. Managing Industry Reputation: The Dynamic Tension between Collective and Competitive Reputation Management Strategies. Corporate Reputation Review, 11(1): 35-55.

Wood, D. 2007. Corporate social performance. In W. Visser, D. Matten, M. Pohl, \& N. Tolhurst (eds.), The A to Z of Corporate Social Responsibility. Chichester, UK: John Wiley \& Sons.

World Business Council for Sustainable Development. 1998. Meeting Changing 
Expectations: Corporate Social Responsibility. Geneva, Switzerland: WBCSD.

World Values Survey Association. 2009. World Values Survey 1981-2008 Official Aggregate v.20090901. Aggregate File Producer: ASEP/JDS, Madrid: Spain.

Yoshikawa, T., Tsui-Auch, L.S., \& McGuire, J. 2007. Corporate governance reform as institutional innovation: The case of Japan. Organization Science, 18: 973-88.

Zajac, E., \& Westphal, J. 2004. The Social Construction of Market Value: Institutionalization and Learning Perspectives on Stock Market Reactions. American Sociological Review, 69: 433-457.

Zollo, M., \& Meier, D. 2007. Understanding the performance of corporate acquisitions. Working paper, INSEAD, Fontainebleau, France.

Zollo, M., \& Reuer, J. 2006. Experience spillovers across corporate development activities Working paper, INSEAD, Fontainebleau, France.

Zollo, M., \& Singh, H. 2004. Deliberate learning in corporate acquisitions: Postacquisition strategies and integration capability in US bank mergers. Strategic Management Journal, 25: 1233-1256. 
VITA

MOHAMMAD ABRAHIM SOLEIMANI

November 22, 1979

Born, Hong Kong

$1998-2003$

B.Sc., Industrial Engineering

Amir Kabir University of Technology

Tehran, Iran

$2003-2006$

M.B.A

Sharif University of Technology

Tehran, Iran

$2007-2010$

Instructor

Graduate Assistant

Florida International University

Miami, Florida

$2010-2011$

Dissertation Year Fellowship Award

Florida International University

Miami, Florida

\section{PUBLICATIONS AND PRESENTATIONS}

Newburry, W. \& Soleimani, A. 2011. Multi-Level Reputation Signals in Service Industries in Latin America, Revista Innovar, forthcoming.

Newburry, W. \& Soleimani, A. 'Corporate Citizenship Perception in Latin America and Spain'. Academy of International Business-Southeast Annual Meeting. October 2008

Newburry, W. \& Soleimani, A. 'Foreignness, Corporate Citizenship Perceptions and Supportive Behavior in Latin America and Spain'. Academy of International Business Annual Meeting. June 2009

Newburry, W. \& Soleimani, A. 'Foreignness and Firm Reputation in Spain and Latin America'. Strategic Management Society Annual Conference. October 2009

Newburry, W. \& Soleimani, A. 'Foreignness, Legitimacy and Corporate Citizenship Perceptions'. Reputation Institute $14^{\text {th }}$ International Conference. May 2010

Newburry, W. \& Soleimani, A. 'Multi-Level Reputation Signals in Service Industries in Latin America'. Academy of International Business - Latin America Chapter Meeting, 
June 2010

Newburry, W., Soleimani, A. \& Borda, A. (forthcoming, 2011). 'Reputations and Supportive Behavior of Spanish and U.S. Firms in Mexico' In Niedrist, G. (Ed.), 'EUMexican, Legal, Commercial and Business Relations'.

Schneper, W., Meyskens, M., Soleimani, A., Celo, S., He, W. \& Leartsuraat, W. 'Organizational Drivers of Corporate Social Responsibility: Disentangling Substance from Rhetoric'. Academy of Management Annual Meeting. August 2009

Soleimani, A., Newburry, W., Taciak, S. \& Ponzi, L. 'Firm- and Country-level Determinants of Individual Corporate Reputation Assessments'. Reputation Institute 14th International Conference. May 2010

Soleimani, A., Newburry, W., Taciak, S. \& Ponzi, L. 'Firm- and Country-level Determinants of Individual Corporate Reputation Assessments'. Academy of International Business Annual Meeting. June 2010

Soleimani, A., Schneper, W. \& Newburry, W. 'The Impact of Stakeholder Power on Corporate Reputation: A Cross-country Corporate Governance Perspective'. Reputation Institute 15th International Conference. May 2011

Soleimani, A., Schneper, W. \& Newburry, W. 'The Impact of Stakeholder Power on Corporate Reputation: A Cross-country Corporate Governance Perspective'. Academy of International Business Annual Meeting. June 2011 